\title{
Adjustment Costs and Factor Demand: New Evidence From Firms' Real Estate
}

\author{
Antonin Bergeaud ${ }^{1} \&$ Simon Ray ${ }^{2}$
}

September 2017, WP \#641

\begin{abstract}
Adjustment costs impair the optimal allocation of production factor across firms. In this paper, we use the cost associated with corporate relocation to explore the effect of the adjustment costs of the premises size on factor demand. We rely on the tax on realized capital gains on real estate asset, which entails varying real estate adjustment costs across firms, to empirically study the effect of these frictions on firms' behaviour. We develop a general equilibrium model, with heterogeneous firms, that sheds light on the implication of the level of the fixed costs associated with the adjustment of real estate on the change in firms' labor demand following productivity shocks. This model predicts that employment growth of firms facing positive productivity shocks shrinks with the level of the frictions. Confronting these results using French firm-level data over the period 1994-2013, we find that higher adjustment costs constrain relocation and reduce job creation of the most dynamic firms. The highlighted frictions have noticeable macroeconomic effects. ${ }^{3}$
\end{abstract}

Keywords: Corporate real estate; Firms' relocation; Adjustment costs; Misallocation of resources JEL classification: D21, D22, H25, J21, O52, R30

\footnotetext{
${ }^{1}$ Paris School of Economics - EHESS and Banque de France, antonin.bergeaud@banque-france.fr

${ }^{2}$ Banque de France and Aix-Marseille University (Aix-Marseille School of Economics), CNRS, EHESS, simon.ray@banque-france.fr

${ }^{3}$ The authors would like to thank, without implicating, Philippe Aghion, Clémence Berson, Sara Calligaris, Gilbert Cette, Thomas Chaney, Pierre-Philippe Combes, Bruno Decreuse, Gilles Duranton, Laurent Gobillon, Rémy Lecat, Claire Lelarge, Sébastien Roux and Grégory Verdugo as well as seminar participants at the Bank of France, Universite Paris-Dauphine, Aix-Marseille School of Economics, AFSE, LAGV, JMA and EEA for helpful comments and suggestions.
}

Working Papers reflect the opinions of the authors and do not necessarily express the views of the Banque de France. This document is available on publications.banque-france.fr/en 


\section{NON-TECHNICAL SUMMARY}

In this study, we explore the effects of the costs associated with change in the volume of firms' premises on factors demand, notably on the firm-level dynamics of the workforce size. More generally, this research contributes to the question regarding the role of adjustment costs on the allocation of production factors by documenting the effect of a quantifiable cost that varies across time and across firms.

As a firm grows, it will eventually be constrained by the size of its premises. Conversely, if it declines, the firm will operate in suboptimal oversized premises. When access to adjacent lands or buildings is constrained, or if sublease of unused premises is not possible, adjustments of the premises are likely to be realized through local relocations of activities. Those local relocations are costly and the associated cost varies across firms notably because of the tax on realized real estate capital gains. For real estate owners, these relocations indeed require the sale of previously occupied premises and the payment of the tax. It entails firm-level variations in the adjustment costs that are empirically exploited in this study. As a result, we expect to see more frequent relocations for firms that are more dynamic in terms of employment; this is indeed confirmed in Figure below.

Employment Growth and Relocation

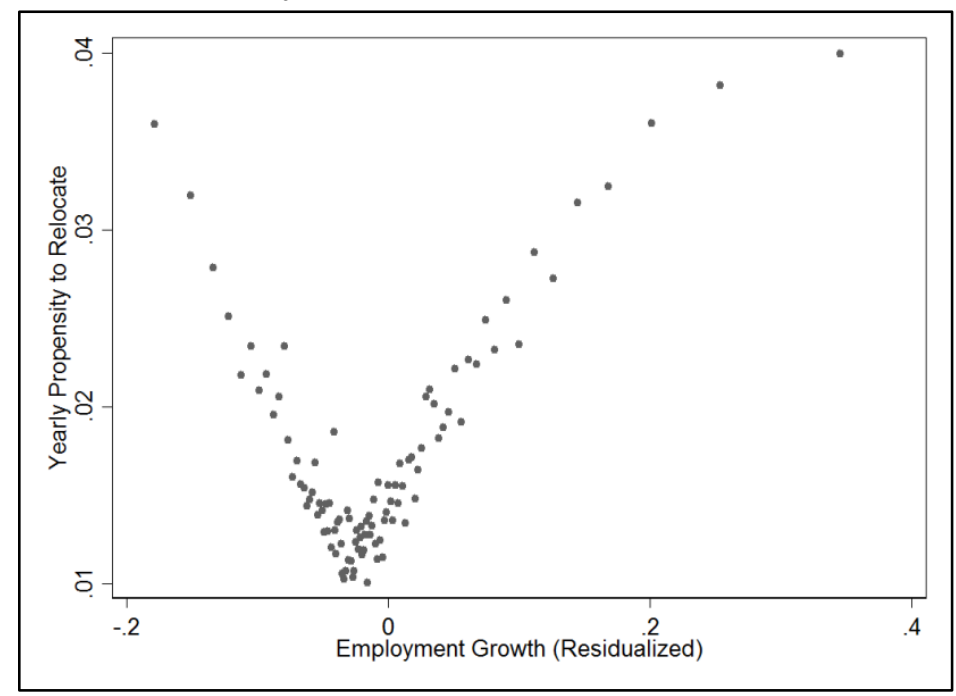

Source: authors' computations using FIBEn data.

To guide the interpretation of our results, we build a general equilibrium model with heterogeneous firms from which we derive predictions on the effect of the level of the fixed costs associated with real estate adjustment on the workforce growth at different level of productivity shocks. In this framework, profit-maximizing firms are heterogeneous with respect to their productivity level and make decisions on labor and real estate inputs in a context of adjustable real estate inputs conditional on paying a fixed cost. The level of these adjustment costs deter some firms from optimally adjusting their real estate inputs to the new productivity level and the complementarity between real estate and labor in the production process implies that it also affects firms' labor demand. We derive the existence of an interval of inaction for the difference in size between the optimal premises and the occupied ones in which firms do not adjust their real estate.

Other consequences of the model comes from the complementarity between real estate and labor which leads these firms to restrain employment growth as compared to their 
optimal employment growth they would observe had those firms adjusted their real estate. We show that the interval of inaction widens with the level of the adjustment costs and so do the number of firms affected. We also show that the non-relocating interval is not centered in zero and that a rise in the fixed adjustment costs has asymmetrical effects on the bounds of the interval. The effect of such a rise is larger in absolute value on the positive bound of the interval than the effect on the negative bound which implies that an increase in the fixed adjustment cost has an overall negative impact on mean firm-level employment growth. This asymmetry property strengthens with the level of the adjustment cost.

We test these predictions using microdata on French single-establishment firms from 1994 to 2013 . We measure the level of the fixed costs associated with relocation by using the tax on capital gains. Different regression models confirm the theoretical predictions, namely that:

(i) Relocation is associated with an increase (respectively decrease) in employment growth for firms that are growing (respectively declining).

(ii) The larger the (latent) fixed costs, the less likely a firm is to relocate.

(iii) The larger the (latent) fixed costs, the less dynamics the employment.

(iv) Overall, employment is negatively affected by the size of the tax on capital gain.

Our baseline results suggest that a reduction of the relocation costs, through a decrease of the share of the real-estate market value that would be paid as a tax on capital gains of 1 standard deviation, would increase the propensity to relocate of affected firms by $10 \%$ and would raise the yearly employment growth rate of the growing firms by $5 \%$. Besides, by reducing job reallocation from the least productive firms to the more productive ones, such fixed adjustment costs generate misallocation and affect global output.

\section{Coûts d'ajustement et demande de facteurs : enseignements de l'immobilier d'entreprise}

Les coûts d'ajustement nuisent à l'allocation optimale des facteurs de production entre les entreprises. Nous utilisons les coûts associés à la mobilité géographique des entreprises pour étudier l'effet des coûts d'ajustement de la taille des locaux sur la demande de facteurs de production. Nous exploitons la taxe sur les plus-values de cession sur les actifs immobiliers qui engendre des coûts d'ajustement variables d'une entreprise à l'autre pour étudier empiriquement l'effet de ces frictions sur le comportement des entreprises. Nous développons un modèle en équilibre général, avec des entreprises hétérogènes, qui met en évidence l'impact du niveau des coûts fixes associés à l'ajustement de l'immobilier sur la demande de travail suite à un choc de productivité. Le modèle prédit que la croissance de l'emploi des entreprises confrontées à des chocs de productivité positifs diminue avec le niveau des coûts d'ajustement. Nous confrontons ces prédictions théoriques à des données d'entreprise françaises sur la période 1994-2013. Nous confirmons que les coûts d'ajustement contraignent la mobilité et réduisent la création d'emplois dans les entreprises les plus dynamiques. Les frictions mises en évidence ont des effets macroéconomiques notables.

Mots-clés : Immobilier des entreprises; mobilité des entreprises; coûts d'ajustement; allocation sous-optimale des ressources

Les Documents de travail reflètent les idées personnelles de leurs auteurs et n'expriment pas nécessairement la position de la Banque de France. Ce document est disponible sur publications.banque-france.fr 


\section{Introduction}

This paper studies the effect of adjustment costs of corporate real estate on factor demand. By linking the adjustment of firms' premises to local relocations, we are able to empirically explore the impact of adjustment costs on firms' dynamics. These costs include a tax on realized capital gains, induced by the selling of the previous premises, that depend on the dynamics of local real estate prices since the acquisition date. Using a large firm-level database merged with local real estate prices, we document sizable effects of the adjustment costs on firms' labor demand and derive new results on the causes and implications of firms' local relocation.

There is a vast literature on the nature and the effect of adjustments cost on firms' factor demand. ${ }^{1}$ This literature notably explores the effect of different structures of costs and uses firm-level data to test their empirical relevance: Cooper and Haltiwanger (2006) document how models that mix both convex and non-convex capital adjustment costs better fit the data. Adjustment costs are also related to a recent literature that has empirically documented the magnitude of the detrimental effect on aggregate productivity of misallocating resources toward less productive firms. Although, as noted by Restuccia and Rogerson (2017), the misallocation of production factors has been chiefly traced to policy distortions (Olley and Pakes, 1996; Restuccia and Rogerson, 2008; Hsieh and Klenow, 2009 and, in the case of France, Garicano et al., 2016), adjustment costs are innately mentioned as impediments to the optimal allocation of resources. For example, Asker et al. (2014) link the dispersion of static measures of capital misallocation to the dynamic choice of production inputs. In our study, we focus on the distorting impact of adjustment costs of real estate assets because of observable heterogeneity in these costs at the firm level. The relevance of studying corporate real estate is arguably substantiated by recent findings on the role of land in the misallocation of production factor. Duranton et al. (2015) use micro data on Indian firms and find that misallocation of manufacturing output is mostly due to an inefficient allocation of land across firms.

Our empirical identification relies on the equivalence between the alteration of the premises' volume and local relocation of single establishment firms. This equivalence matters because relocation costs vary across firms and across time and because the underlying determinants of those costs are observable for both non-relocating and relocating firms. This equivalence is warranted by the argument put forward by Schmenner (1980) that on-site expansion, out-site expansion (branching) and relocation are not substitute to one another and that the latter is the only option for many firms when it comes to altering the size of the premises. ${ }^{2}$ Firms' relocation is actually a fairly frequent event: with definitions that will be clarified below, we find that $1.7 \%$ of the French firms relocate their activities to a neighbouring city, on average, each year. In line with our argument on the intertwining of factors' adjustment and relocation, this yearly propensity to relocate reaches more than $4 \%$

\footnotetext{
${ }^{1}$ In the case of employment see Hamermesh (1989); Caballero et al. (1997); Cooper and Willis (2009) and Bloom (2009). In the case of capital see Caballero et al. (1995); Cooper and Haltiwanger (2006) and Bloom (2009)

${ }^{2}$ On-site expansion, especially in the non-manufacturing sector and/or in urban areas, is often an option that has to be discarded because access to adjacent land or premises is constrained. Informal talks with market participants indicate that sublease of unused premises has been at a very early stage of development over the studied period. Out-site expansion is potentially associated with additional on-going costs resulting from fixed expenses per establishment and important losses of synergies. This point is further discussed in Section 2.
} 
for firms at the upper workforce growth decile.

To guide our empirical investigations, we build a general equilibrium model with heterogeneous firms to derive predictions on the effect of the level of the fixed costs associated with real estate adjustment on the workforce growth across the productivity shocks distribution. In this framework, profit-maximizing firms are heterogeneous with respect to their productivity level and make decisions on labor and real estate inputs in a context of adjustable real estate inputs conditional on paying a non-convex cost. The level of these adjustment costs deter some firms from optimally adjusting their real estate inputs to the new productivity level and the complementarity between real estate and labor in the production process implies that it also affects firms' labor demand. We derive the existence of an interval of inaction for the difference in size between the optimal premises and the occupied ones in which firms prefer not to adjust their real estate inputs. Such an interval is a classical result of the literature on investment with non-convex adjustment costs (see e.g. Grossman and Laroque, 1990). In our framework, this non-relocating interval entails that firms affected by low positive productivity shocks operate in sub-optimally small premises whereas those affected by low negative productivity shocks operate in sub-optimally large premises. The complementarity between real estate and labor leads these firms to restrain employment growth as compared to the counter-factual employment growth that would be observed had those firms adjusted real estate. We show that the interval of inaction widens with the level of the adjustment costs and so do the number of firms affected. We also show that the non-relocating interval is not centered in zero and that a rise in the fixed adjustment costs has asymmetrical effects on the bounds of the interval. The effect of such a rise is larger in absolute value on the positive bound of the interval than the effect on the negative bound which implies that an increase in the fixed adjustment cost has an overall negative impact on mean firm-level employment growth. This asymmetry property strengthens with the level of the adjustment cost. As noted by Elsby and Michaels (2014), it is weak when the frictions is small. Nonetheless, for values that, as we shall see, are empirically relevant, it become significant.

We then test these predictions using data on single-establishment firms and their location covering mainland France from 1994 to 2013. Our empirical study focuses on intermunicipality relocations occurring over a short distance that leave the economic environment of the firm (e.g, localized aggregate increasing return, real estate prices or wages) largely unaltered and are more likely to be primarily triggered by the inappropriateness of the site's characteristics. ${ }^{3}$ We study the effect of adjustment costs of real estate by exploiting two types of heterogeneity in relocation costs. First, by comparing firms that own their premises and firms that rent them. Second, and in order to deal with the important unobserved differences between these two groups of firms, by restricting to real estate owners and by exploiting the latent tax on realized capital gains affecting real estate assets that owning firms must pay when they relocate. ${ }^{4}$ Heterogeneity in the level of this tax naturally come from the way it is designed. In a nutshell, the tax base is determined by the size of

\footnotetext{
${ }^{3}$ Focusing on local relocations is also justified by the fact that in such cases, employees are more likely to remain in the firm; which is not the case for relocations over longer distances: Weltevreden et al. (2007) shows that when the relocation distance exceeds $20 \mathrm{~km}$, most employees quit there jobs in anticipation of the relocation decision.

${ }^{4}$ Indeed, for single-establishment firms holding the real estate assets in which they operate, a relocation is necessarily associated with the sale of previously occupied premises if we make the reasonable assumption that limited access to funding prevents the firms from concomitantly owning various premises.
} 
the real estate assets, the acquisition date and the dynamic of local prices since this acquisition. This scheme introduces important variability across firms and across time in the level of the relocation costs. We document that higher relocation costs lower firms' propensity to relocate and namely constrain employment growth of the growing firms. Our baseline results suggest that a reduction of the relocation costs, through a decrease of the share of the real-estate market value that would be paid as a tax on capital gains of 1 standard deviation, would increase the propensity to relocate of affected firms by $10 \%$ and would raise the yearly employment growth rate of the growing firms by $5 \%$. Such reduction in the adjustment costs would therefore result in an important increase in job creation and job reallocation in the most productive firms. Additional empirical evidences suggest that this reduction in the adjustment costs would foster optimal allocation of factor inputs.

Our identification strategy shares similarities with the emerging literature on the effect of tax friction on real estate transactions and households' mobility. Dachis et al. (2012), Best and Kleven (2013) and Hilber and Lyytikäinen (2013) all study the effect of transaction tax on residential real estate dynamic and find large aggregate effects. Hilber and Lyytikäinen (2013) exploit cut-off values in the tax associated with housing transactions to claim that an increase in transaction cost by 2 to 3 percentage points reduces mobility by $30 \%$; this is only true for short distance relocations, suggesting that frictions may lead to misallocation of dwellings in the housing market.

The paper is organized as follows: section 2 presents stylized facts on the interaction between relocation behaviour and employment dynamics. Section 3 presents a theoretical framework development to formulate testable predictions on firms' behaviour. Section 4 presents our empirical analysis, findings and comments and section 5 concludes.

\section{Background}

Little is known about firms' local relocations and their connection to firms' employment dynamism. Most of the existing literature has rather focused on explaining the determinants of relocation and the choice of the destination. It is acknowledged that, although external factors (characteristics of potential new sites) are at play in the choice of the place of relocation, internal factors (size, age, tenure status, sector and growth) are the main predictors of firms' relocation decision (see for example Pellenbarg et al., 2002 and Brouwer et al., 2004). This first section sheds light on stylized facts supporting our views that there exists a close relationship between firms' local relocation and factors' adjustment. After briefly presenting the databases, we look at some general characteristics of firms' relocation. We then document that employment dynamics and local relocations are closely intertwined.

\section{$2.1 \quad$ Data}

To derive our results, we use a firm level database with information on a large number of French firms over the period 1994-2013 called FiBEn. FiBEn is built by the Bank of France from fiscal documents and contains detailed information on flow and stock accounting variables, notably on real estate assets, as well as information on firms' activities, location and workforce. We restrict to single-establishment firms that remain below 250 employees $^{5}$.

\footnotetext{
${ }^{5}$ This size restriction is made to limit measurement errors in real estate volume and location, see Appendix A for more details.
} 
Below this threshold, $85.7 \%$ of the firms are single-establishment. The firm reports the code of its current municipality and we use changes in this code to detect inter-municipality relocations. This database is then merged with local residential real estate prices. We use the Notaires-INSEE ${ }^{6}$ apartment price indices built by Fougère and Poulhes (2012) which are based on the data collected by the French solicitor association to derive capital gains on real estate assets. Residential housing prices are used in this study because French corporate real estate prices at the local level are not available over the studied period. ${ }^{7}$ We describe our dataset and the variable construction in more detail in Appendix A.

\subsection{Firms' mobility in France}

Our firm-level database allows to identify inter-municipality relocations of single-establishment firms between 1994 and 2013. We observe 124,191 single-establishment firms over an average period of 9.93 years. Among these firms, 22, 057 have relocated their activities to another municipalities over the period of observation; that is approximately $18 \%$ of the firms. Half of the relocations concerns a relocation where the municipality of departure and the municipality of settlement are distant by less than $8 \mathrm{~km}$. For a little more than $70 \%$ of the relocations, this distance is inferior to $15 \mathrm{~km}$. These first empirical results are in line with other studies that report statistics on the distance between the place of departure and the place of settlement of relocating firms. They find that local relocations account for the large majority of the relocations (Pen and Pellenbarg, 1998; Delisle and Laine, 1998; Weltevreden et al., 2007 and Knoben et al., 2008). In France, Delisle and Laine (1998) document that $6.2 \%$ of the firms had relocated between 1989 and 1992, with more than three quarters of the inter-municipality relocations being characterized by a distance inferior to $23 \mathrm{~km}$. Similarly, in Netherlands, Weltevreden et al. (2007) shows that between 1999 and 2006, most relocations are made within the same labor market area. We hereafter define as "local" a relocation that is characterized by a distance of less than $15 \mathrm{~km}$, between the municipality of departure and the municipality of settlement. ${ }^{8}$ The distribution of the relocating distance is given in Figure A1 in Appendix A.

Table 1 presents some basic descriptive statistics to compare relocating firms to a control group made of static firms. We notice that relocating firms do not differ much by their size, their employment level and their profitability (even if some of those small differences are statistically significant). Slightly larger differences are observed for the age of the firm; static firms being in average 1.8 year older than relocating firms. Yet, sizable and statistically significant differences are observed regarding two characteristics: (i) the yearly mean employment growth over the observation period: while the mean yearly workforce growth of relocating firms is equal to $5.2 \%$, it is $2.2 \%$ for static firms; (ii) the tenure status of the firm: $28 \%$ of the relocating firms report real estate holdings while this share is equal

\footnotetext{
${ }^{6}$ Solicitor is the English equivalent for the French word notaire and INSEE is the French National Statistical Bureau.

${ }^{7}$ As noted by Fougère et al. (2017), there is evidence that, at the national level, prices in the different segments of the real estate market, and notably residential and corporate real estate, follow similar trends

${ }^{8}$ Following this definition $73.4 \%$ of the relocations observed in our sample are local. There is of course a degree of arbitrariness in setting such a threshold. As mentioned before, it reflects the idea that relocations over farther distance are more likely to alter the local economic conditions and might require that the existing employees change their place of residence, inducing higher costs and new risks. All our subsequent results are robust to using different thresholds or to defining as local the relocations occurring within the local labor market area based on commuter flows from census data, see Appendix D.
} 
to $41 \%$ for static firms.

Table 1: Key summary statistics - relocating locally and static firms

\begin{tabular}{|c|c|c|c|c|}
\hline \multirow[b]{3}{*}{ Employment } & \multicolumn{2}{|l|}{ Mean } & \multicolumn{2}{|c|}{ Difference } \\
\hline & Relocating locally & Static & & \\
\hline & 18.9 & 20.1 & $-1.17^{* * *}$ & $(0.19)$ \\
\hline Sales & 3.14 & 2.98 & $0.16^{* * *}$ & $(0.06)$ \\
\hline BS size & 2.11 & 2.27 & -0.16 & $(0.20)$ \\
\hline Profits & 0.135 & 0.124 & $0.011^{* * *}$ & $(0.0013)$ \\
\hline Age & 12.0 & 13.8 & $-1.8^{* * *}$ & $(0.11)$ \\
\hline Employment growth & $5.3 \%$ & $2.5 \%$ & $2.8 \% * * *$ & $(0.0013)$ \\
\hline Real estate owner & $26 \%$ & $39 \%$ & $13 \% * * *$ & $(0.004)$ \\
\hline $\mathrm{Nb}$ of obs. & 18,193 & 105,998 & - & \\
\hline
\end{tabular}

Notes: This table shows the mean of different key variables, in initial year of observation, for firms that locally relocate and for firms that neither relocate nor shift towards a multi-establishment structure over the observed period. Employment is given in full-time equivalent (FTE) number of workers as reported by the firm; Employment growth in the mean yearly percentage change in FTE over the observation period; Sales are in millions of euros; BS size is the net value of the assets reported in the balance sheet and is given in millions of euros; Profits is the Earning Before Interest and Tax margin (i.e., EBIT to Sales ratio); Age is the number of year since company's incorporation; Real estate owner is a dummy variable equal to 1 if the firm reports real estate holdings and 0 otherwise. Source: FiBEn, see Appendix A for more detail about the data. The latest column show the mean and standard deviation of the difference between the two coefficients and the Student t-stat on the nullity of this difference. $* * *, * *$ and $*$ indicate that the null hypothesis of this test is rejected at the $1 \%, 5 \%$ and $10 \%$ level of significance, repectively.

\subsection{Relocating behaviour and workforce growth}

The average workforce growth of relocating firms reported in table 1 suggests that relocation is markedly related to factors' adjustment. In order to explore this relationship, we rank firms according to their mean yearly workforce growth rate over the observation period. In each percentile of this average workforce growth distribution, we compute the propensity to relocate by dividing the number of observed local relocations by the number of observations in this percentile. The results are presented in Figure 1 where average employment growth has been residualized on a complete set of sector-département dummies. We find that firms located in the first two deciles (resp. in the three last deciles) in the workforce growth distribution, which corresponds to an average yearly workforce growth rate below $-4.0 \%$ (resp. above $1.5 \%$ ), have a much higher propensity to relocate than firms characterized by limited change in their workforce size.

These results are robust to restricting to different sectors or areas. One could for example believe that service firms are more prone to relocate than manufacturing ones and are in larger quantities in major cities which are rich and dynamic areas where firms grow faster. In Appendix B, we report the results of a similar analysis focusing on Paris (Figure B1), Lyon (Figure B2) and Marseilles (Figure B3) areas which are the three largest cities in France. We also present the relationship between the propensity to relocate and employment growth 
Figure 1: Propensity to relocate and employment growth

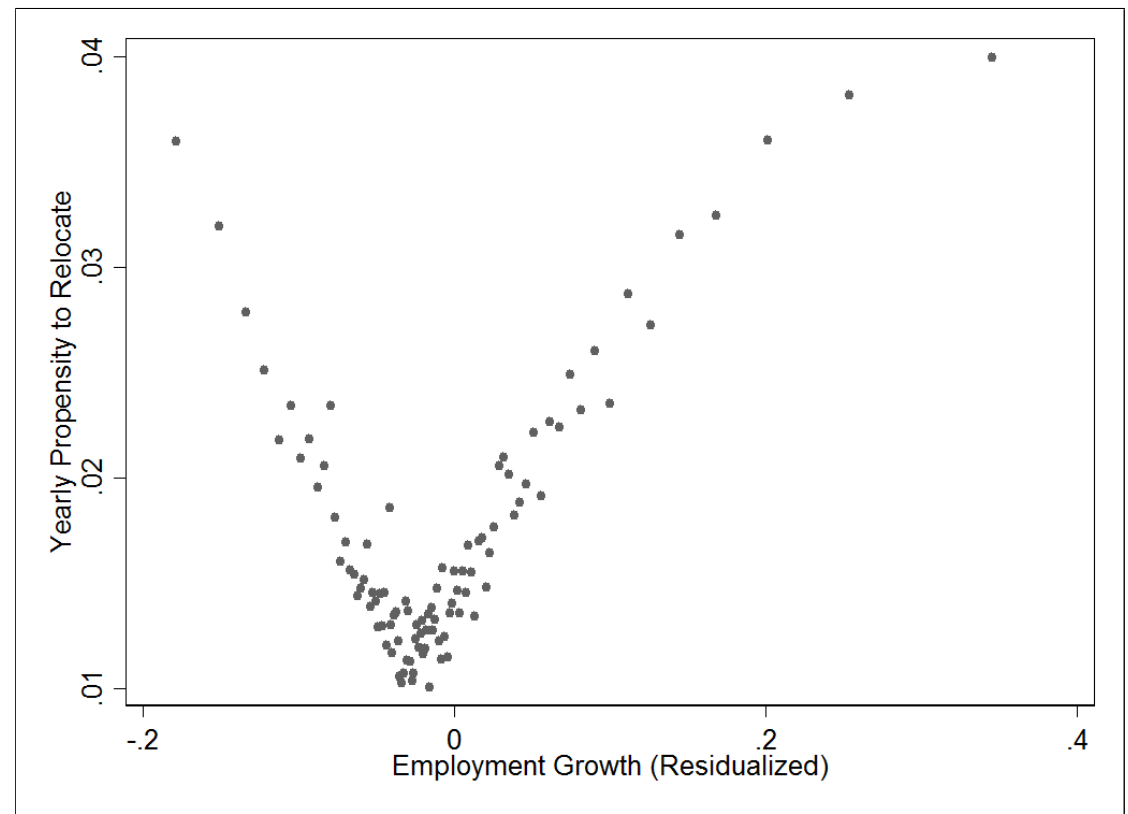

Notes: Employment growth is taken as the average employment growth over the period of observation and residualized on a set of sector-département dummies. The propensity to relocate is calculated as the number of observed local relocation divided by the number of years of observations. These two variables are averaged for each percentiles of the distribution of the residualized employment growth. The first and the last percentiles have been removed to focus on the core of the distribution. Period of observation: 1994-2013. Source: FiBEn, see Appendix A for more details about the data.

in the whole country but these three areas in Figure B4. We can see that the U-shaped relationship is robust to such stratification and seems to be, as expected, stronger in the Paris area where on-site expansion is arguably more constrained. Finally, Figures B5 and B6 report the results when focusing on service industries (Figures B5) and manufacturing firms (Figures B6). The link looks stronger in the service industries, where relocating costs are arguably lower and on-site expansion is more constrained.

In the following section, we develop a theoretical framework that relies on this link between real estate adjustment and local relocations.

\section{Model}

In this section, we develop a standard model of monopolistic competition with heterogeneous firms in the spirit of Melitz (2003). Firms face a productivity shock and make the decision to adjust the size of its premises or not. Premises' size adjustment is associated with fixed relocation costs. This model sheds light upon the effect of the fixed adjustment costs of real estate on firms' behavior across the productivity distribution. 


\subsection{Model setup}

\subsubsection{Demand}

There is a continuum of products $i \in[0,1]$ and a final sector using all products $i$ as inputs to produce $Y$ with a CES technology:

$$
Y=\left[\int_{0}^{1} y(i)^{1-\varepsilon} d i\right]^{\frac{1}{1-\varepsilon}} .
$$

where $\varepsilon$ is the inverse of the elasticity of substitution.

The conditional demand function for $y(i)$ can be written as

$$
y(i)=\left[\frac{P}{p(i)}\right]^{\frac{1}{\varepsilon}} Y,
$$

where $P$ is the final good price and $p(i)$ is the price of $y(i)$. From the zero profit condition of the final good producer, we obtain:

$$
P=\left[\int_{0}^{1} p(i)^{\frac{\varepsilon-1}{\varepsilon}} d i\right]^{\frac{\varepsilon}{\varepsilon-1}} .
$$

\subsubsection{Production}

Each product $i$ is produced by a monopolistic firm indexed by $i$ with a Cobb-Douglas production function using labor and real estate as inputs. ${ }^{9}$ These firms differ by their parameters $\theta(i)$ such that:

$$
y(i)=\theta(i)\left(\frac{l(i)}{\alpha}\right)^{\alpha}\left(\frac{r(i)}{1-\alpha}\right)^{1-\alpha} .
$$

$\theta$ can be understood in many different ways, it can encompass a firm-specific demand shock, technology level or the quality of the intermediate input as in Aghion and Howitt (1992) or managerial ability as in Garicano et al. (2016), in what follows we will refer to it as the firm productivity. Labor and real estate are mobile across firms in the intermediate sector. The endogenous market wage, $w$, and the endogenous market price of one unit cost of real estate, $u$, that can be thought as either the user cost of real estate capital or its renting rate, are the same at each firm $i \in[0,1]$. The firm $i$ considers the demand function and takes into account the fact that prices $p(i)$ adjust to:

$$
p(i)=\frac{Y^{\varepsilon} P}{\theta(i)^{\varepsilon}}\left(\frac{l(i)}{\alpha}\right)^{-\alpha \varepsilon}\left(\frac{r(i)}{1-\alpha}\right)^{-(1-\alpha) \varepsilon},
$$

hence, firm $i$ 's revenue is given by:

$$
p(i) y(i)=\Omega(i)\left(\frac{l(i)}{\alpha}\right)^{\alpha(1-\varepsilon)}\left(\frac{r(i)}{1-\alpha}\right)^{(1-\alpha)(1-\varepsilon)},
$$

\footnotetext{
${ }^{9}$ Including productive capital stock as an input won't affect our theoretical prediction if we assume that adjustment costs in real estate are not affected by the level of capital stock. Hence, in this framework, $l$ already encompasses the stock of capital.
} 
where $\Omega(i)=\theta(i)^{1-\varepsilon} Y^{\varepsilon} P$ is the revenue productivity (see Foster et al., 2008 and Hsieh and Klenow, 2009).

\subsubsection{Resource constraint}

We consider a closed economy where a representative consumer owns the intermediate firms, real estate assets and provide labor. Aggregate labor and real estate are in fixed-supply and we set them to $L_{s}$ and $R_{s}$, respectively. In equilibrium, aggregate demand for labor and real estate equal aggregate supply.

\subsubsection{The problem of the firm}

Each firm $i$ faces an unanticipated productivity shock on $\theta(i)$. This shock is assumed to be idiosyncratic and uncorrelated with the observable characteristics of the firm. After observing its new level of productivity $\theta(i)$, the firm adjusts labor and can adjust real estate conditional on relocating. This condition relies upon the constrained on-site expansion and the constrained sublease of vacated premises hypotheses. We denote $z(i)$ the decision variable with $z(i)=1$ if firm $i$ relocates and $z(i)=0$ otherwise. Relocating is associated with costs that we will specify below in order to relate them to actual costs faced by relocating firms. In this theoretical framework, we model these costs as proportional to the size of the endowed premises. This specification aims at capturing the fact the fixed costs vary with the size of the premises and at simplifying mathematical expressions. Formally, the costs are equal to $\operatorname{ar}_{0}(i)$, where $r_{0}(i)$ is firm $i$ 's initial premises volume and $a$ is a non-negative real number. ${ }^{10}$

Because of the fixed adjustment costs, a firm may decide to remain in its latest premises even it is hit by a non-zero productivity shock (see Cooper et al., 1999 and Cooper and Haltiwanger, 2006 for a thorough discussion on the implication of non-convex adjustment costs on investment decision).

The price of both inputs are taken as given by the profit maximizing firms. Finally, firm $i$ 's decision problem can be written:

$$
\max _{z(i) \in\{0,1\}}\left[z(i) \max _{\substack{r(i)>0 ; l(i)>0 \\ p(i)>0}}\left[\pi(i, r(i))-a r_{0}(i)\right]+(1-z(i)) \max _{\substack{l(i)>0 \\ p(i)>0}}\left[\pi\left(i, r_{0}(i)\right)\right]\right],
$$

where $\pi(i, r(i))$ denotes the profit function of firm $i$ defined as $p(i) y(i)-w l(i)-u r(i)$. In what follows, we shall call $\pi^{(1)}(i)$ the optimal profit in the case of a relocation and $\pi^{(0)}(i)$ in the case of no relocation.

\subsection{Solving the model}

\subsubsection{Decentralized equilibrium}

The equilibrium is defined by a vector of allocation $\{r(i), l(i), y(i), z(i), Y\}$ and a vector of prices $\{P, p(i), u, w\}$ such that:

\footnotetext{
${ }^{10}$ Notice also that the predictions of the model are unaltered if we introduce linear or/and convex adjustment costs in addition to those fixed costs. We focus on the consequences of changes in the value of parameter $a$, that is to say of the parameter governing the level of the fixed costs, because we observed firm level variation with respect to a fixed costs in the data.
} 
- Given $\theta(i), u$ and $w,\{r(i), l(i), z(i), p(i)\}$ maximize firm $i$ 's profit for every $i$ as defined in equation (7) (and $r(i)=r_{0}(i)$ if $z(i)=0$ ).

- Final good producing competitive firm chooses $y(i)$ for all $i$ to produce $Y$ by maximizing its profit taking $p(i)$ as given.

- Labor and real-estate market clear.

\subsubsection{The friction-less case}

In the simple case where $a=0$, we show in Appendix C.1 that our model yields the following optimal allocation:

$$
z(i)=1 ; l(i)=\frac{\theta(i)^{\frac{1-\varepsilon}{\varepsilon}}}{\int_{0}^{1} \theta(i)^{\frac{1-\varepsilon}{\varepsilon}} d i} L_{s} \text { and } r(i)=\frac{\theta(i)^{\frac{1-\varepsilon}{\varepsilon}}}{\int_{0}^{1} \theta(i)^{\frac{1-\varepsilon}{\varepsilon}} d i} R_{s} \forall i \in[0,1]
$$

Normalizing $P$ to 1 , we show that prices are endogenously set as follows:

$$
u=(1-\varepsilon) \frac{1-\alpha}{R_{s}} Y ; w=(1-\varepsilon) \frac{\alpha}{L_{s}} Y \text { and } p(i)=\frac{1}{\theta(i)}\left(\int_{0}^{1} \theta(i)^{\frac{1-\varepsilon}{\varepsilon}} d i\right)^{\frac{\varepsilon}{1-\varepsilon}}
$$

and that aggregate production is equal to:

$$
Y=\left(\int_{0}^{1} \theta(i)^{\frac{1-\varepsilon}{\varepsilon}} d i\right)^{\frac{\varepsilon}{1-\varepsilon}}\left(\frac{L_{s}}{\alpha}\right)^{\alpha}\left(\frac{R_{s}}{1-\alpha}\right)^{1-\alpha} .
$$

In particular, without friction, this model generates an optimal factor allocation in the sense that the allocation maximizes $Y$ and is uniquely determined by the firm's productivity.

\subsubsection{The case with frictions}

To find the equilibrium allocation following productivity shocks in the case with frictions on real estate adjustment, we need to make an assumption on the distribution of $r_{0}(i)$. We hence consider that, before the productivity shock, the allocation of production factors corresponds to the one derived in the friction-less case. This implies that $r_{0}(i)$ only depends on $\theta_{0}(i)$, the initial level of productivity. In our baseline experiments, to simplify the interpretation of the results, we consider that the productivity distribution is left unaltered by the productivity shocks. Firms merely redraw their productivity level from a stationary productivity distribution. ${ }^{11}$ Doing so, we abstract from the general equilibrium effect resulting from aggregate productivity shocks and we focus on the general equilibrium effects attributable to changes in the allocation of resources entailed by the adjustment costs. Labor adjustment being friction-less, $l(i)$ always satisfies the first order conditions. Conversely, $r(i)$ only satisfies first-order conditions if $z(i)=1$, otherwise $r(i)=r_{0}(i)$. If $z(i)=1$, it is easy to show that firm $i$ 's profit, denoted $\pi^{(1)}(i)$, is:

$$
\pi^{(1)}(i)=\frac{u \varepsilon}{(1-\alpha)(1-\varepsilon)} r^{*}(i)-a r_{0}(i)
$$

\footnotetext{
${ }^{11}$ In the following subsection, presenting results from numerical simulations, we explore the behaviour of the model when the economy faces an aggregate productivity shock in addition to idiosyncratic shocks.
} 
where $r^{*}(i)$ denotes the optimal volume of real estate conditional on $z(i)=1$.

Whereas if $z(i)=0$ :

$$
\pi^{(0)}(i)=\frac{u(1-\alpha(1-\varepsilon))}{(1-\alpha)(1-\varepsilon)} r^{*}(i)^{\frac{\varepsilon}{1-\alpha(1-\varepsilon)}} r_{0}(i)^{\frac{(1-\alpha)(1-\varepsilon)}{1-\alpha(1-\varepsilon)}}-u r_{0}(i)
$$

The relocation condition, $\pi^{(1)}(i)>\pi^{(0)}(i)$, can be written as a simple condition on $\Delta_{r}(i)=\frac{r^{*}(i)}{r_{0}(i)}-1$, the percentage change in size between the optimal premises following the shock and the endowed premises:

$$
\frac{u}{(1-\alpha)(1-\varepsilon)}\left(\varepsilon\left(1+\Delta_{r}(i)\right)-(1-\alpha(1-\varepsilon))\left(1+\Delta_{r}(i)\right)^{\frac{\varepsilon}{1-\alpha(1-\varepsilon)}}\right)+u-a>0 .
$$

Because endowed premises' size $r_{0}(i)$ is proportional to $\theta_{0}(i)^{\frac{1-\varepsilon}{\varepsilon}}$ and optimal premises' size $r^{*}(i)$ is proportional to $\theta(i)^{\frac{1-\varepsilon}{\varepsilon}}$, there exist a direct relation between $\Delta_{r}(i)$ and the percentage change in productivity $\Delta_{\theta}(i)$. Formally, $1+\Delta_{r}(i)=\lambda\left(1+\Delta_{\theta}(i)\right)^{\frac{1-\varepsilon}{\varepsilon}}$ where $\lambda$ only depends on aggregate quantities. ${ }^{12}$

We show in Appendix C.2 that, as long as $a<u$, there exist threshold values $\Delta_{r}^{-}<0$ and $\Delta_{r}^{+}>0$ such that if $\Delta_{r}(i)$ is included in $\left[\Delta_{r}^{-} ; \Delta_{r}^{+}\right]$it is optimal for firm $i$ not to relocate. We label this interval the "non-relocating interval". We show that the width of this nonrelocating interval is increasing with the fixed costs. The existence of such an interval of inaction is a classical result of the literature on lumpy and intermittent adjustments resulting from fixed lump-sum cost per adjustment decision (the (S,s) rules). This literature typically finds a range of inaction defined by two outer adjustment points between which the agent allows a state variable to diverge from its optimal value. ${ }^{13}$

The intuition for the existence of such an interval in our framework is straightforward. When a firm receives a positive shock, its profits can be optimized by using a larger amount of inputs. Because altering the level of inputs requires to pay a fixed cost, the positive productivity shock has to be large enough so that the difference between the profits when factors optimally adjust and when factors' adjustment is constrained covers these fixed costs. Similarly, when the firm receives a negative productivity shock, its profits can be improved by trimming down the amount of inputs. Reducing the amount of input is also associated with a fixed cost that is worth to be paid only if the profits saved by optimally adjusting the production factor are substantial enough. That is to say, if the negative shock is important enough.

\subsection{Results from simulations}

To study general equilibrium effects in a model with non-zero adjustment costs, we run simulations of the model. We draw $\mathrm{N}=100,000$ productivity levels from a normal distribution

\footnotetext{
${ }^{12}$ We indeed have $\lambda=(1-\alpha) \int_{0}^{1} \theta(i)^{\frac{1-\varepsilon}{\varepsilon}} d i Y P^{\frac{1}{\varepsilon}}(1-\varepsilon)^{\frac{1}{\varepsilon}} \frac{1}{R_{s} u^{\frac{1}{\varepsilon}}}\left(\frac{w}{u}\right)^{\frac{-\alpha}{1-\alpha(1-\varepsilon)}}$

${ }^{13}$ See Bertola and Caballero (1990) for a survey on discontinuous adjustment control policy and Grossman and Laroque (1990)'s model of consumer durable purchase for a example of such a range of inaction. Perhaps more closely related to our result, Gobillon and Le Blanc (2004) study residential mobility and find that the difference in terms of utility between the relocating household and the non-relocating household linearly depends on the square value of the difference between optimal housing stock and the previously occupied housing stock.
} 
with mean $\mu$ and variance $\sigma^{2}$ and build the friction-less factors' endowment resulting from those draws. We then shock our economy by redrawing new productivity levels from the same distribution in order to study how factors subsequently adjust. Our function objective is to find values for $Y, w$ and $u$ built from the individual decisions of the 100,000 firms and satisfying all market clearing conditions. Based on this numerical resolution of the model, we explore the effect of the frictions on individual firms' behaviour and aggregate outcomes. Parameters value can be found in Table 2. The value of the intermediate output elasticity to real estate, $1-\alpha$, is derived from the average ratio of the market value of structures and land over the aggregate value added of Non-Financial Corporations since 1979, based French aggregate series produced by the INSEE. The calibration of the parameter $\epsilon$ is taken from the literature that usually finds a value around 0.2 or 0.25 (Redding and Weinstein, 2016; Hottman et al., 2016). The results presented below are derived with a parameter value of $0.2{ }^{14}$ We study the behaviour of the model for values of $a$ ranging between 0 and 0.1 . When $a$ is equal 0.1 , the relocation costs correspond to, in average, $0.5 \%$ of the value-added. ${ }^{15}$

Table 2: Value of parameters used in the simulation procedure.

\begin{tabular}{|c|c|c|c|c|}
\hline $\mathrm{N}$ & $\mu$ & $\sigma$ & $\epsilon$ & $\alpha$ \\
\hline 100,000 & 1 & 0.1 & 0.2 & 0.925 \\
\hline
\end{tabular}

\subsubsection{Adjustment costs and firm level behaviour}

In the model with frictions, the non-relocating interval generates discontinuities at the bounds of the interval in the reaction of firms' labor demand to productivity shocks. Those discontinuities directly result from the complementarity between real estate and labor in the production function that conditioned optimal labor demand to the amount of real estate input. Crossing the thresholds for productivity shocks that trigger relocation has a direct impact on the firm's employment dynamics.

We illustrate this effect by simulating the firms' labor demand, across the whole distribution of $\theta$, for varying levels of friction $a$. Those experiments are presented in Figure 2 .

Absent any adjustment costs (red plain line ; $a=0$ ), because real estate and employment jointly adjust for any productivity shocks, employment smoothly varies with changes in productivity and no discontinuity is observed as described in the friction-less model. When introducing adjustment costs, two regimes appear. Outside of the non-relocating interval, firms jointly adjust real estate and employment leading to similar dynamics as in the frictionless case. ${ }^{16}$ Within the non-relocating interval, employment adjusts to productivity shocks more sluggishly because of the predetermined level of real estate. Comparing the dynamics associated with two levels of fixed-costs (blue dotted lines ; $a=0.05$, black dashed line $a=0.1$, we observe that, as already noticed, the non-relocating interval widens with $a$.

\footnotetext{
${ }^{14}$ The results are qualitatively unchanged when we consider $\varepsilon=0.25$. In accordance with the results analytically derived above, the asymmetrical effect of the adjustment costs is lowered for such a value of $\varepsilon$.

${ }^{15}$ This corresponds to the $95^{t h}$ percentile in the distribution of the tax on real estate capital gains (extensively described in the following section) over value added in our firm level database

${ }^{16}$ The differences observed between the various curves outside the intervals of inaction result from changes
} 


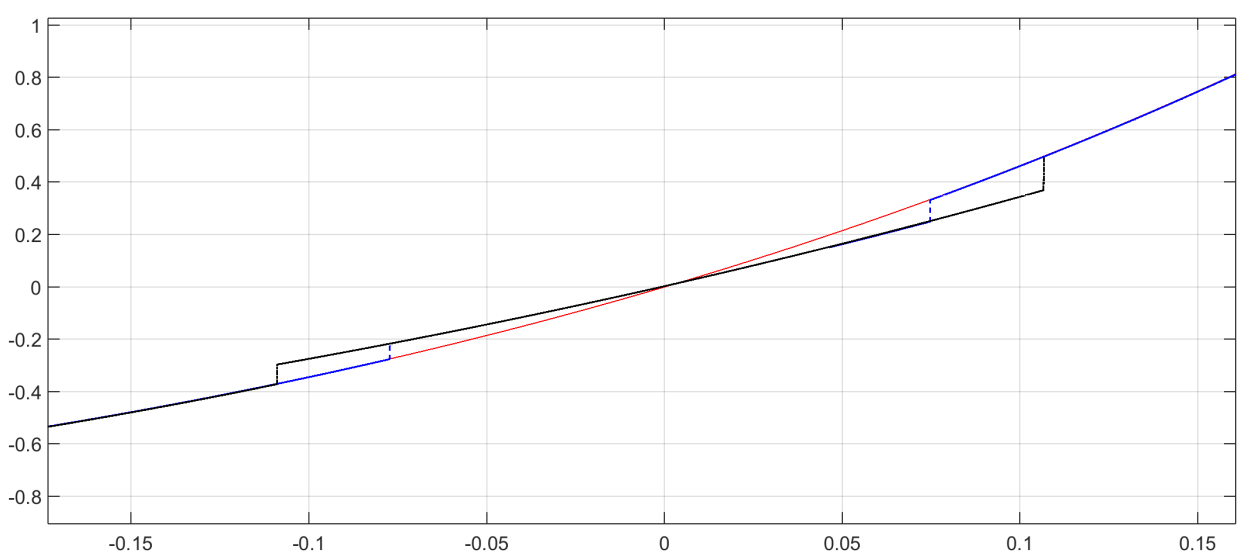

Figure 2: Employment growth as a function of productivity shocks for different values of a

Predictions: (i) relocating firms are characterized by larger employment growth; (ii) because of the asymmetrical effect of the adjustment costs, the growth differential is larger when the firms are growing.

\subsubsection{Adjustment costs and aggregate relocating behaviour}

We have analytically derived that the non-relocating interval widens with the level of the adjustment costs. We numerically solve the model for varying parameter values of $a$ while keeping the productivity distribution constant. We report in Figure 3 the share of relocating firms as function of the parameter value $a$. Because of the increasing width of the nonrelocating interval, we observe that this share strictly decreases as $a$ increases.

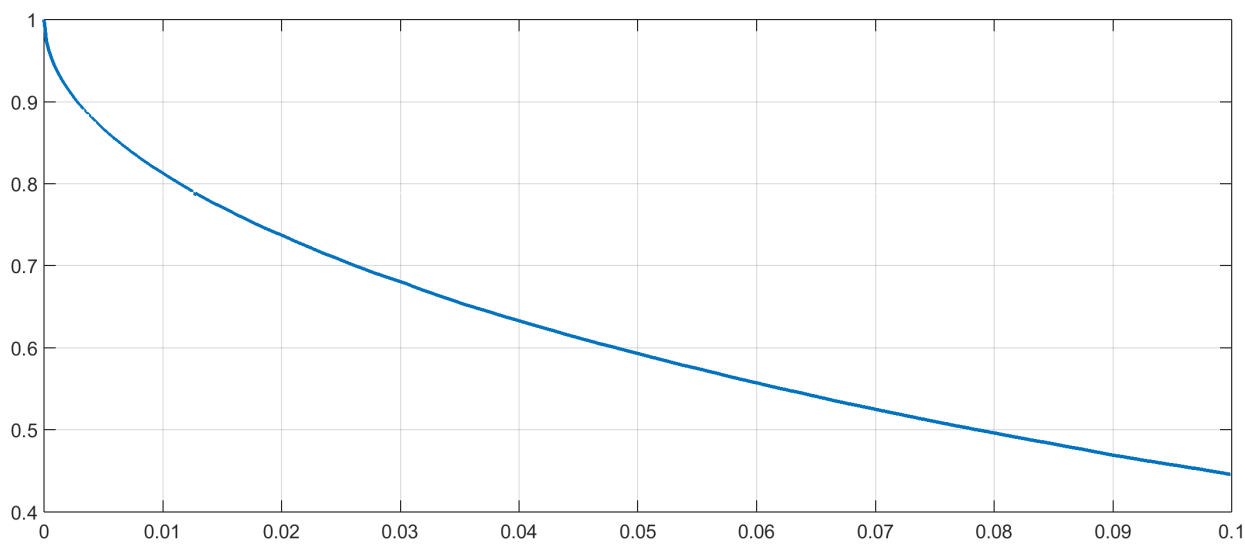

Figure 3: Share of relocating firms for different values of a

Prediction: for a given productivity distribution, the share of relocating firm is decreasing with the level of the adjustment costs.

in input prices that are discussed below 


\subsubsection{Adjustment costs and workforce growth distribution}

Ultimately, we are interested in deriving the effect of the adjustment costs on moments of the workforce growth distribution.

As the fixed costs associated with real estate adjustment rise, for a given distribution of the productivity shocks, a higher share of firms are located in the non-relocating interval. Within this interval, firms affected by positive shocks are stuck in under-sized premises that constrain employment growth whereas firms affected by negative shocks operate in over-sized premises that slow down job destruction. When studying how frictions affect the mean employment growth, we are capturing those two opposite effects.

Our simulations show that those two effects do not cancel out and that the negative effect of the frictions on the growing firms dominates. We indeed find that the mean employment growth decreases with the level of the adjustment costs (upper left panel of Figure C4). This is a direct consequence of the result stating that the asymmetrical effect of the adjustment costs on relocation grows with the level of the frictions. In other words, when $a$ rises, more growing firms than declining firms enter the non-relocating interval. This can be illustrated by plotting the difference between the smallest positive percentage change in real estate size that triggers relocation and the absolute value of the largest negative percentage change that triggers relocation, for different levels of friction. We notice that when $a$ equals 0.1 , the difference between the smallest positive and the largest negative change in real estate size triggering relocation is more than 7 percentage points.

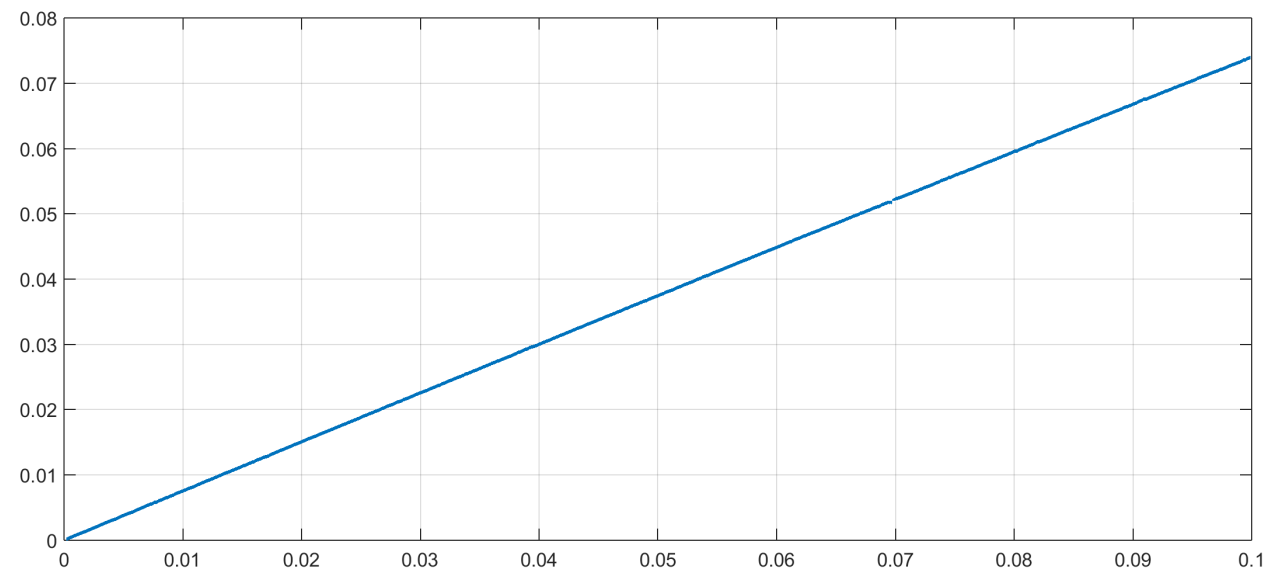

Figure 4: Difference between the smallest positive percentage change in real estate size that triggers relocation and the absolute value of the largest negative percentage change that triggers relocation for different values of $a$

The differentiated effect of adjustment costs on employment growth depending on the sign of the productivity shock can be highlighted by studying positive and negative productivity shocks separately. We plot the mean employment growth as a function of $a$, conditional on positive and negative productivity shocks in the upper right panel and lower left panel of Figures C4, respectively. The mean employment growth of firms affected by a positive productivity shocks is sharply decreasing with $a$ whereas $a$ has a less marked positive impact on the employment decrease of firms stricken by negative productivity shocks.

Prediction: (i) overall average employment growth decreases with the level of adjust- 

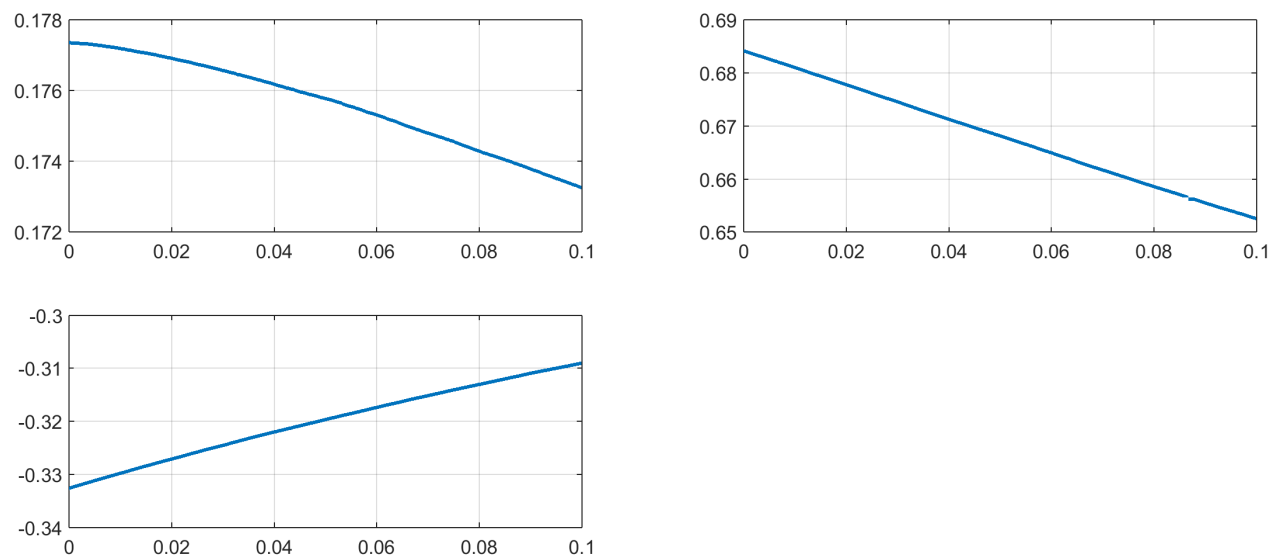

Figure 5: Mean employment growth as a function of a
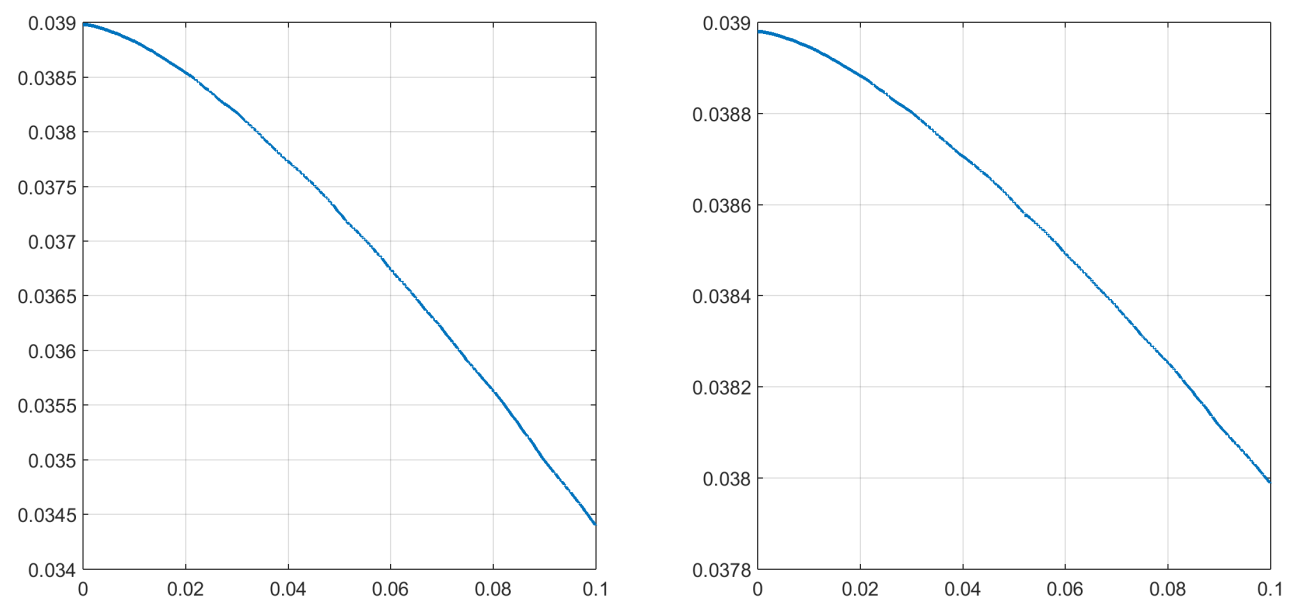

Figure 6: Covariance between $r(i)$ and $\theta(i)$ as a function of a

ment costs; (ii) mean employment growth of growing firms markedly decrease with the level of adjustment costs whereas mean employment growth of declining firms slightly increases

\subsubsection{Aggregate effects of the frictions}

The adjustment costs hinder the optimal allocation of inputs. This results clearly appears when we observe the change in the covariance between inputs' allocation and firm level productivity as the level of the adjustment costs rise (Figure C5). We notice a very sharp decline in the covariance between $r(i)$ and $\theta(i)$ (left panel). We observe a similar pattern for the fall of the covariance between $l(i)$ and $\theta(i)$ but the magnitude of the fall is much less pronounced (right panel) because, even if firms are constrained by their premises' size, they are still able to adjust labor following the productivity shock.

The allocation of labor across firms primarily governs the dynamics of output. In this model where aggregate supplies of corporate real estate and labor are fixed, the effect of 


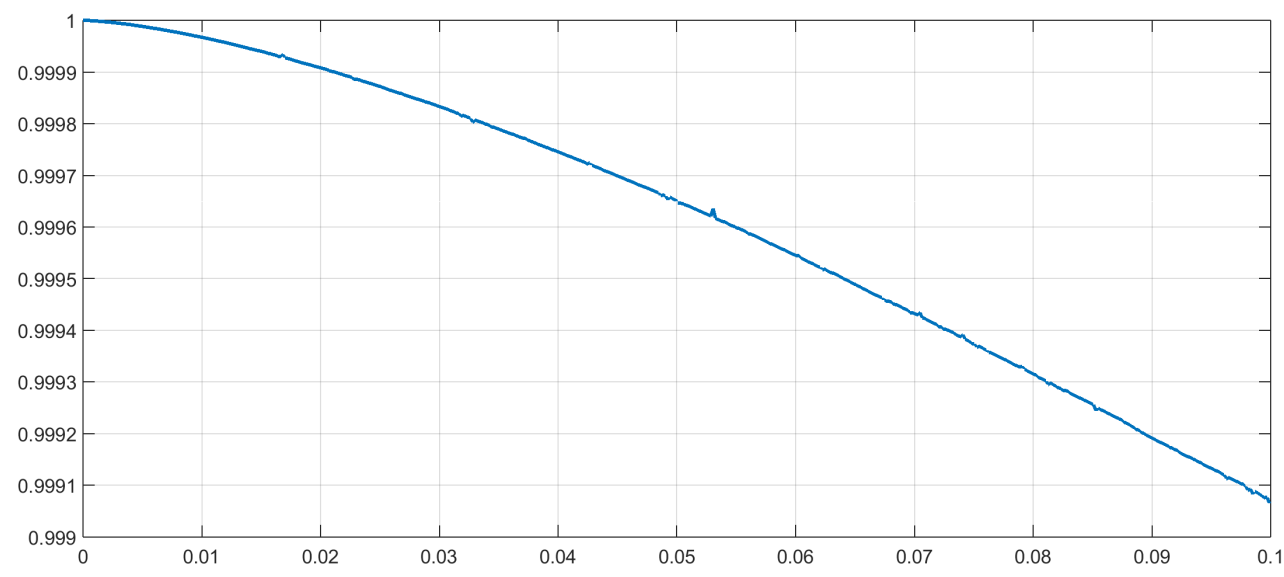

Figure 7: Aggregate output as a function of a $($ no friction $=1)$
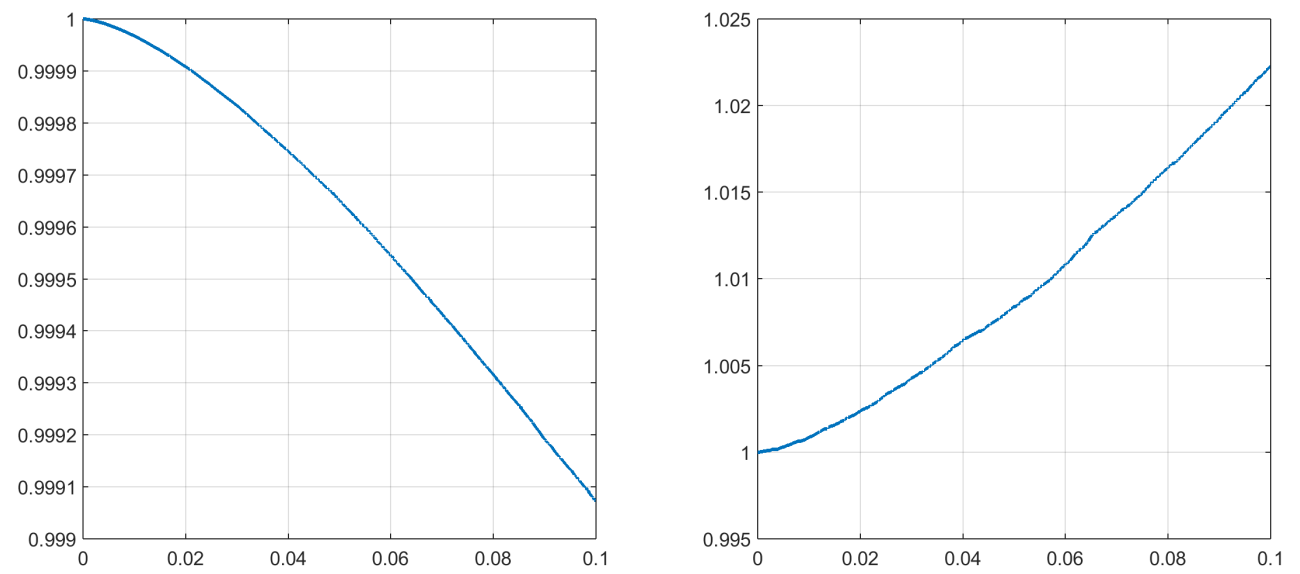

Figure 8: Equilibrium inputs' price as a function of a $($ no friction $=1)$

the frictions on aggregate output is exclusively channeled by the allocation of inputs across firms. Because the allocation of labor is only mildly impaired by the frictions, we obtained negative, but small, negative effect of the friction on the aggregate output (Figure C6).

Our general equilibrium model sets input prices so that the real estate and the labor markets both clear. Figures C7 present the dynamics of the equilibrium inputs' prices when $a$ rises. While the negative impact of the adjustment costs on the weighted average productivity of labor puts downward pressures of the wages (left panel),${ }^{17}$ the distortion induced by the real estate adjustment costs increases the equilibrium price of real estate (right panel). The reason for this result is the following. A rise in $a$ implies that more firms are locked in their premises. It turns out that the supply cut induced by this additional non-relocating firms is larger than the counter-factual optimal real estate size that would be used by those non-relocating firms. As a result, a rise in $a$ has a larger negative impact on aggregate supply than on aggregate demand and causes a sharp increase in $u$.

\footnotetext{
${ }^{17}$ In their model, Garicano et al. (2016) also find a negative effect of the regulation on wage.
} 
These results are derived in a framework where shocks are idiosyncratic and centered in 0 . It is relevant to study the behaviour of the model in presence of an aggregate productivity shock. It can be done by shifting the productivity distribution in period 1 . We present in appendix C.3 the figures that synthesize the simulation results obtained when the mean of the normal distribution from which individual productivity levels are redrawn in period 1 is shifted by $+5 \%$. We observe that the interval of inaction for the productivity shocks shifts to the right as a direct consequence of the general equilibrium effects affecting factor prices. Nevertheless, all the predictions that we have derived are robust to this aggregate productivity shock.

\section{Empirical evidence}

In this section, we use the firm-level dataset described in section 2 to test the predictions of the model. In particular, we show that firms that relocate experience a higher growth rate in their workforce (in absolute value) and that relocations and workforce adjustments are contemporaneous. We find evidence of an asymmetric impact of relocation on the number of employees between growing and declining firms. We show that relocation costs and notably the latent capital gains is negatively correlated with the occurrence of a premises adjustments. We then explore the direct effect of those adjustment costs on the workforce growth distribution.

\subsection{Effect of a local relocation on employment dynamics}

Our first set of regressions aims at confirming the predictions of our model regarding the interaction between relocation and employment growth:

(i) Among growing (resp. declining) firms, the ones that relocate are characterized by higher (resp. lower) employment growth rates than the ones that do not.

(ii) Employment growth gap between relocating and non-relocating firms should be larger for growing firms than for declining firms, resulting in an overall positive effect of relocation on employment.

\section{Cross-Section results}

For a firm $i$, in sector $s$ and département $d$, we denote $\Delta l_{i}$ the average growth of employment over the period of observation and we first consider the following model:

$$
\Delta l_{i}=\beta_{1} z_{i}+\beta_{2} X_{i}+\varepsilon_{i, s, d},
$$

where $z_{i}$ is the yearly frequency of (local) relocation (the number of relocations over the number of years of observation) and $X_{i}$ is a vector of firm specific characteristics taken at the initial year of observation (age, size...). $\varepsilon_{i, s, t}$ includes fixed effects at the sector times département level $(s, d)$ plus an idiosyncratic error. We allow for correlation of this error terms each group of département and sector. ${ }^{18}$

\footnotetext{
${ }^{18}$ In our baseline specification, recall that we consider a relocation to be local if its distance is over $15 \mathrm{~km}$. Tables D1, D2, D3 and D4 show what happens if we change this definition.
} 
Table 3: Relocation and employment dynamics - Cross section results

Dependent variable: Yearly average employment growth (in \%)

\begin{tabular}{lccc}
\cline { 2 - 4 } & All & Growing & Declining \\
& $\mathbf{( 1 )}$ & $\mathbf{( 2 )}$ & $\mathbf{( 3 )}$ \\
\hline Relocate & $0.125^{* * *}$ & $0.209^{* * *}$ & $-0.063^{* * *}$ \\
& $(0.012)$ & $(0.021)$ & $(0.005)$ \\
Age & $-0.078^{* * *}$ & $-0.116^{* * *}$ & $0.020^{* * *}$ \\
& $(0.004)$ & $(0.008)$ & $(0.001)$ \\
Size & $-4.078^{*}$ & $-8.476^{* * *}$ & $4.334^{* * *}$ \\
& $(2.095)$ & $(3.102)$ & $(1.608)$ \\
& & & \\
$\mathrm{R}^{2}$ & 0.059 & 0.110 & 0.158 \\
Observations & 118,980 & 56,983 & 46,605 \\
\hline \hline
\end{tabular}

Notes: The dependent variable, average employment growth, is measured as the mean of yearly employment growth over the period of observation and given in \%. Variables definitions are given in Table A3. Age and Size are taken in the first year the firm appears in the database. Column 1 uses all firms, column 2 (resp. 3) restricts to firms with positive (resp. negative) employment growth. Relocate is equal to the yearly frequency of local relocation (with a distance below 15km) in \% from 1994 to 2013. Regressions include a département $\times$ sector fixed effect. Cross section OLS regression with robust standard errors clustered at the département $\times$ sector level reported in parenthesis. ***, ** and * respectively indicate $0.01,0.05$ and 0.1 levels of significance.

Coefficients of equation (14) are estimated using ordinary least square on different samples: first for all firms, then for firms with a positive average employment growth rate and finally for firms with a negative average employment growth rate. Results are respectively presented in columns 1,2 and 3 of Table 3. Overall, the occurrence of a local relocation is positively associated with employment growth (column 1). The effect is positive for growing firms and negative for declining firms. For the former, results suggest that an increase in the frequency of relocation of 1 percentage point is associated with an increase in employment growth of 0.13 percentage point. Consistently with the model, relocating seems to allow firms to adjust its workforce either upward or downward. However, as suggested by the positive coefficient in column 1 , the overall effect on employment growth is positive. Our results are robust to a number of robustness tests, such as considering smaller time periods to give more relevance to initial conditions or to considering alternative definition of a local relocation. All these additional results can be found in Appendix D.1.

Next, to gain further insight on the heterogeneous effect of a relocation across the distribution of employment growth, we estimate equation (14) using quantile regression model focusing on each of the different deciles. We plot the coefficient on variable $z_{i}$ along with confident intervals in Figure 9. Results confirm those of Table 3, namely that relocating is associated with a different effect depending on the firm's position in the distribution of average employment growth. This effect changes sign around the $40^{\text {th }}$ percentile, which corresponds to an average employment growth of 0 . 
Figure 9: Relocation and employment dynamics - Quantile regression results

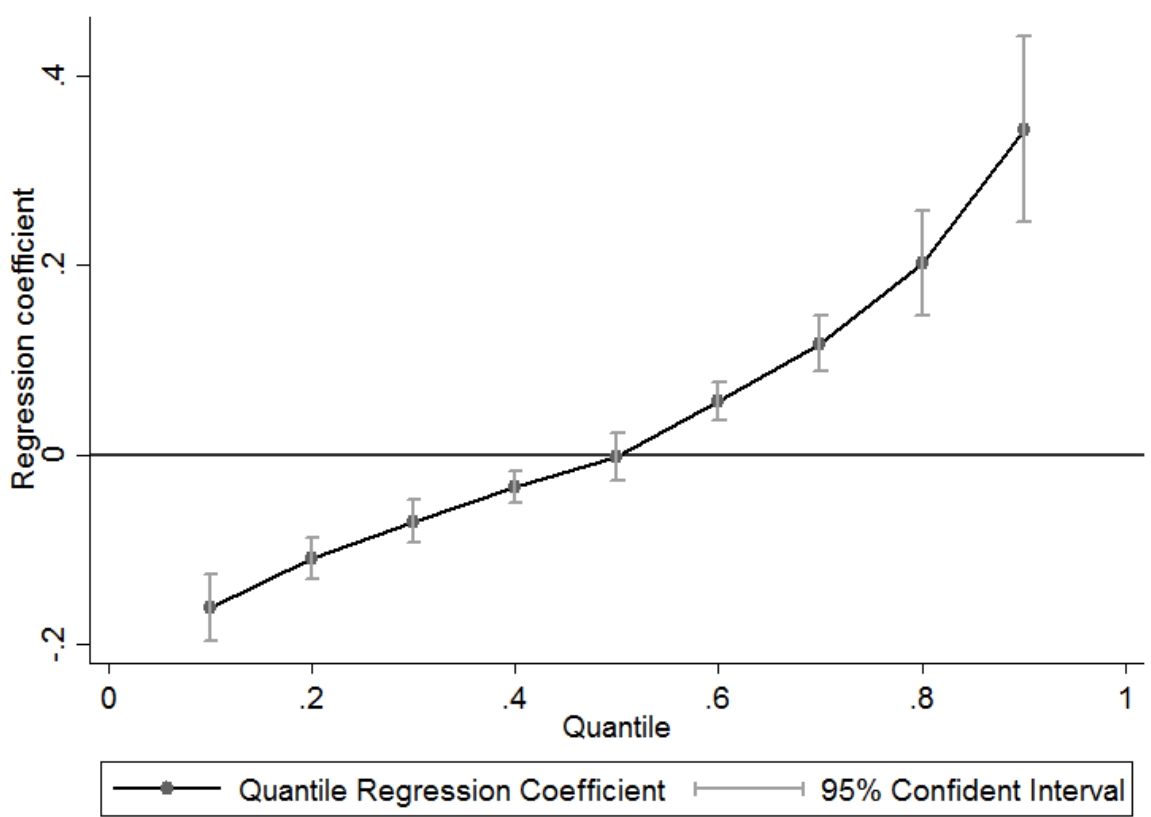

Notes: This graph plots the coefficients on the observed frequency of local relocation during the observed period from a cross-section quantile regression with employment growth as a dependent variable (equation (14)) residualized on a département-sector fixed effect. We plot the coefficient obtained for each of the quantile: $0.1,0.2,0.3,0.4,0.5$, 0.6, 0.7, 0.8 and 0.9 along with the $95 \%$ confidence interval. Regression also includes our usual control variables: Age and Size (both taken in the first year of observation). Confidence intervals at the $95 \%$ level have been estimated with a variance-covariance matrix built with 40 bootstrap replications.

\section{Potential concerns}

One may worry that our regression capture agglomeration effects. As documented by Delgado et al. (2014) and Combes et al. (2012), regional clusters can result in an increasing growth rate of nearby firms that benefit from spillover, even if competition is stiffer. Firms are likely to be attracted by such clusters and subsequent employment growth may be affected by the new site. However, comparing the characteristics between the municipality of departure and the municipality of settlement for growing relocating firms and declining relocating firms does not show support for this alternative mechanism, as far as local relocations are concerned. Indeed, agglomeration effect would predict that growing firms relocate to larger or denser cities, or to cities where the industry in which they operate is more represented while declining firms would act conversely. Yet, in the data, we observe that both growing and declining firms tend to relocate to smaller and less dense municipalities where the level of concentration in the industry as well as its overall size are larger (see Table D7 in Appendix D). This rather corroborates the results on the urban sprawling, documented in the Paris area by Delisle and Laine (1998). ${ }^{19}$ We do not observe any significant

\footnotetext{
${ }^{19}$ This results could also be related to the idea that firms switch to mass production and relocate to specialized cities where production costs are lower as put forward by Duranton and Puga (2001)
} 
asymmetrical behaviour between growing and declining firms in that respect. ${ }^{20}$

\section{Panel Fixed-Effect}

Next, we take advantage of the time dimension of our sample to control for unobserved firm characteristics using fixed-effects panel regressions. We consider the following model:

$$
\Delta l_{i, t}=\gamma_{1, k} z_{i, t-k}+X_{i, t} \gamma_{2}+\epsilon_{i, t, s}
$$

where this time, $\Delta l_{i, t}$ denotes employment growth between $t-1$ and $t, z_{i, t}$ a binary variable for having locally relocated between $t-1$ and $t$ and where control variables vector $X$ is taken at $t . \varepsilon_{i, t, s, d}$ includes fixed effects at the sector times year level $(s, t)$ a firm fixed effect and an idiosyncratic error. We allow for correlation of this error terms within firm.

Estimation results of equation (15) for $k=0, k=1$ and $k=2$ can be found in Table 4. The sample used in columns 1 and 3 is the same as in column 2 of Table 3 whereas the sample used in columns 2 and 4 is the same as in column 3 of Table 3. From these regressions, we see that firms experience a statistically significant modification in the size of their workforce contemporaneously with their relocation. When looking at other lags, the effect of a relocation is not significant for declining firms and only significant for $k=1$ for growing firms.

\subsection{Effects of adjustment costs on employment dynamics}

\section{Owners and Renters}

Our second step is to identify the effect of real estate adjustment costs on employment growth. We need to find an observable measure of relocation costs that is heterogeneous across firms. One first natural candidate is the tenure status (whether the firm owns or rents its premises). Relocating is indeed less costly for renting firms than for real estate owning firms. For example, owners pay legal fees associated with real estate transactions and taxes triggered by the sales of their previous real estate assets. Besides, searching costs are likely to be higher for this type of firms. We therefore expect different relocation behaviour between real estate owner firms and renting firms. This intuition is confirmed by Figure 10 where we replicate Figure 1 but separating for owners and renters. It clearly appears that not only renting firms relocate on average more than others, they also exhibit smaller changes in their workforce for a given propensity to relocate as compared to owners.

However, the choice of the tenure status is not exogenous and is likely to depend on unobservable growth prospects. One can for example imagine that a firm expecting significant increases in its workforce would prefer to rent its premises in order to be more flexible. This would cause a reverse causality issue preventing us from associating a difference in

\footnotetext{
${ }^{20}$ Of course, other external factors may explain both a higher propensity to relocate and employment dynamics. For example, the displacement effect of publicly funded place-based programs documented by Givord et al. (2013); Mayer et al. (2015) and Overman and Einio (2012) can offer a potential alternative story to explain our results. A famous example in France, documented by Mayer et al. (2015) is the case of Zone France Urbaine (ZFU). Our results are however only marginally altered when we remove all firms located less than 15km away from a ZFU (see Table D8 in Appendix D). There exist other differences in the level of local taxes that can also alter location choices (Devereux and Griffith, 2003; Rathelot and Sillard, 2008 and Duranton et al., 2011). Unfortunately, we do not have access to precise information on the local indirect taxes at the level of the municipality over the observation period that would allow us to take them into account.
} 
Table 4: Relocation and employment dynamics - Panel Fixed-Effect results

\begin{tabular}{|c|c|c|c|c|c|c|}
\hline \multicolumn{7}{|c|}{ Dependent variable: Employment growth at $t$ (in \%) } \\
\hline & $\begin{array}{c}\text { Growing } \\
\text { (1) }\end{array}$ & $\begin{array}{l}\text { Declining } \\
\quad(2)\end{array}$ & $\begin{array}{c}\text { Growing } \\
\text { (3) }\end{array}$ & $\begin{array}{c}\text { Declining } \\
\text { (4) }\end{array}$ & $\begin{array}{c}\text { Growing } \\
\text { (5) }\end{array}$ & $\begin{array}{c}\text { Declining } \\
\text { (6) }\end{array}$ \\
\hline Relocate $t$ & $\begin{array}{c}3.663^{* * *} \\
(0.674)\end{array}$ & $\begin{array}{c}-1.706^{* * *} \\
(0.369)\end{array}$ & & & & \\
\hline Relocate $_{t-1}$ & & & $\begin{array}{c}4.079^{* * *} \\
(0.694)\end{array}$ & $\begin{array}{l}-0.085 \\
(0.328)\end{array}$ & & \\
\hline Relocate $t-2$ & & & & & $\begin{array}{c}0.805 \\
(0.606)\end{array}$ & $\begin{array}{c}0.288 \\
(0.319)\end{array}$ \\
\hline Age & $\begin{array}{c}-0.259^{*} \\
(0.145)\end{array}$ & $\begin{array}{c}-0.199 \\
(0.150)\end{array}$ & $\begin{array}{c}-0.256^{*} \\
(0.145)\end{array}$ & $\begin{array}{l}-0.197 \\
(0.150)\end{array}$ & $\begin{array}{c}0.062 \\
(0.146)\end{array}$ & $\begin{array}{c}-0.118 \\
(0.159)\end{array}$ \\
\hline Size & $\begin{array}{c}-75.674^{* * *} \\
(23.791)\end{array}$ & $\begin{array}{c}-18.514^{* *} \\
(8.272)\end{array}$ & $\begin{array}{c}-75.754^{* * *} \\
(23.852)\end{array}$ & $\begin{array}{c}-18.475^{* *} \\
(8.266)\end{array}$ & $\begin{array}{c}-69.808^{* * *} \\
(23.326)\end{array}$ & $\begin{array}{c}-27.582^{* *} \\
(11.486)\end{array}$ \\
\hline $\mathrm{R}^{2}$ & 0.149 & 0.100 & 0.149 & 0.100 & 0.167 & 0.138 \\
\hline Observations & 574,352 & 426,728 & 574,352 & 426,728 & 516,131 & 379,077 \\
\hline
\end{tabular}

Notes: Variables definitions are given in Table A3. Columns 1, 3 and 5 (resp. 2, 4 and 6) restrict to firms with positive (resp. negative) average employment growth over the period 1994-2013. Relocate $t$ is a binary variable equal to 1 if the firm has locally relocated (with a distance below $15 \mathrm{~km}$ ) between year $t-1$ and year $t$. The regressions include a firm fixed effect and a sector times year fixed effect. Panel fixed effect OLS regression with robust standard errors clustered at the firm level reported in parenthesis. ${ }^{* * *},{ }^{* *}$ and $*$ respectively indicate $0.01,0.05$ and 0.1 levels of significance. 
Figure 10: Propensity to relocate and employment growth: owners vs renters

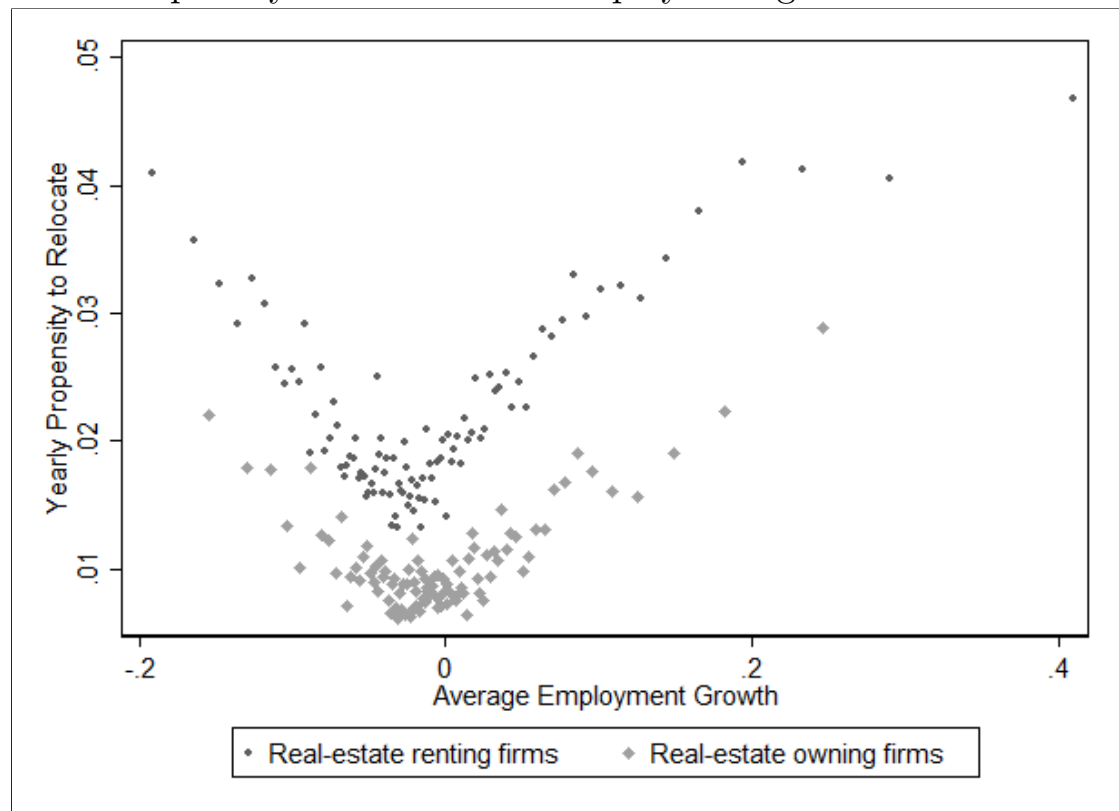

Notes: See Figure 1. Owners and renters have been selected on the first year they appear in the dataset based on their reported volume of real estate. Period of observation: 1994-2013. Source: FiBEn, see Appendix A for more details about the data.

the relocating behaviour or the employment dynamics to higher relocation costs. In fact, we show in Table D9 of Appendix D that the group of renting firms and owning firms are different in many aspects. For this reason, we turn to another measure of the relocation costs: the tax on capital gains that the firm would have to pay upon relocating.

\section{The tax on capital gain}

The tax on capital gains is a tax on the difference between the purchase and selling price of an asset. This tax is only paid by real estate owning firms when they sell their premises. However, we can always proxy its latent level at a yearly frequency at the using local real estate price dynamics. Based on balance sheet data, we recover the market value of real estate holdings by applying the accrued change in the local real estate prices since the acquisition date (approximated thanks to the ratio of the accumulated amortizations of buildings over the gross book value of buildings) to the historical value of building. The latent capital gains correspond to the market value minus the the historical value. The tax scheme takes into a account the holding period and allows to diminish the amount of capital gains by $10 \%$ each year after a five-year holding period (see appendix A for more detail). The latent tax $C$ is obtained by multiplying the marginal corporate income tax $\tau$, which has been equal to $33 \%$ in France over the studied period, and the tax base, determined by the interaction between the acquisition date, the local dynamics of real estate prices since this acquisition and the volume of the premises. Formally:

$$
C_{i, t}=\tau\left[p_{t}^{d}\left(1-A\left(T_{i, t}\right)\right)-p_{t-T_{i, t}}^{d}\right] r_{t-T_{i, t}} \max \left[0,\left(1-0.1 \max \left(T_{i, t}-T_{0}\right)\right)\right],
$$


where $p_{t}^{d}$ is the local observed real-estate price level (taken at the département level), $T_{i, t}$ is the difference between year $t$ and the date of acquisition of real-estate, $r_{t-T_{i, t}}$ is the volume of the premises at the date of acquisition and $\tau, T_{0}$ are two parameters equal to $33 \%$ and 5 years respectively.

For the sake of comparability across firms, we normalize the amount of the latent tax by dividing it by the market value of real estate assets in order to obtain the share of the proceeds from the sale that would be paid under the heading of "tax on capital gains" in the event of the sale of real estate assets. The firm level variation for this quantity is driven by the interaction of the timing of the acquisition of the premises and the local price dynamism since this acquisition, the latter being mostly driven by household and larger firms that we are not considering in our analysis. In addition, because the latent tax level varies with the interaction of these two factors, the impact of each of these factors considered individually can be controlled for in our analysis. The variable that we shall denote Tax $x_{i, t}$ can theoretically takes values between 0 and the marginal corporate income tax $\tau .{ }^{21}$ We observe large variation across firms, with a little less than half of the real estate owners being unaffected by the tax on capital gain $(\operatorname{Tax}=0)$, notably because the tax scheme takes into a account the holding period, and an overall average value of $3.9 \%$ that reaches $7.7 \%$ conditional on being non null with a standard deviation of $4.6 \%$. To get a sense of these rather high values, one may keep in mind that real estate prices have been multiplied by 2.5 in real terms between 1998 and 2008 .

\section{Frictions and relocation}

We proceed in two steps. In the first step, we run various cross-section regressions to show that higher relocation costs, as proxied by the tenure status or, for owning firms, by the latent capital gains, are indeed associated with a lower propensity to relocate. More precisely, we run the following specification for firm $i$ 's decision to relocate:

$$
z_{i}=\mu_{1} T e_{i}+\mu_{2} X_{i}+\varepsilon_{i, s, d}
$$

where $T e_{i}$ is our dummy equal to 1 if the firm reports real estate holdings in initial year of observation. We also consider:

$$
z_{i}=\beta_{1} \operatorname{Tax}_{i}+\beta_{2} X_{i}+\varepsilon_{i, s, d}
$$

where $\operatorname{Tax}_{i}$ has been defined previously. This regression is close to the theoretical results shown in Figure 3. In Figure 11 we plot the observe probability to relocate and the average value of the variable Tax for each percentile of the distribution of Tax. We find a downward curve that shows the same shape as the one in Figure 3.

The estimation results can be found in Table 5: column 1 corresponds to the model presented in equation (17) while columns 2 to 6 correspond to model defined by equation (18). As previously, we control for the age and the size of the firm and a département $\times$ sector fixed effect is added. In columns 3 and 4, we also add covariates capturing the age and the volume of the premises owned by the firm, both of which having direct influence on the propensity to relocate. Column 5 adds a département $\times$ first year of observation fixed effect.

\footnotetext{
${ }^{21}$ Note that $\operatorname{Tax}_{i, t}=\frac{C_{i, t}}{p_{t}^{d}\left(1-A\left(T_{i, t}\right)\right) r\left(t-T_{i, t}\right)}=\tau\left(1-\frac{p_{t-T_{i, t}}^{d}}{p_{t}^{d}\left(1-A\left(T_{i, t}\right)\right)}\right) \max \left[0,\left(1-0.1 \max \left(T_{i, t}-T_{0}\right)\right)\right]$ does not directly depends on the volume of real-estate.
} 
Figure 11: Propensity to relocate and relocation costs as measured by the latent tax on capital gains

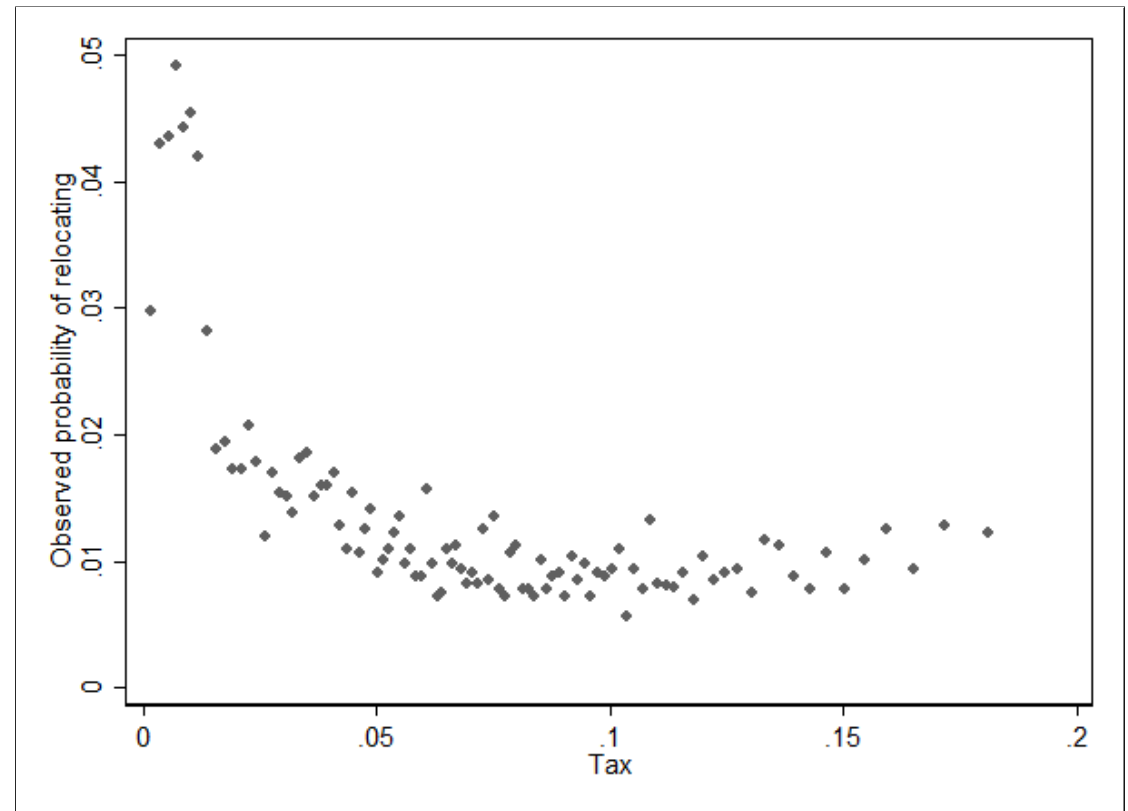

Notes: Tax denotes the share of the proceeds from a potential real estate sale that must be paid as a tax on capital gains. We separate each observations into 100 percentiles of Tax and plot the within percentile share of relocating firms. Period of observation: 1994-2013. Source: FiBEn, see Appendix A for more details about the data.

From column 1, we see that a real estate owning firm has a 0.6 percentage points lower yearly propensity to relocate than an otherwise observably similar renting firm.

In columns 2 to 5 , the main coefficient of interest is the one associated with Tax, the share of the proceeds from the real estate asset sales that would be paid under the heading of the "tax on capital gains". As explained above, this share results from a marginal tax rate, identical across firms, and a tax base, that varies across firms and across time. The variability of the tax base across firms and across time results from heterogeneity in the acquisition dates and in the dynamics of local prices since the acquisition. Results suggest that a one standard deviation increase in this tax share is associated with a 0.8 to 0.9 percentage point reduction in the propensity to relocate among real estate owning firms.

One may be concerned that the level of the latent tax on capital gains is correlated with unobservable growth prospects and that the distributions of changes in productivity is affected by the level of these latent capital gains. However, because the latent capital gains are growing with the positive change in local real estate prices, we are expecting that the higher the latent capital gains, the better the local economic conditions and the more likely the firms are to relocate. We hence argue that any correlation between the latent capital gains and unobservable growth prospects upward bias our coefficient of interest and that the negative effect of the latent tax on the propensity to relocate is an upper bound. In addition, in column 6 of Table 5, we replace variable Tax by another proxy constructed in the exact same way as Tax, but using an index of real estate prices computed at the 
Table 5: Relocation cost and relocation choice - Cross section OLS

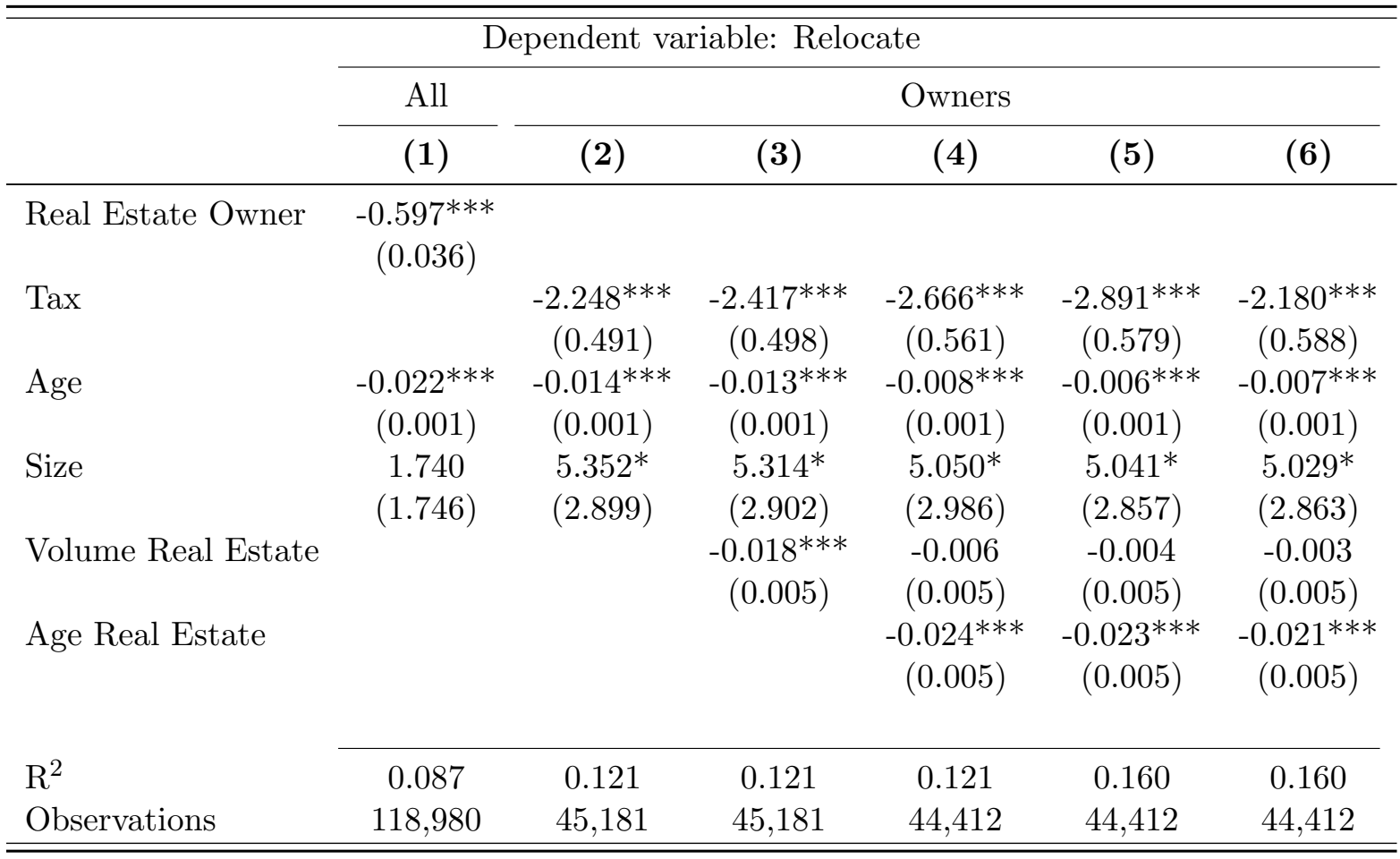

Notes: Variables definitions are given in Table A3. Column 1 uses all firms while columns 2 to 5 restrict to real estate owners. The dependent variable, Relocate, is equal to the yearly frequency of local relocation (with a distance below $15 \mathrm{~km}$ ) in \% from 1994 to 2013. Other variables are taken in the first year of observation. Regressions include a département $\times$ sector fixed effect. Column 5 adds a département $\times$ first year of observation fixed effect. Column 6 uses an alternative proxy for the latent tax on capital gain built from national price level. Cross section OLS regression with robust standard errors clustered at the département $\times$ sector level reported in parenthesis. ${ }^{* * *}$, ** and * respectively indicate $0.01,0.05$ and 0.1 levels of significance. 
Table 6: Relocation cost and relocation choice - Panel Fixed-Effect results

\begin{tabular}{lccccc}
\hline \hline \multirow{5}{*}{ Dependent variable: } & Dummy for having relocated at $t$ \\
\cline { 2 - 6 } & Owners & Owners & Owners & Owners & Owners \\
& $(\mathbf{1})$ & $\mathbf{( 2 )}$ & $\mathbf{( 3 )}$ & $\mathbf{( 4 )}$ & $\mathbf{( 5 )}$ \\
\hline $\operatorname{Tax}_{t-1}$ & $-0.181^{* * *}$ & & & $-0.179^{* * *}$ & $-0.168^{* * *}$ \\
& $(0.007)$ & & & $(0.010)$ & $(0.009)$ \\
$\operatorname{Tax}_{t-2}$ & & $-0.120^{* * *}$ & & -0.001 & -0.008 \\
& & $(0.006)$ & & $(0.009)$ & $(0.009)$ \\
$\operatorname{Tax}_{t-3}$ & & & $-0.067^{* * *}$ & -0.007 & 0.001 \\
& & & $(0.005)$ & $(0.007)$ & $(0.007)$ \\
Age & $0.001^{* * *}$ & 0.001 & $0.001^{* * *}$ & $0.001^{* * *}$ & $0.001^{* * *}$ \\
& $(0.000)$ & $(0.001)$ & $(0.000)$ & $(0.000)$ & $(0.000)$ \\
Size & -0.015 & -0.030 & -0.030 & -0.022 & -0.024 \\
& $(0.017)$ & $(0.020)$ & $(0.025)$ & $(0.024)$ & $(0.024)$ \\
Real Estate Age & $-0.003^{* * *}$ & $-0.002^{* * *}$ & $-0.002^{* * *}$ & $-0.002^{* * *}$ & $-0.002^{* * *}$ \\
\multirow{4}{*}{ Real Estate Volume } & $(0.000)$ & $(0.000)$ & $(0.000)$ & $(0.000)$ & $(0.000)$ \\
& $0.001^{* * *}$ & $0.001^{* * *}$ & $0.001^{* * *}$ & $0.001^{* * *}$ & $0.001^{* * *}$ \\
& $(0.000)$ & $(0.000)$ & $(0.000)$ & $(0.000)$ & $(0.000)$ \\
$\mathrm{R}^{2}$ & & & & & \\
\cline { 2 - 6 } Observations & 0.152 & 0.160 & 0.161 & 0.164 & 0.164 \\
\hline \hline
\end{tabular}

Notes: Variables definitions are given in Table A3. The dependent variable is a binary variable equal to 1 if the firm has locally relocated (with a distance below $15 \mathrm{~km}$ ) between $t$ and $t+1$. Regression includes a firm fixed effect and a sector times year fixed effect. Column 5 uses an alternative proxy for the latent tax on capital gain based on national price level. Panel fixed effect OLS regression with robust standard errors clustered at the département level reported in parenthesis. ${ }^{* * *},{ }^{* *}$ and ${ }^{*}$ respectively indicate $0.01,0.05$ and 0.1 levels of significance.

national level, excluding the area where the firm is based. ${ }^{22}$

Another potential concern is that the latent tax on capital gains is in fact capturing many different features, and namely the fact that it mechanically decreases with the age of real-estate. However, when moving from column 2 to column 5 of Table 5 , the coefficient on the latent tax variable is stronger (in absolute value) as we add more control variables on the nature of the real estate.

Finally, to control for firm specific characteristics that are unobservable with our data, we run a panel fixed effects model. In terms of timing, the dependent variable, $z_{i, t}$ is a binary variable equal to 1 if the firm has relocated locally between $t$ and $t+1$ and the variable $\operatorname{Tax}_{i, t}$ is computed at the end of the year. Results are presented in Table 6 and are consistent with what was found in the OLS estimation of the cross-section model.

All these results speak to the intuitive idea that relocation costs dampen the firms'

\footnotetext{
${ }^{22}$ Formally, we use formula (16) where we replaced $p_{t}^{d}$ by ${\tilde{p_{t}}}^{d}=\sum_{\delta \neq d} w^{\delta} p_{t}^{\delta}$, with $w^{\delta}$ being a weight associated with département $\delta$ based on its population. See Table D12, for more results using this alternative definition of the tax on capital gain.
} 
propensity to relocate. By highlighting the role of the latent tax on capital gains, they provide empirical evidence to support our model. They also echo those of the existing literature that emphasized the "lock-in" effect of the tax on capital gains (see for example Yitzhaki, 1979; Feldstein et al., 1980 or Kanemoto, 1996).

\section{Direct effect of relocation costs}

We now turn to our second step where we explore the effect of the relocation costs on employment dynamics though its direct negative effect on the propensity to relocate. Our model predicts that the relationship between relocation costs and employment growth differ across the distribution of productivity shocks.

As in Table 3, we run cross-section $O L S$ regressions where the dependent variable is the average employment growth over the observed time period. As in Table 5, we focus on the two distinct sources of heterogeneity with regard to relocation costs. Specifically, we estimate the following equation:

$$
\Delta l_{i}=\mu T e_{i}+\mu_{2} X_{i}+\varepsilon_{i, s, d}
$$

where $T e$ is, as previously, a binary variable equal to 1 if the firm owns its real estate and $\varepsilon_{i, s, d}$ contains an idiosyncratic error term and a département-sector fixed effect. Restricting our sample to owning firms, we also estimate:

$$
\Delta l_{i}=\beta_{1} \operatorname{Tax}_{i}+\beta_{2} X_{i}+\varepsilon_{i, s, d} .
$$

Results can be found in Table 7. Columns 1 and 2 report estimates of equation (19) and restrict attention respectively to growing and declining firms. We include our usual set of control variables considered in the first year the firm appears in the sample. For growing firms, we find that holding real estate assets is associated with a mean employment growth lower by almost 1 percentage point as compared to similar renting firms. For declining firm, the estimate is positive but smaller in magnitude (around 0.2). We turn to the model presented in equation (20) using the latent tax on capital gains. Results are presented in columns 3 and 4, where we have also added covariates to control for the age and volume of owned real estate assets. We observe that the latent tax on capital gains has a negative effect for growing firms. A one standard deviation reduction in the (latent) share of the proceeds from the premises' sales that would be paid as a tax on capital gains is associated with an increase of 0.25 percentage point in yearly employment growth for growing firms. Finally, notice that the fact that the latent tax on capital gains is only paid in the case of a relocation, it is unlikely that it has any other direct effects on the employment growth once we control for any local dynamism through département-sector fixed effects.

Just like previously, we estimate the same equation (20) using a quantile regression model. The results, presented in Figure 12, is consistent with what we described above and the prediction of the model: relocation costs have a negative effect on employment for growing firms and a positive effect for declining firms.

Overall, relocation costs have a negative effect on employment. We can show this by taking advantage of our panel and we run the following model for various value of $k$ :

$$
\Delta l_{i, t}=\beta_{1} \operatorname{Tax}_{i, t-k}+X_{i, t} \beta_{2}+\varepsilon_{i, s, d, t} .
$$


Table 7: Relocation costs and employment dynamics - Cross section results

Dependent variable: Yearly average employment growth (in \%)

\begin{tabular}{|c|c|c|c|c|c|c|}
\hline & $\begin{array}{c}\text { Growing } \\
\text { (1) }\end{array}$ & $\begin{array}{c}\text { Declining } \\
\text { (2) }\end{array}$ & $\begin{array}{c}\text { Growing } \\
\text { Owners } \\
(\mathbf{3})\end{array}$ & $\begin{array}{c}\text { Declining } \\
\text { Owners } \\
(4)\end{array}$ & $\begin{array}{c}\text { Growing } \\
\text { Owners } \\
(5)\end{array}$ & $\begin{array}{c}\text { Declining } \\
\text { Owners } \\
(\mathbf{6})\end{array}$ \\
\hline Real Estate Owner & $\begin{array}{c}-0.987^{* * *} \\
(0.149)\end{array}$ & $\begin{array}{c}0.228^{* * *} \\
(0.046)\end{array}$ & & & & \\
\hline Tax & & & $\begin{array}{c}-4.855^{* *} \\
(2.309)\end{array}$ & $\begin{array}{l}-0.243 \\
(0.767)\end{array}$ & $\begin{array}{c}-5.260^{* *} \\
(2.390)\end{array}$ & $\begin{array}{l}-0.127 \\
(0.737)\end{array}$ \\
\hline Age & $\begin{array}{c}-0.076^{* * *} \\
(0.007)\end{array}$ & $\begin{array}{c}0.010^{* * *} \\
(0.001)\end{array}$ & $\begin{array}{c}-0.035^{* * *} \\
(0.008)\end{array}$ & $\begin{array}{c}0.006^{* * *} \\
(0.002)\end{array}$ & $\begin{array}{c}-0.035^{* * *} \\
(0.008)\end{array}$ & $\begin{array}{c}0.006^{* * *} \\
(0.002)\end{array}$ \\
\hline Size & $\begin{array}{l}-3.309 \\
(2.059)\end{array}$ & $\begin{array}{c}4.187^{* * *} \\
(1.531)\end{array}$ & $\begin{array}{l}-2.680 \\
(6.220)\end{array}$ & $\begin{array}{c}9.785^{* *} \\
(4.085)\end{array}$ & $\begin{array}{l}-2.732 \\
(6.221)\end{array}$ & $\begin{array}{c}9.785^{* *} \\
(4.082)\end{array}$ \\
\hline Age Real Estate & & & $\begin{array}{c}-0.087^{* * *} \\
(0.024)\end{array}$ & $\begin{array}{l}-0.003 \\
(0.007)\end{array}$ & $\begin{array}{c}-0.089^{* * *} \\
(0.024)\end{array}$ & $\begin{array}{l}-0.003 \\
(0.007)\end{array}$ \\
\hline Volume Real Estate & & & $\begin{array}{c}0.078 \\
(0.055)\end{array}$ & $\begin{array}{c}-0.034^{* *} \\
(0.017)\end{array}$ & $\begin{array}{c}0.079 \\
(0.055)\end{array}$ & $\begin{array}{c}-0.034^{* *} \\
(0.017)\end{array}$ \\
\hline $\mathrm{R}^{2}$ & 0.105 & 0.216 & 0.243 & 0.310 & 0.243 & 0.310 \\
\hline Observations & 72,375 & 46,605 & 24,855 & 19,557 & 24,855 & 19,557 \\
\hline
\end{tabular}

Notes: The dependent variable, average employment growth, is measured as the mean of yearly employment growth over the period of observation and given in \%. Variables definitions are given in Table A3. All covariates are taken in the first year the firm appears in the database. Columns 1, 3 and 5 (resp. 2, 4 and 6) restrict to firms with positive (resp. negative) employment growth over the period of observation. Columns 3 to 6 in addition restrict to real estate owning firms. Regressions include the number of years of observation for each firm and a sector times département fixed effect. Columns 5 and 6 uses a proxy for the tax on capital gain based on real-estate prices at the national level. Cross section OLS regression with robust standard errors clustered at the département level reported in parenthesis. $* * *,{ }^{* *}$ and $*$ respectively indicate $0.01,0.05$ and 0.1 levels of significance.

Just like previously, $\varepsilon_{i, t, s, d}$ includes fixed effects at the sector times year level $(s, t)$ a firm fixed effect and an idiosyncratic error. We allow for correlation of this error terms within firm. Results are shown in Table 8 and confirm our previous findings even after controlling for any firm specific unobserved time-invariant characteristics.

\subsection{Implication in terms of misallocation}

Our results suggest that frictions in the real-estate market generate a suboptimal allocation of premises volume and in turns of workforce due to the complementarity between the two inputs. To illustrate this, we construct a measure of misallocation based on Olley and Pakes (1996) and following Duranton et al. (2015), by calculating the covariance between the market share of a firm and its labor productivity level. We should expect that areas in which the real estate market is more constrained have a higher misallocation of inputs. In Figure 13, we have plotted the misallocation index against the share of firms that are real- 
Table 8: Relocation costs and employment dynamics - Panel Fixed-Effect results

\begin{tabular}{|c|c|c|c|c|}
\hline \multicolumn{5}{|c|}{ Dependent variable: employment growth at $t$ (in \%) } \\
\hline & $\begin{array}{c}\text { Owners } \\
(1)\end{array}$ & $\begin{array}{c}\text { Owners } \\
(\mathbf{2})\end{array}$ & $\begin{array}{c}\text { Owners } \\
(\mathbf{3})\end{array}$ & $\begin{array}{c}\text { Owners } \\
(4)\end{array}$ \\
\hline $\operatorname{Tax}_{t-1}$ & $\begin{array}{c}-13.732^{* * *} \\
(1.717)\end{array}$ & & & $\begin{array}{c}-6.522^{* * * *} \\
(2.384)\end{array}$ \\
\hline $\operatorname{Tax}_{t-2}$ & & $\begin{array}{c}-11.709^{* * *} \\
(1.316)\end{array}$ & & $\begin{array}{c}-5.811^{* *} \\
(2.434)\end{array}$ \\
\hline $\operatorname{Tax}_{t-3}$ & & & $\begin{array}{c}-8.192^{* * *} \\
(1.517)\end{array}$ & $\begin{array}{l}-2.199 \\
(2.146)\end{array}$ \\
\hline Age & $\begin{array}{c}-0.220^{* *} \\
(0.096)\end{array}$ & $\begin{array}{l}-0.121 \\
(0.110)\end{array}$ & $\begin{array}{c}-0.275^{* *} \\
(0.110)\end{array}$ & $\begin{array}{c}-0.268^{* *} \\
(0.110)\end{array}$ \\
\hline Size & $\begin{array}{c}-0.112^{\text {*** }} \\
(0.025)\end{array}$ & $\begin{array}{c}-0.115^{* * *} \\
(0.025)\end{array}$ & $\begin{array}{c}-0.135^{* * *} \\
(0.030)\end{array}$ & $\begin{array}{c}-0.133^{* * *} \\
(0.030)\end{array}$ \\
\hline Real Estate Age & $\begin{array}{c}-0.247^{* * *} \\
(0.022)\end{array}$ & $\begin{array}{c}-0.192^{* * *} \\
(0.017)\end{array}$ & $\begin{array}{c}-0.152^{\text {*** }} \\
(0.018)\end{array}$ & $\begin{array}{c}-0.184^{* * *} \\
(0.021)\end{array}$ \\
\hline Real Estate Volume & $\begin{array}{c}0.142^{* * *} \\
(0.036)\end{array}$ & $\begin{array}{c}0.107^{* * *} \\
(0.026)\end{array}$ & $\begin{array}{c}0.100^{* * *} \\
(0.025)\end{array}$ & $\begin{array}{c}0.099^{* * * *} \\
(0.025)\end{array}$ \\
\hline Observations & 424,912 & 381,535 & 338,238 & 338,238 \\
\hline $\mathrm{R}^{2}$ & 0.155 & 0.167 & 0.171 & 0.171 \\
\hline
\end{tabular}

Notes: Variables definitions are given in Table A3. Regression includes a firm fixed effect and a sector times year fixed effect. Panel fixed effect OLS regression with robust standard errors clustered at the firm level reported in parenthesis. $* * *, * *$ and $*$ respectively indicate $0.01,0.05$ and 0.1 levels of significance.

estate owners for each département. The correlation between the two is clearly positive. ${ }^{23}$ As in Hsieh and Klenow (2009), misallocation induced by the distortion of the real estate market account for a reduction in aggregate productivity and consequently in aggregate output.

\footnotetext{
${ }^{23}$ In Figure 13, we show results for the year 1994 but using another year or pooling all years together show similar upward slopping fitting line.
} 
Figure 12: Relocation costs and employment dynamics - Quantile regression results

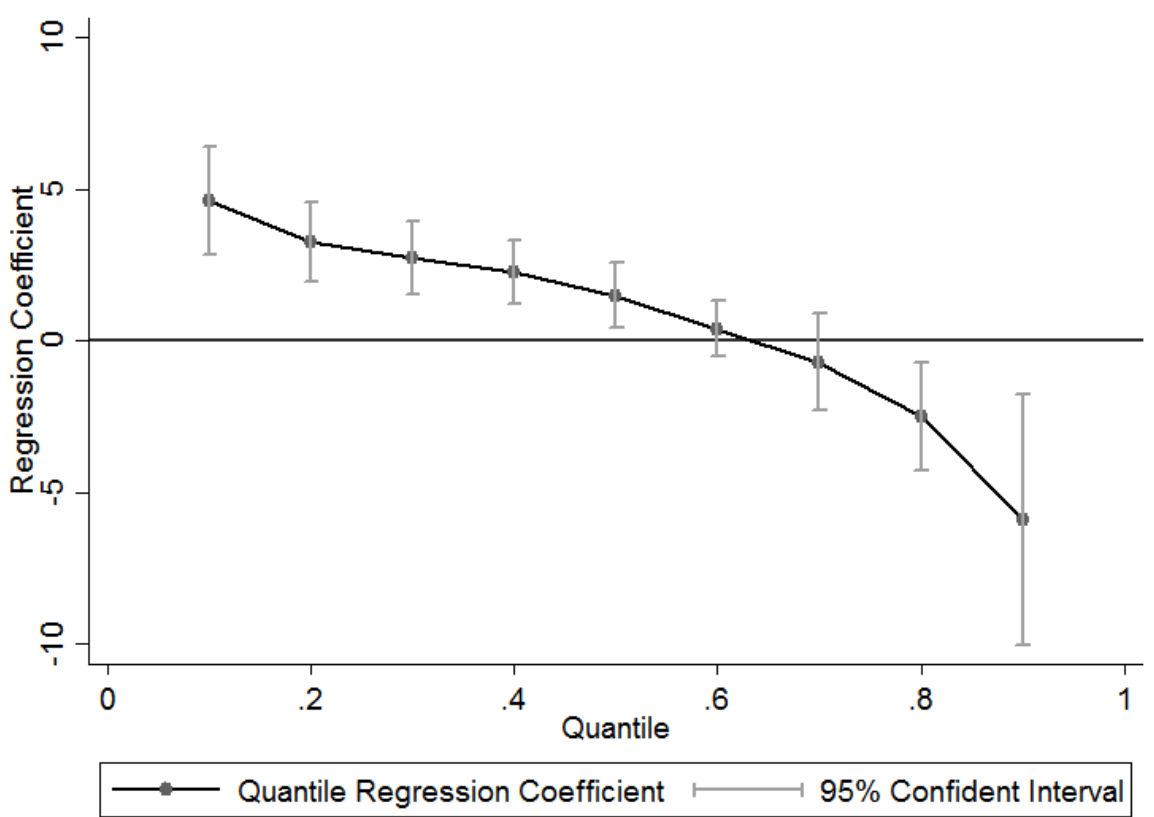

Notes: This graph plots the coefficients on the latent tax on capital gain (Tax) from a cross-section quantile regressions with employment growth as a dependent variable (equation (17)) residualized on a département-sector fixed effect. We plot the coefficient obtained for each of the quantile: $0.1,0.2,0.3,0.4,0.5,0.6,0.7,0.8$ and 0.9 along with the $95 \%$ confidence interval. Regression also includes our usual control variables: Age, Size, Age and Volume of real-estate (all taken in the first year of observation). Confidence intervals at the $95 \%$ level have been estimated with a variance-covariance matrix built with 40 bootstrap replications. 
Figure 13: Relocation frictions and misallocation

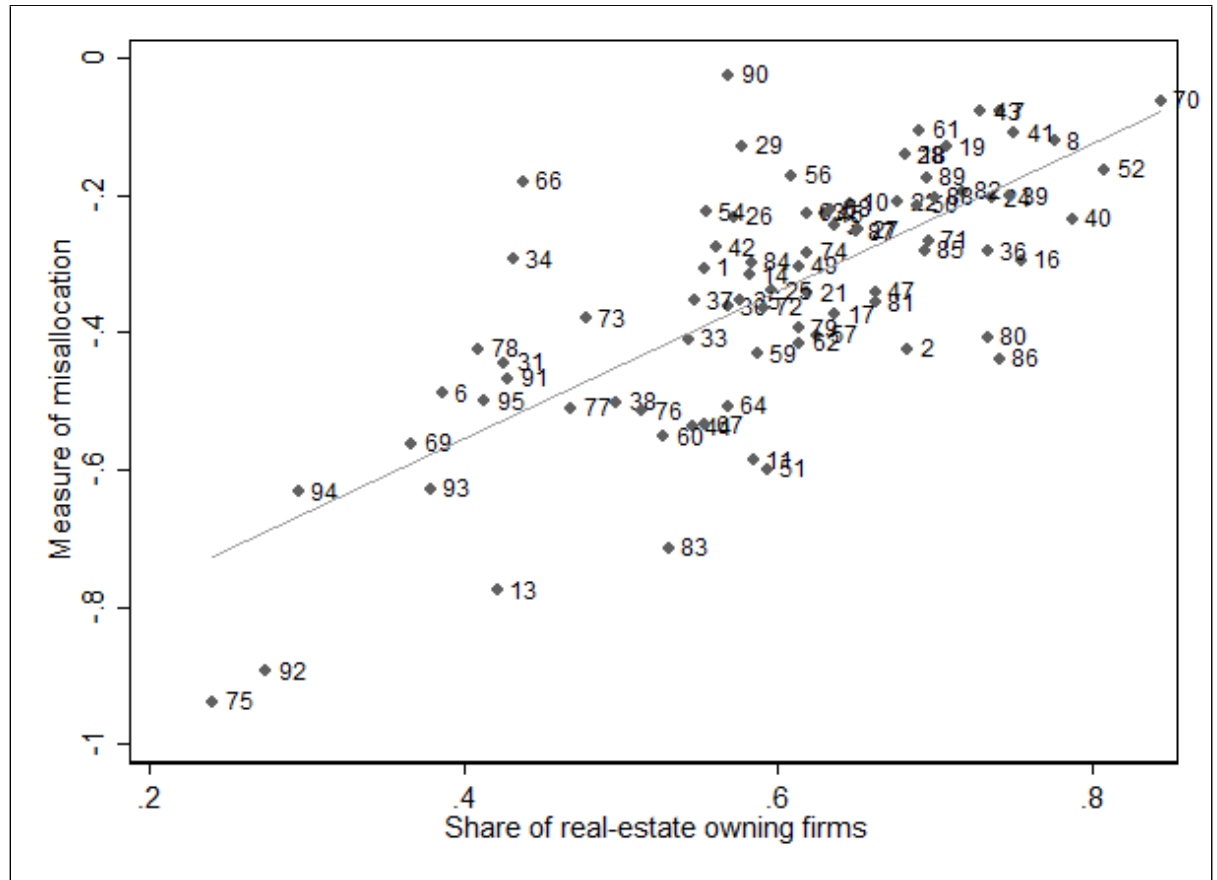

Notes: This graph plots the measure of misallocation presented in subsection 4.3 against the share of real-estate owning firms in each departement in 1994. Département codes are explained in Table A1. Source: FiBEn, see Appendix A for more details about the data. 


\section{Conclusion}

This paper derives the theoretical implications of adjustment costs of real estate assets on firm level factors' demand and explores the empirical relevance of the derived theoretical prediction.

First, we build a general equilibrium model in which firms make decisions on inputs' adjustment following productivity shocks against a background of fixed adjustment costs of real estate induced by relocation. The model predicts that a relocation is associated with a concomitant adjustment of employment level. The magnitude of those adjustments may differ whether the firm is growing or slackening; the relocation of a growing firms being typically associated with larger change in the workforce. Our model also predicts that relocation costs reduce the propensity to relocate and distort the employment growth distribution with a particularly marked negative impact on firms facing positive productivity shocks.

Second, we confront these predictions to the data using a large dataset on French firms over the period 1994-2013 and taking advantage of the firm-level heterogeneity in the real estate adjustment costs entailed by the latent tax on real estate capital gains. All the results derived from the theoretical framework are confirmed. Relocating is associated with significant adjustment in the workforce size and the level of the adjustment costs reduces the propensity to relocate, and constrains jobs creation of the growing firms.

This paper documents an example of costs that prevent the optimal adjustment of inputs across firms following productivity shocks and provides evidence of their effect on misallocation of inputs across firms. 


\section{References}

Aghion, Philippe and Peter Howitt, "A Model of Growth through Creative Destruction," Econometrica, March 1992, 60 (2), 323-351.

Asker, John, Allan Collard-Wexler, and Jan De Loecker, "Dynamic Inputs and Resource (Mis)Allocation," Journal of Political Economy, 2014, 122 (5), 1013 - 1063.

Bertola, Giuseppe and Ricardo Caballero, "Kinked adjustment costs and aggregate dynamics," in "NBER Macroeconomics Annual 1990, Volume 5," MIT Press, 1990, pp. 237-296.

Best, Michael Carlos and Henrik Jacobsen Kleven, "Housing market responses to transaction taxes: Evidence from notches and stimulus in the UK," 2013. Mimeo, London School of Economics.

Bloom, N., "The impact of uncertainty shocks," econometrica, 2009, 77 (3), 623-685.

Brouwer, Aleid E., Ilaria Mariotti, and Jos N. van Ommeren, "The firm relocation decision: An empirical investigation," The Annals of Regional Science, 06 2004, 38 (2), $335-347$.

Caballero, R., E. Engel, and J. Haltiwanger, "Aggregate Employment Dynamics: Building from Microeconomic Evidence," The American Economic Review, 1997, pp. 115137.

_, _, , M. Woodford, and R. Hall, "Plant-level adjustment and aggregate investment dynamics," Brookings papers on economic activity, 1995, pp. 1-54.

Chaney, Thomas, David Sraer, and David Thesmar, "Real Estate Collateral and Labor Demand," 2013. Mimeo, Toulouse School of Economics.

Combes, Pierre-Philippe, Gilles Duranton, Laurent Gobillon, Diego Puga, and Sebastien Roux, "The productivity advantages of large cities: Distinguishing agglomeration from firm selection," Econometrica, 2012, 80 (6), 2543-2594.

Cooper, R. and J. Haltiwanger, "On the nature of capital adjustment costs," The Review of Economic Studies, 2006, 73 (3), 611-633.

- and J. Willis, "The cost of labor adjustment: Inferences from the gap," Review of Economic dynamics, 2009, 12 (4), 632-647.

_ , J. Haltiwanger, and L. Power, "Machine Replacement and the Business Cycle: Lumps and Bumps," American Economic Review, 1999, 89 (4), 921-946.

Dachis, Benjamin, Gilles Duranton, and Matthew Turner, "The effects of land transfer taxes on real estate markets: evidence from a natural experiment in Toronto," Journal of Economic Geography, 2012, 12 (2), 327-354.

Delgado, Mercedes, Michael E. Porter, and Scott Stern, "Clusters, convergence, and economic performance," Research Policy, 2014, 43 (10), 1785-1799. 
Delisle, Jean-Pierre and Frédéric Laine, "Les transferts d'établissements contribuent au desserrement urbain," Économie et Statistique, 1998, 311 (1), 91-106.

Devereux, Michael P. and Rachel Griffith, "Evaluating tax policy for location decisions," International Tax and Public Finance, 2003, 10 (2), 107-126.

Duranton, G. and D. Puga, "Nursery cities: Urban diversity, process innovation, and the life cycle of products," American Economic Review, 2001, pp. 1454-1477.

Duranton, Gilles., Laurent Gobillon, and Henry G. Overman, "Assessing the effects of local taxation using microgeographic data," The Economic journal, 2011, 121 (555), $1017-1046$.

Duranton, Gilles, Syed Ejaz Ghani, Arti Grover Goswami, and William Robert Kerr, "The misallocation of land and other factors of production in India," March 2015.

Elsby, M. and R. Michaels, "Fixed adjustment costs and aggregate fluctuations," 2014. Mimeo, University of Edinburgh.

Feldstein, Martin, Joel Slemrod, and Shlomo Yitzhaki, "The Effects of Taxation on the Selling of Corporate Stock and the Realization of Capital Gains," The Quarterly Journal of Economics, 1980, 94 (4), 777-791.

Foster, Lucia, John Haltiwanger, and Chad Syverson, "Reallocation, Firm Turnover, and Efficiency: Selection on Productivity or Profitability?," American Economic Review, March 2008, 98 (1), 394-425.

Fougère, D., R. Lecat, and S. Ray, "Real Estate and Corporate Investmeent: Theory and Evidence of Heterogeneous Effects Across Firms," 2017.

Fougère, Denis and Mathilde Poulhes, "The Effect of Housing on Portfolio Choice: A Reappraisal Using French Data," CEPR Discussion Paper, 2012, (9213).

Friggit, Jacques, "Le prix des logements sur longue période," Informations sociales, 2009, 155 (5), 26-33.

Garicano, L., C. Lelarge, and J. Van Reenen, "Firm Size Distortions and the Productivity Distribution: Evidence from France," American Economic Review, November 2016, 106 (11), 3439-79.

Givord, P., R. Rathelot, and P. Sillard, "Place-based tax exemptions and displacement effects: An evaluation of the Zones Franches Urbaines program," Regional Science and Urban Economics, 2013, 43 (1), 151-163.

Gobillon, L. and D. Le Blanc, "L'impact des contraintes d'emprunt sur la mobilité résidentielle et les choix entre location et propriété," Annales d'Économie et de Statistique, 2004, pp. 15-45.

Grossman, S. and G. Laroque, "Asset Pricing and Optimal Portfolio Choice in the Presence of Illiquid Durable Consumption Goods," Econometrica, 1990, 58 (1), 25-51.

Hamermesh, D., "Labor Demand and the Structure of Adjustment Costs," The American Economic Review, 1989, pp. 674-689. 
Hilber, C. and T. Lyytikäinen, "Housing transfer taxes and household mobility: Distortion on the housing or labour market?," 2013. Government Institute for Economic Research VATT Working Papers 47/2013.

Hottman, Colin J., Stephen J. Redding, and David E. Weinstein, "Quantifying the Sources of Firm Heterogeneity," The Quarterly Journal of Economics, 2016, 131 (3), $1291-1364$.

Hsieh, C. and P. Klenow, "Misallocation and Manufacturing TFP in China and India," The Quarterly Journal of Economics, 2009, pp. 1403-1448.

Kanemoto, Y., "On the "Lock-In" Effects of Capital Gains Taxation," Journal of Urban Economics, 1996, 40 (3), 303-315.

Knoben, J., L. Oerlemans, and R. Rutten, "The effects of spatial mobility on the performance of firms," Economic Geography, 2008, 84 (2), 157-183.

Mayer, T., F. Mayneris, and L. Py, "The impact of Urban Enterprise Zones on establishment location decisions and labor market outcomes: evidence from France," Journal of Economic Geography, 2015, p. lbv035.

Melitz, Marc J., "The Impact of Trade on Intra-Industry Reallocations and Aggregate Industry Productivity," Econometrica, November 2003, 71 (6), 1695-1725.

Olley, G. and A. Pakes, "The Dynamics of productivity in the telecommunication equipment industry," Econometrica, 1996, 64 (6), 1263-1297.

Overman, Henry G. and Elias Einio, "The Effects of Spatially Targeted Enterprise Initiatives: Evidence from UK LEGI," 2012. ERSA conference papers No. 12p164.

Pellenbarg, P., L. Van Wissen, and J. Van Dijk, Firm relocation: state of the art and research prospects, University of Groningen, Research Institute SOM, 2002.

Pen, C. and P. Pellenbarg, "Firm migration and central government policy; An overview," in "Paper from the Regional Science Association conference, Groningen" 1998.

Rathelot, Roland. and Patrick. Sillard, "The importance of local corporate taxes in business location decisions: Evidence from French micro data," The Economic Journal, 2008, 118 (527), 499-514.

Redding, J. and D. Weinstein, "A Unified Approach to Estimating Demand and Welfare," August 2016.

Restuccia, D. and R. Rogerson, "Policy Distortions and Aggregate Productivity with Heterogeneous Plants," Review of Economic Dynamics, October 2008, 11 (4), 707-720.

_ and _, "The causes and costs of misallocation," 2017.

Schmenner, Roger W., "Choosing New Industrial Capacity: On-Site Expansion, Branching, and Relocation," The Quarterly Journal of Economics, 1980, 95 (1), 103-119. 
Weltevreden, J., F. Van Oort, J. Van Vliet, P. Pellenbarg, H. Van Amsterdam, and M. Traa, "Firm relocation and regional employment development in the Netherlands (1999-2006)," European Regional Science Association, 2007.

Yitzhaki, S., "An empirical test of the lock-in-effect of the capital gains tax," The Review of Economics and Statistics, 1979, pp. 626-629. 


\section{A Data description}

\section{A.1 Data sources}

We use French firm-level data merged with real estate prices at the département level. ${ }^{24}$

\section{A.1.1 firm-level information}

We exploit a large French firm-level database constructed by the Bank of France: FiBEn. FiBEn is based on fiscal documents, including balance sheet and P\&L statements, and contains detailed information on flow and stock accounting variables as well as information on firms' activities, location and workforce size.

The database includes French firms with annual sales exceeding 750, 000 euros or with outstanding credit exceeding 380,000 euros. It has a large coverage of French medium and large firms. Using a dummy variable indicating if firms operate in more than one establishment, we only retain single establishment firms and we restrict our sample to firms with total headcount below 250 to ensure the validity of this information. We also exclude from our sample firms operating in the retail industry and the hotel and catering industry. Those sectors are indeed characterized by small catchment areas than can be affected by short-distance relocations. ${ }^{25}$ We keep firms that declare data over at least three consecutive years. Our panel is unbalanced as firms may enter and exit the sample between 1994 and $2013 .^{26}$

\section{A.1.2 Real estate prices}

We need real estate prices to compute capital gains on real estate assets as well as real estate volume. Commercial real estate local prices being not available in France, we use residential prices. More precisely, we use the Notaires-INSEE ${ }^{27}$ apartment price indices built by Fougère and Poulhes (2012) which are based on the data collected by French notaires and the methodology developed by the INSEE. ${ }^{28}$ These indices take into account changes in the quality of apartments since hedonic characteristics of the flats are used to build the indices. The indices in each département are standardized to be equal to 100 in 2000. In addition, we have apartment per square meter prices in each département in 2013. Apartment per square meter prices at the département level are collected by the Chambre des Notaires. They correspond to the average price per square meter of all apartment transactions registered in a given year. ${ }^{29}$ We retropolate apartment prices using the apartment price index to build apartment prices per square meter at the département level from 1994 onwards. Prior to 1994, housing price indices used to retropolate the series are taken from Friggit (2009). We use the Paris housing price index (available from 1840

\footnotetext{
${ }^{24}$ There are 94 départements in mainland France, a complete list can be found in Table A1. Because of the lack of reliable regarding data on real estate price, we excluded departments 12 (Aveyron), 46 (Lot) and 53 (Mayenne).

${ }^{25}$ Note that keeping those sectors in the database has no effects on the results

${ }^{26}$ We cannot conclude that a firm exiting the sample has gone bankrupt as it may have merely crossed the above-mentioned declaration thresholds; alternatively it may have been bought by another firm.

${ }^{27}$ Solicitor is the English equivalent for the French word notaire

${ }^{28}$ The National Institute of Statistics and Economic Studies, the French National Statistical Bureau.

${ }^{29}$ The Chambre des Notaires de Paris has registered apartment prices in the database Bien from 1992 onwards and the Notaires de France started to register those prices for the rest of mainland France in the database Perval in 1994.
} 
onwards) for départements located in the Paris area (Île-de-France) and the national housing price index (available from 1936 onwards) for all the other départements. We report the evolution of real estate prices given in thousand of 2013 euros in each Département in Table A2.

Real estate prices at the département level being less precise before 1994, we start our analysis in 1994. We also restrict our study to the firms headquartered in so-called "départements de France métropolitaine" (mainland France), excluding overseas territories and Corsica.

\section{A.2 Variable construction and further descriptive statistics}

\section{A.2.1 Firms mobility}

We derive information on firms relocation behaviour thanks to the reported location of headquarters. FiBEn provides, at annual frequencies, the municipality where the headquarters are located at the end of the year. We identify the occurrence of a relocation when we observe a change in the municipality of the headquarters. Hence, we only identify relocations across municipalities and clearly underestimate the number of relocations.

Besides, in order to insure that the headquarters' relocation coincides with the relocation of the whole firm's activities, we restrict our analysis to single establishment firms. Single establishment firms account for around $80 \%$ of the firms registered in FiBEn.

We mentioned in the introduction that a concurrent strategy to local relocation might consist in opening new establishments (branching). We find that $2 \%$ of the firms initially identified as single-establishment turn to multi-establishment structures. When compared to the $13.2 \%$ of firms relocating locally, this finding shows that local relocation is a much more common event than branching.

For each relocation observed we compute the "as-the-crow-flies" distance between the municipality of departure and the municipality of arrival using the latitude and the longitude of the center of the municipality from the National Geographic Institute (IGN). The distance is below $7.5 \mathrm{~km}$ for $50 \%$ of the relocations; it is below $16 \mathrm{~km}$ for 75 percent of the relocating firms. We report in Figure A1 the histogram of the distances between the place of departure and the place of settlement.

\section{A.2.2 Real estate assets and capital gains}

Real estate assets reported in the balance sheet are not mark-to-market. The market value of firms real estate holdings is important in our analysis because it determines the capital gains on which a tax is levied in the event of a sale.

Nevertheless, firm's balance sheets provide information on gross value of land and buildings and on accumulated amortizations of buildings. The gross value of land and buildings corresponds to their historical value adjusted by accounting reevaluations. A proxy for the mean age of real estate assets can be recover thanks to the ratio of the accumulated amortizations of buildings over the gross book value of buildings when we assume that buildings are linearly amortized. ${ }^{30}$

We do not have precise information on the location of the firm's real estate assets. Consequently, we use the département where the firm is headquartered as a proxy for the

\footnotetext{
${ }^{30}$ The accounting standard for the length of the amortization period depends on the nature of the buildings. We retain an average length of 25 years following Chaney et al. (2013).
} 
Table A1: French Départements in 2013

\begin{tabular}{|c|c|c|c|c|c|}
\hline Département name & Département code & Population & Département name & Département code & Population \\
\hline Ain & 01 & 634173 & Lozère & 48 & 76204 \\
\hline Aisne & 02 & 538743 & Maine-et-Loire & 49 & 809505 \\
\hline Allier & 03 & 343680 & Manche & 50 & 500019 \\
\hline Alpes-de-Haute-Provence & 04 & 162924 & Marne & 51 & 572968 \\
\hline Hautes-Alpes & 05 & 140706 & Haute-Marne & 52 & 179638 \\
\hline Alpes-Maritimes & 06 & 1081821 & Mayenne & 53 & 307831 \\
\hline Ardèche & 07 & 323543 & Meurthe-et-Moselle & 54 & 729664 \\
\hline Ardennes & 08 & 278970 & Meuse & 55 & 190550 \\
\hline Ariège & 09 & 153011 & Morbihan & 56 & 747458 \\
\hline Aube & 10 & 308085 & Moselle & 57 & 1047013 \\
\hline Aude & 11 & 370056 & Nièvre & 58 & 212111 \\
\hline Aveyron & 12 & 278062 & Nord & 59 & 2607174 \\
\hline Bouches-du-Rhône & 13 & 2007684 & Oise & 60 & 822858 \\
\hline Calvados & 14 & 693277 & Orne & 61 & 286256 \\
\hline Cantal & 15 & 146299 & Pas-de-Calais & 62 & 1466483 \\
\hline Charente & 16 & 354586 & Puy-de-Dôme & 63 & 646537 \\
\hline Charente-Maritime & 17 & 639596 & Pyrénées-Atlantiques & 64 & 670434 \\
\hline Cher & 18 & 311768 & Hautes-Pyrénées & 65 & 228304 \\
\hline Corrèze & 19 & 238713 & Pyrénées-Orientales & 66 & 472033 \\
\hline Corse-du-Sud & $2 \mathrm{~A}$ & 152720 & Bas-Rhin & 67 & 1118009 \\
\hline Haute-Corse & $2 \mathrm{~B}$ & 174178 & Haut-Rhin & 68 & 763716 \\
\hline Côte-d'Or & 21 & 533023 & Rhône & 69 & 1816373 \\
\hline Côtes-d'Armor & 22 & 599438 & Haute-Saône & 70 & 238181 \\
\hline Creuse & 23 & 119381 & Saône-et-Loire & 71 & 555840 \\
\hline Dordogne & 24 & 418219 & Sarthe & 72 & 572135 \\
\hline Doubs & 25 & 536474 & Savoie & 73 & 429253 \\
\hline Drôme & 26 & 501154 & Haute-Savoie & 74 & 791094 \\
\hline Eure & 27 & 599518 & Paris & 75 & 2218536 \\
\hline Eure-et-Loir & 28 & 435171 & Seine-Maritime & 76 & 1255587 \\
\hline Finistère & 29 & 907423 & Seine-et-Marne & 77 & 1391429 \\
\hline Gard & 30 & 748509 & Yvelines & 78 & 1424411 \\
\hline Haute-Garonne & 31 & 1335366 & Deux-Sèvres & 79 & 372586 \\
\hline Gers & 32 & 191639 & Somme & 80 & 571595 \\
\hline Gironde & 33 & 1542964 & Tarn & 81 & 386004 \\
\hline Hérault & 34 & 1123990 & Tarn-et-Garonne & 82 & 255666 \\
\hline Ille-et-Vilaine & 35 & 1039983 & Var & 83 & 1041681 \\
\hline Indre & 36 & 225590 & Vaucluse & 84 & 554619 \\
\hline Indre-et-Loire & 37 & 606164 & Vendée & 85 & 667970 \\
\hline Isère & 38 & 1253614 & Vienne & 86 & 433682 \\
\hline Jura & 39 & 259455 & Haute-Vienne & 87 & 375363 \\
\hline Landes & 40 & 405213 & Vosges & 88 & 371792 \\
\hline Loir-et-Cher & 41 & 332775 & Yonne & 89 & 340884 \\
\hline Loire & 42 & 761357 & Territoire de Belfort & 90 & 145074 \\
\hline Haute-Loire & 43 & 227509 & Essonne & 91 & 1279864 \\
\hline Loire-Atlantique & 44 & 1358627 & Hauts-de-Seine & 92 & 1603379 \\
\hline Loiret & 45 & 670906 & Seine-Saint-Denis & 93 & 1573959 \\
\hline Lot & 46 & 173021 & Val-de-Marne & 94 & 1372018 \\
\hline Lot-et-Garonne & 47 & 334106 & Val-d'Oise & 95 & 1210318 \\
\hline
\end{tabular}

Notes: List of French département in 2013 and population. The codes presented in this table are consistent from 1994 to 2013. Source: INSEE. 
Table A2: Real estate prices and propensity to relocation across départements

\begin{tabular}{|c|c|c|c|c|c|c|c|c|c|c|c|c|c|c|}
\hline Département & $(1)$ & $(2)$ & (3) & (4) & Département & $(1)$ & $(2)$ & (3) & $(4)$ & Département & $(1)$ & $(2)$ & (3) & $(4)$ \\
\hline 1 & 1101 & 0.76 & 1.89 & $1.19 \%$ & 33 & 2032 & 0.81 & 2.6 & $1.78 \%$ & 66 & 559 & 0.91 & 2 & $0.97 \%$ \\
\hline 2 & 657 & 0.83 & 1.36 & $0.87 \%$ & 34 & 1212 & 1.5 & 2.75 & $1.52 \%$ & 67 & 1831 & 1.25 & 2.15 & $1.36 \%$ \\
\hline 3 & 399 & 0.43 & 1.05 & $1.13 \%$ & 35 & 1593 & 1.32 & 2.28 & $1.14 \%$ & 68 & 1236 & 0.59 & 1.52 & $1.28 \%$ \\
\hline 4 & 183 & 0.81 & 1.87 & $1.03 \%$ & 36 & 305 & 0.47 & 1.06 & $0.75 \%$ & 69 & 3396 & 1.74 & 2.77 & $2.51 \%$ \\
\hline 5 & 217 & 0.71 & 2.15 & $0.77 \%$ & 37 & 902 & 0.97 & 2.02 & $1.65 \%$ & 70 & 357 & 0.5 & 1.03 & $0.73 \%$ \\
\hline 6 & 1452 & 1.96 & 3.75 & $1.31 \%$ & 38 & 2230 & 1.24 & 2.16 & $1.45 \%$ & 71 & 987 & 0.73 & 1.14 & $0.95 \%$ \\
\hline 7 & 426 & 0.68 & 1.4 & $1.06 \%$ & 39 & 541 & 0.54 & 1.33 & $0.69 \%$ & 72 & 687 & 0.66 & 1.39 & $1.05 \%$ \\
\hline 8 & 431 & 0.57 & 1.13 & $1.14 \%$ & 40 & 473 & 1.01 & 2.3 & $0.79 \%$ & 73 & 894 & 1.36 & 2.61 & $1.50 \%$ \\
\hline 9 & 196 & 0.97 & 1.72 & $0.86 \%$ & 41 & 513 & 0.7 & 1.47 & $0.70 \%$ & 74 & 1571 & 1.38 & 3.26 & $1.44 \%$ \\
\hline 10 & 532 & 0.49 & 1.28 & $1.20 \%$ & 42 & 1511 & 0.66 & 1.14 & $1.17 \%$ & 75 & 4990 & 2.89 & 8.14 & $3.40 \%$ \\
\hline 11 & 396 & 0.93 & 2.11 & $0.49 \%$ & 43 & 401 & 0.41 & 1.12 & $0.82 \%$ & 76 & 1672 & 0.98 & 1.93 & $1.71 \%$ \\
\hline 13 & 2932 & 1.07 & 2.54 & $1.43 \%$ & 44 & 1738 & 1.13 & 2.52 & $1.32 \%$ & 77 & 2005 & 1.16 & 2.69 & $1.56 \%$ \\
\hline 14 & 888 & 1.66 & 2.37 & $1.59 \%$ & 45 & 925 & 1.05 & 1.8 & $1.16 \%$ & 78 & 1746 & 1.65 & 3.78 & $2.12 \%$ \\
\hline 15 & 199 & 0.52 & 1.3 & $0.68 \%$ & 47 & 528 & 0.4 & 1.15 & $1.00 \%$ & 79 & 591 & 0.6 & 1.19 & $0.90 \%$ \\
\hline 16 & 535 & 0.42 & 1.02 & $1.07 \%$ & 48 & 110 & 0.68 & 1.49 & $0.37 \%$ & 80 & 672 & 1.02 & 2.08 & $0.86 \%$ \\
\hline 17 & 827 & 1.7 & 2.97 & $0.83 \%$ & 49 & 1400 & 0.96 & 1.7 & $1.10 \%$ & 81 & 656 & 0.81 & 1.45 & $0.70 \%$ \\
\hline 18 & 438 & 0.72 & 1.26 & $0.87 \%$ & 50 & 637 & 0.77 & 1.51 & $1.09 \%$ & 82 & 344 & 0.51 & 1.39 & $0.48 \%$ \\
\hline 19 & 331 & 0.52 & 1.18 & $0.68 \%$ & 51 & 1044 & 1.15 & 1.93 & $0.96 \%$ & 83 & 1123 & 1.3 & 3.08 & $1.34 \%$ \\
\hline 21 & 846 & 0.97 & 2 & $1.45 \%$ & 52 & 275 & 0.7 & 1.1 & $0.51 \%$ & 84 & 882 & 0.92 & 1.91 & $0.93 \%$ \\
\hline 22 & 905 & 0.92 & 1.6 & $0.93 \%$ & 54 & 801 & 0.73 & 1.62 & $1.60 \%$ & 85 & 1240 & 1.35 & 2.33 & $0.68 \%$ \\
\hline 23 & 139 & 0.47 & 0.94 & $0.42 \%$ & 55 & 209 & 0.48 & 1.13 & $0.75 \%$ & 86 & 640 & 1.18 & 1.59 & $0.98 \%$ \\
\hline 24 & 601 & 0.64 & 1.35 & $1.03 \%$ & 56 & 1020 & 1.15 & 2.08 & $1.01 \%$ & 87 & 515 & 0.71 & 1.22 & $0.86 \%$ \\
\hline 25 & 892 & 0.77 & 1.64 & $1.14 \%$ & 57 & 1068 & 0.8 & 1.59 & $1.41 \%$ & 88 & 629 & 0.57 & 1.11 & $0.77 \%$ \\
\hline 26 & 1015 & 0.63 & 1.46 & $1.05 \%$ & 58 & 243 & 0.47 & 0.95 & $0.86 \%$ & 89 & 486 & 0.86 & 1.4 & $0.96 \%$ \\
\hline 27 & 716 & 0.9 & 1.67 & $1.27 \%$ & 59 & 3185 & 1.08 & 2.39 & $1.79 \%$ & 90 & 169 & 0.67 & 1.21 & $1.53 \%$ \\
\hline 28 & 625 & 1.11 & 2.01 & $1.09 \%$ & 60 & 1006 & 1.45 & 2.35 & $1.50 \%$ & 91 & 1819 & 1.28 & 2.69 & $2.30 \%$ \\
\hline 29 & 1191 & 0.45 & 1.37 & $0.85 \%$ & 61 & 404 & 0.47 & 1 & $0.94 \%$ & 92 & 2511 & 2.27 & 5.26 & $3.51 \%$ \\
\hline 30 & 853 & 0.88 & 1.92 & $1.08 \%$ & 62 & 1625 & 1.25 & 2.02 & $1.33 \%$ & 93 & 1943 & 1.48 & 3.2 & $2.71 \%$ \\
\hline 31 & 1830 & 1.04 & 2.39 & $1.60 \%$ & 63 & 954 & 0.6 & 1.68 & $1.18 \%$ & 94 & 1888 & 1.87 & 4.19 & $2.47 \%$ \\
\hline 32 & 261 & 0.51 & 1.44 & $0.25 \%$ & 64 & 1127 & 0.99 & 2.36 & $1.32 \%$ & 95 & 1330 & 1.17 & 2.76 & $2.08 \%$ \\
\hline 33 & 2032 & 0.81 & 2.6 & $1.78 \%$ & 65 & 272 & 0.62 & 1.54 & $1.10 \%$ & & & & & \\
\hline
\end{tabular}

Notes: This table presents some descriptive statistics across départements. Column 1 gives the number of monoestablishments firms observed across the time period 1994-2013, column 2 gives the level of real estate prices in 1994 in thousands euros of 2010 per square meters, column 3 gives the level of real estate prices in 2013 in thousands euros of 2010 per square meters and column 4 gives the percentage of firms that have relocated, on average, each year over the period 1994-2013. Départements names are given in Table A1. Source: FiBEn, INSEE 
Figure A1: Histogram of the distances between the place of departure and the place of settlement

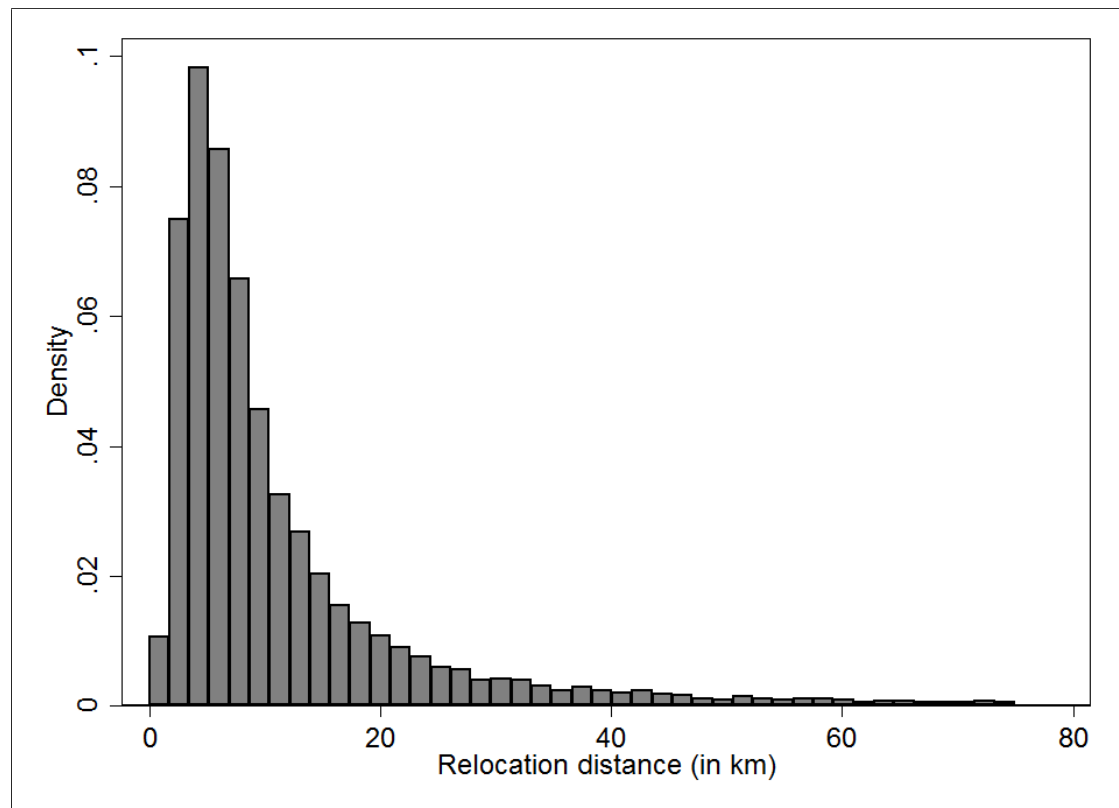

Notes: This Figure plots the distribution of the as-the-crow-flies distances between the place of departure and the place of settlement of a relocating firm. For the sake of readability, we restrict our analysis to relocations characterized by a distance inferior to $50 \mathrm{~km}$; the percentile 90 in the distances distribution is $60 \mathrm{~km}$ and the percentile 99 is around 600km. Period of observation: 1994-2013. Source: authors calculations based on FiBEn. 
location of real estate assets. ${ }^{31}$ In order to recover the market value of real estate units held by the firm, we multiply the historical value of real estate holdings by the accrued changes in the real estate prices in the headquarters's département since the average acquisition date. We eventually obtain, for each firm $\times$ year observation, the market-value of real estate holdings.

With the market-value, we can compute the capital gains on real estate assets by subtracting the historical value to the market-value. The amount of realised capital gains does not necessarily constitute the fiscal base. Indeed, the tax scheme takes into a account the holding period. After a five-year holding period the gains retained in the tax base are diminished by $10 \%$ each year; so that after a fifteen-year holding period the firm is not anymore subject to the tax.

For each firm $\times$ year observations, we build a variable indicating the share of the proceeds that would paid by the firm under the heading of tax on capital gains in the event of a sale of the real estate assets. This variable varies with:

(i) The marginal tax rate: constant across firms and equal to the corporate tax rate as capital gains are added to the net income of the firm.

(ii) The dynamics of real estate prices since the acquisition date: varying with the département.

(iii) The length of time since acquisition: varying with the acquisition date and the year in which the firm is observed.

\section{A.2.3 Variable desciption}

Variable description and construction is summarized in Table A3.

\footnotetext{
${ }^{31}$ As we restrict our analysis to single-establishment firms, this is a mild assumption.
} 
Table A3: Variable descriptions

\begin{tabular}{l|l}
\hline \hline Variable & Description \\
\hline Employment & $\begin{array}{l}\text { Full-time equivalent (FTE) number of workers as reported by } \\
\text { the firm. }\end{array}$ \\
Real Estate Owner & $\begin{array}{l}\text { Dummy variable equal to one if the firm reports real estate } \\
\text { assets in its balance-sheet. } \\
\text { Number of local relocations over the observed period divided by } \\
\text { the size of this period. }\end{array}$ \\
Age & $\begin{array}{l}\text { Number of years since company's incorporation. } \\
\text { Net value of the assets reported in the balance sheet in constant } \\
\text { million of euros of 2010. } \\
\text { Average age, in years, of real estate assets held by the firm. } \\
\text { Share, in \%, of the proceeds from the real estate asset sales that } \\
\text { would be paid under the heading of the tax on capital gains if } \\
\text { the real estate assets were to be sold by the firm in a given year. } \\
\text { Numbers of square meters normalised the net value of the bal- } \\
\text { ance sheet. }\end{array}$ \\
Volume of Real Estate
\end{tabular}

Notes: This table gives the definition of the variables used in the empirical analysis. For a detailed description of these variables construction, see appendix A.

\section{B Additional figures}

Figure B1: Propensity to relocate at dif- Figure B2: Propensity to relocate at different percentiles of employment growth ferent percentiles of employment growth - within $\hat{I l}$ e-de-France (Paris area)

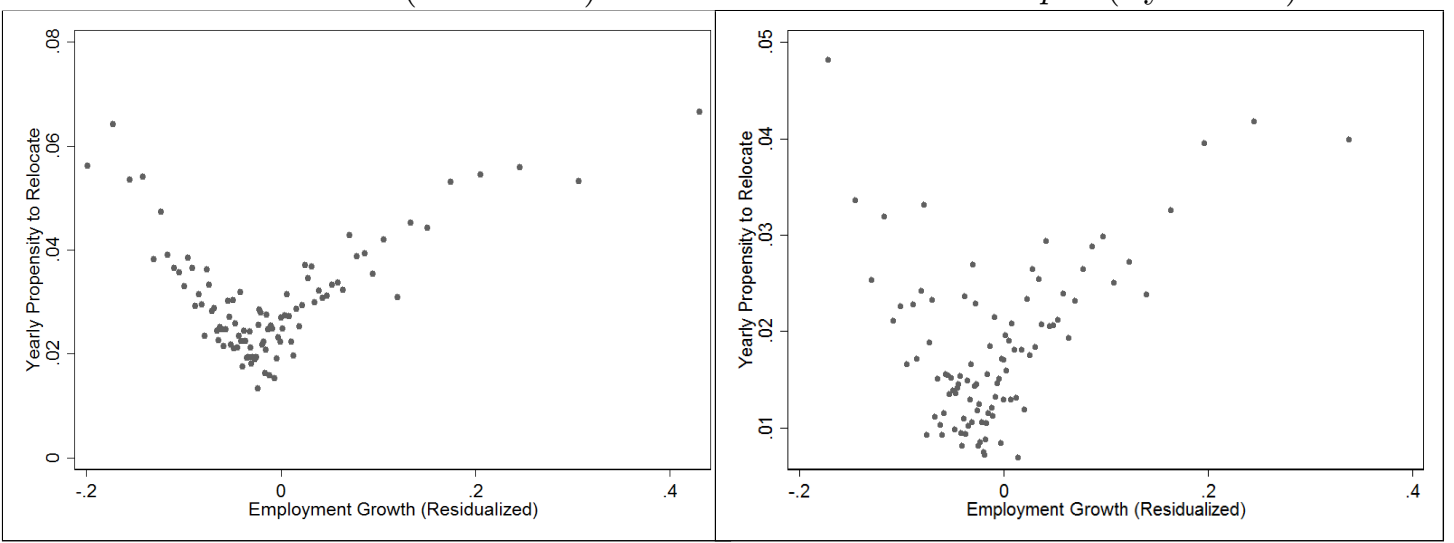

Notes: see Figure 1. Period of observation: 1994-2013. Right-hand side figure only includes observations from Lyon Area (Region Rhone-Alpes, D'epartements 01, 07, 26, 38, 42, 69, 73, 74) while left-hand side figure only includes observations from Paris Area (Region Ile de France, D'epartements 75, 77, 78, 91 , $92,93,94$,95). Source: FiBEn. 
Figure B3: Propensity to relocate at dif- Figure B4: Propensity to relocate at different percentiles of employment growth ferent percentiles of employment growth - (Marseille area) - w/o Paris, Marseille and Lyon areas

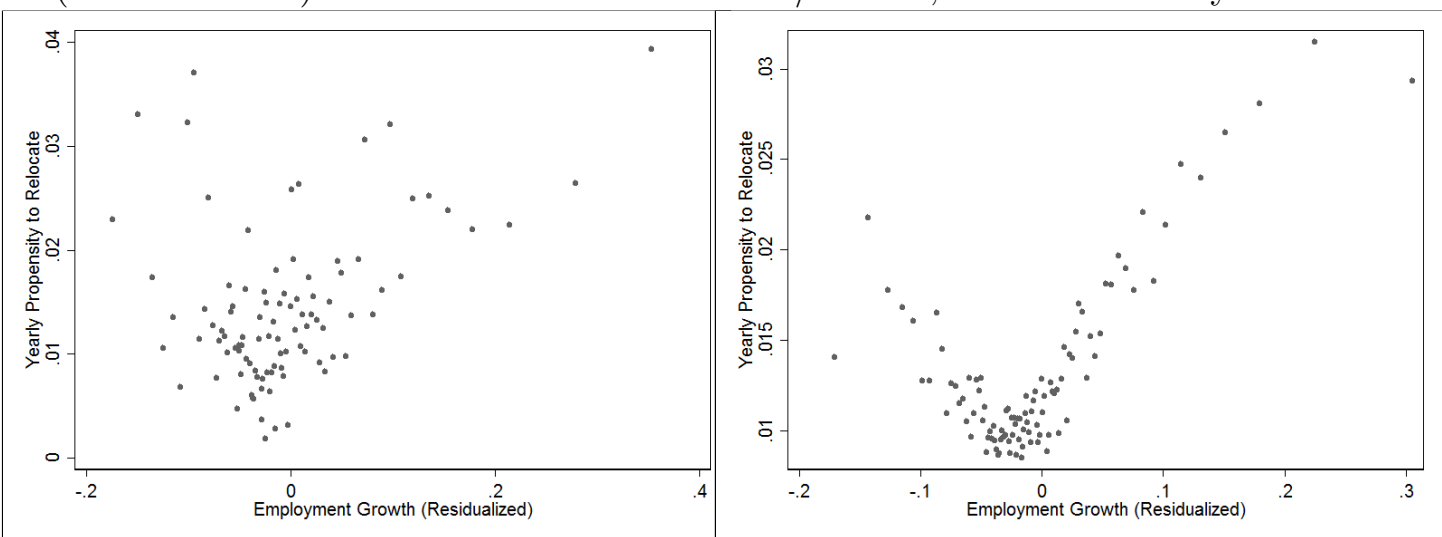

Notes: see Figure 1. Period of observation: 1994-2013. Right-hand side figure excludes all observations from Paris, Lyon and Marseille areas while left-hand side figure only includes observations from Marseille Area (Region ProvenceAlpes-Cote-d'Azur, D'epartements 04, 05, 06, 13, 83, 84) Source: FiBEn.

Figure B5: Propensity to relocate at dif- Figure B6: Propensity to relocate at different percentiles of employment growth ferent percentiles of employment growth - service industries - manufacturing industries.

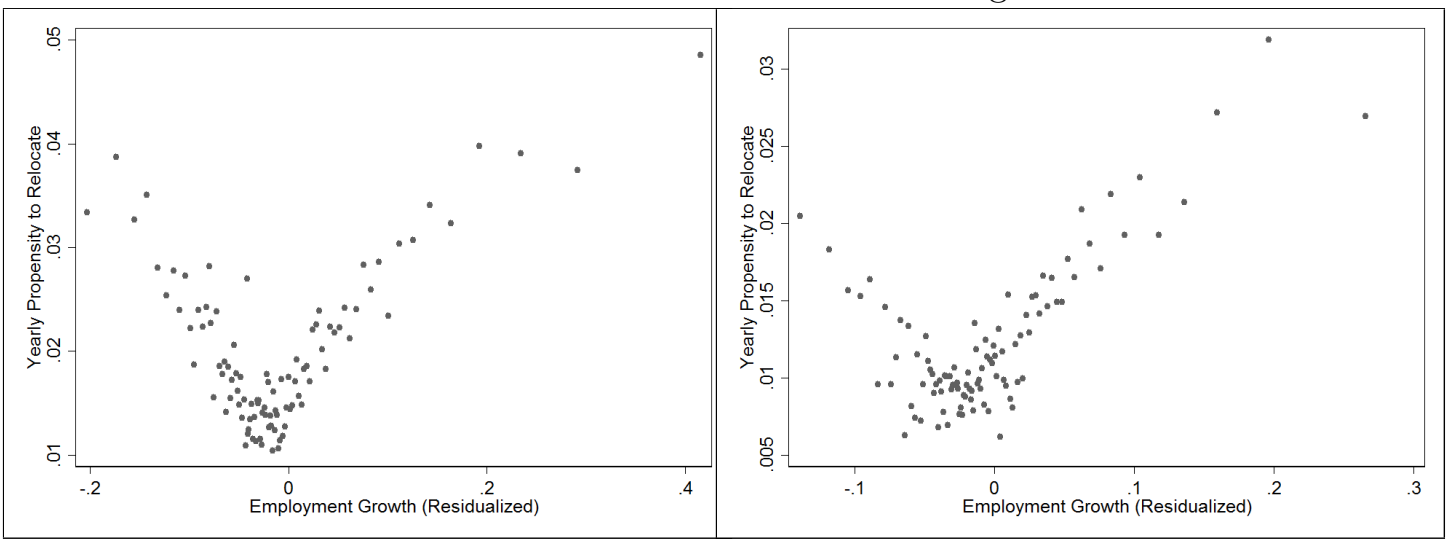

Notes: see Figure 1. Period of observation: 1994-2013. Right-hand side figure only includes observations from manufacturing industry while left-hand side figure only includes observations from the service industry. Source: FiBEn. 


\section{Theory appendix}

\section{C.1 Model without friction}

In a model without friction, each intermediate firm maximizes its revenue by choosing $r(i)$ and $l(i)$. First order conditions yields:

$$
\begin{gathered}
l(i)=\alpha\left[\frac{\Omega(i)(1-\varepsilon)}{w}\right]^{\frac{1}{\varepsilon}}\left(\frac{w}{u}\right)^{\frac{(1-\alpha)(1-\varepsilon)}{\varepsilon}} \\
r(i)=(1-\alpha)\left[\frac{\Omega(i)(1-\varepsilon)}{u}\right]^{\frac{1}{\varepsilon}}\left(\frac{w}{u}\right)^{\frac{-\alpha(1-\varepsilon)}{\varepsilon}}
\end{gathered}
$$

which implies that firm $i$ 's output price is a fixed markup over its marginal costs:

$$
p(i)=\frac{1}{1-\varepsilon} \frac{w^{\alpha} u^{1-\alpha}}{\theta(i)}
$$

and hence:

$$
P=\frac{1}{1-\varepsilon}\left(w^{\alpha} u^{1-\alpha}\right)\left(\int_{0}^{1} \theta(i)^{\frac{1-\varepsilon}{\varepsilon}} d i\right)^{\frac{\varepsilon}{\varepsilon-1}}
$$

We can then write:

$$
y(i)=\theta(i)[\Omega(i)(1-\varepsilon)]^{\frac{1}{\varepsilon}}\left(w^{\alpha} u^{1-\alpha}\right)^{\frac{-1}{\varepsilon}}=\theta(i)^{\frac{1}{\varepsilon}}(1-\varepsilon)^{\frac{1}{\varepsilon}} Y P^{\frac{1}{\varepsilon}}\left(w^{\alpha} u^{1-\alpha}\right)^{\frac{-1}{\varepsilon}}
$$

using the value of $P$ yields:

$$
y(i)=\theta(i)^{\frac{1}{\varepsilon}}\left(\int_{0}^{1} \theta(i)^{\frac{1-\varepsilon}{\varepsilon}} d i\right)^{\frac{1}{\varepsilon-1}} Y
$$

from the FOCs, note that

$$
w l(i)+u r(i)=\theta(i)^{\frac{1-\varepsilon}{\varepsilon}} w^{\alpha} u^{1-\alpha}\left(\int_{0}^{1} \theta(i)^{\frac{1-\varepsilon}{\varepsilon}} d i\right)^{\frac{1}{\varepsilon-1}} Y
$$

on the other hand:

$$
p(i) y(i)=\frac{w_{t}^{\alpha} u^{1-\alpha}}{1-\varepsilon} \theta(i)^{\frac{1-\varepsilon}{\varepsilon}}\left(\int_{0}^{1} \theta(i)^{\frac{1-\varepsilon}{\varepsilon}} d i\right)^{\frac{1}{\varepsilon-1}} Y
$$

We then show that the profit is equal to the production up to a markup

$$
\pi(i)=\frac{\varepsilon}{1-\varepsilon}\left(w^{\alpha} u^{1-\alpha}\right) \theta(i)^{\frac{1-\varepsilon}{\varepsilon}}\left(\int_{0}^{1} \theta(i)^{\frac{1-\varepsilon}{\varepsilon}} d i\right)^{\frac{1}{\varepsilon-1}} Y
$$

and

$$
\int_{0}^{1} \pi(i) d i=\frac{\varepsilon}{1-\varepsilon}\left(w^{\alpha} u^{1-\alpha}\right)\left(\int_{0}^{1} \theta(i)^{\frac{1-\varepsilon}{\varepsilon}} d i\right)^{\frac{\varepsilon}{\varepsilon-1}} Y
$$

From market clearing condition

$$
\begin{aligned}
L_{s} & =\int_{0}^{1} l(i) d i \\
R_{s} & =\int_{0}^{1} r(i) d i \\
P Y & =\int_{0}^{1} p(i) y(i) d i,
\end{aligned}
$$


we can show that in equilibrium: ${ }^{32}$

$$
Y=\left(\frac{L_{s}}{\alpha}\right)^{\alpha}\left(\frac{R_{s}}{1-\alpha}\right)^{1-\alpha}\left(\int_{0}^{1} \theta(i)^{\frac{1-\varepsilon}{\varepsilon}} d i\right)^{\frac{\varepsilon}{1-\varepsilon}}
$$

plugging into $\Omega(i)$ yields:

$$
(1-\varepsilon) \Omega(i)=\theta(i)^{1-\varepsilon}\left(\frac{L_{s}}{\alpha}\right)^{\varepsilon \alpha}\left(\frac{R_{s}}{1-\alpha}\right)^{\varepsilon(1-\alpha)}\left(\int_{0}^{1} \theta(i)^{\frac{1-\varepsilon}{\varepsilon}} d i\right)^{\varepsilon}\left(w^{\alpha} u^{1-\alpha}\right) .
$$

we can rewrite:

$$
l_{t}(i)=\theta_{t}(i)^{\frac{1-\varepsilon}{\varepsilon}}\left(\frac{L_{s}}{\alpha}\right)^{\alpha}\left(\frac{R_{s}}{1-\alpha}\right)^{(1-\alpha)}\left(\int_{0}^{1} \theta(i)^{\frac{1-\varepsilon}{\varepsilon}} d i\right)^{-1}\left(\frac{u}{w}\right)^{1-\alpha}
$$

We know that $\frac{r(i)}{l(i)}=\frac{R_{s}}{L_{s}}=\frac{(1-\alpha) w}{\alpha u}$, hence:

$$
l(i)=\theta(i)^{\frac{1-\varepsilon}{\varepsilon}}\left(\frac{L_{s}}{\alpha}\right)^{\alpha}\left(\frac{R_{s}}{1-\alpha}\right)^{(1-\alpha)}\left(\int_{0}^{1} \theta(i)^{\frac{1-\varepsilon}{\varepsilon}} d i\right)^{-1}\left(\frac{L_{s}}{\alpha}\right)^{1-\alpha}\left(\frac{R_{s}}{1-\alpha}\right)^{\alpha-1}
$$

Finally:

$$
l(i)=\frac{\theta(i)^{\frac{1-\varepsilon}{\varepsilon}}}{\int_{0}^{1} \theta(i)^{\frac{1-\varepsilon}{\varepsilon}} d i} L_{s} \text { and } r(i)=\frac{\theta(i)^{\frac{1-\varepsilon}{\varepsilon}}}{\int_{0}^{1} \theta(i)^{\frac{1-\varepsilon}{\varepsilon}} d i} R_{s}
$$

Normalizing $P$ to 1 ; we obtain:

$$
u=(1-\varepsilon) \frac{1-\alpha}{R_{s}} Y
$$

and

$$
w=(1-\varepsilon) \frac{\alpha}{L_{s}} Y
$$

and

$$
p(i)=\frac{1}{\theta(i)}\left(\int_{0}^{1} \theta(i)^{\frac{1-\varepsilon}{\varepsilon}} d i\right)^{\frac{\varepsilon}{1-\varepsilon}}
$$

\section{C.2 Existence of an interval of inaction}

The relocating condition $d=\pi^{1}-\pi^{0}>0$ is a function of $\Delta_{r}$ and we have:

$$
\left.d\left(\Delta_{r}\right)=\frac{u}{(1-\alpha)(1-\varepsilon)}\left(\varepsilon\left(1+\Delta_{r}\right)-(1-\alpha(1-\varepsilon))\left(1+\Delta_{r}\right)\right)^{\frac{\varepsilon}{1-\alpha(1-\varepsilon)}}\right)+u-a .
$$

${ }^{32}$ This result comes from the fact that the market clearing condition implies: $Y P=\int_{0}^{1} p(i) y(i) d i$ and that $\frac{L_{s}}{R_{s}}=\frac{l(i)}{r(i)}$. 
The function $d$ is differentiable and continuous in $\Delta_{r}$. It is straightforward to show that $d$ is decreasing with $\Delta_{r}$ when $\Delta_{r}<0$ and increasing with $\Delta_{r}$ when $\Delta_{r}>0$. The function $d$ takes the value $u-a$ when $\Delta_{r}$ equals $-1,-a$ when $\Delta_{r}$ equals 0 and tends to the infinity when $\Delta_{r}$ tends to infinity. Hence, if $u>a$, there exist only two values of $\Delta_{r}$, one being negative and the other positive, such that $d=0$. We denote them $\Delta_{r}^{-}$and $\Delta_{r}^{+}$, respectively. The function $d$ is negative when $\Delta_{r}$ is between $\Delta_{r}^{-}$and $\Delta_{r}^{+}$and positive otherwise. Then, $\Delta_{r}^{-}$and $\Delta_{r}^{+}$are the bounds of the non-relocating interval. We can easily show that $\left|\Delta_{r}^{-}\right|$ and $\left|\Delta_{r}^{+}\right|$are increasing in $a$.

We explore further the properties of the bounds of the non-relocating interval when $\Delta_{r}$ is close to 0 using a third-order local approximation of the function $d$ around 0 .

$$
d\left(\Delta_{r}\right)=0: \Leftrightarrow \frac{2((1-\alpha)(1-\varepsilon))+\varepsilon}{3(1-\alpha(1-\varepsilon))} \Delta_{r}^{3}-\Delta_{r}^{2}+\frac{2 a(1-\alpha(1-\varepsilon))}{u \varepsilon} \approx 0
$$

Let us denote $P$ the above-derived polynomial of degree 3 . We can easily show that $P^{\prime}$ is negative when $\Delta_{r}$ is between 0 and $\frac{2(1-\alpha(1-\varepsilon))}{2(1-\varepsilon)(1-\alpha)+\varepsilon}$ and positive otherwise. $P$ goes to $-\infty$ in $-\infty$ and to $+\infty$ in $+\infty$. We can also show that $P(0)>0$ and $P\left(\frac{2(1-\alpha(1-\varepsilon))}{2(1-\varepsilon)(1-\alpha)+\varepsilon}\right)<0$ when $u>>a$. Then, $P$ has three real roots, $\lambda_{1}, \lambda_{2}$ and $\lambda_{3}$ with $\lambda_{1}<0<\lambda_{2}<\lambda_{3}$. The two roots that are solutions to our problem $\pi^{1}-\pi^{0}=0$ are $\lambda_{1}$ and $\lambda_{2}$ and $\lambda_{3}$ is only an artifact due to the third order approximation generating large error as $\Delta_{r}$ is far from 0 . We know from usual properties of polynomials on degree 3 that:

$$
\begin{aligned}
& \lambda_{1}+\lambda_{2}+\lambda_{3}=\frac{3(1-\alpha(1-\varepsilon))}{2((1-\alpha)(1-\varepsilon))+\varepsilon} \\
& \lambda_{1} \lambda_{2}+\lambda_{1} \lambda_{3}+\lambda_{2} \lambda_{3}=0 \\
& \lambda_{1} \lambda_{2} \lambda_{3}=\frac{-6 a(1-\alpha(1-\varepsilon))^{2}}{u \varepsilon(2(1-\alpha)(1-\varepsilon)+\varepsilon)}
\end{aligned}
$$

From which we obtain:

$$
\lambda_{1}+\lambda_{2}=\left(\lambda_{1} \lambda_{2}\right)^{2} \frac{u \varepsilon(2(1-\alpha)(1-\varepsilon)+\varepsilon)}{6 a(1-\alpha(1-\varepsilon))^{2}}>0
$$

which implies $\left|\Delta_{r}^{+}\right|>\left|\Delta_{r}^{-}\right|$.

We also have:

$$
{\sqrt{\lambda_{1}+\lambda_{2}}}^{3}=\sqrt{\lambda_{1}+\lambda_{2}} \frac{2((1-\alpha)(1-\varepsilon))+\varepsilon}{3(1-\alpha(1-\varepsilon))}+\sqrt{\frac{6 a(1-\alpha(1-\varepsilon))^{2}}{u \varepsilon(2(1-\alpha)(1-\varepsilon)+\varepsilon)}}
$$

From which we deduce that $\sqrt{\lambda_{1}+\lambda_{2}}$ is increasing in $a$ and decreasing in $\varepsilon$.

\section{C.3 Results from simulation: the case of a positive aggregate productiv- ity shock $(+5 \%)$}




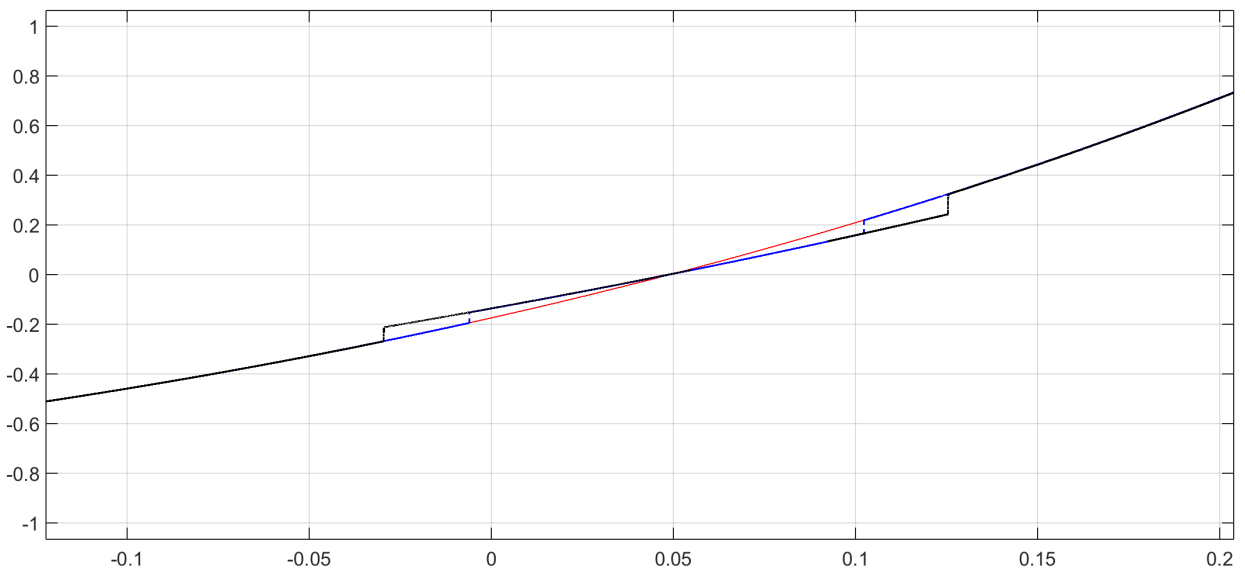

Figure C1: Employment growth as a function of productivity shocks for different values of a - aggregate productivity shock : $+5 \%$

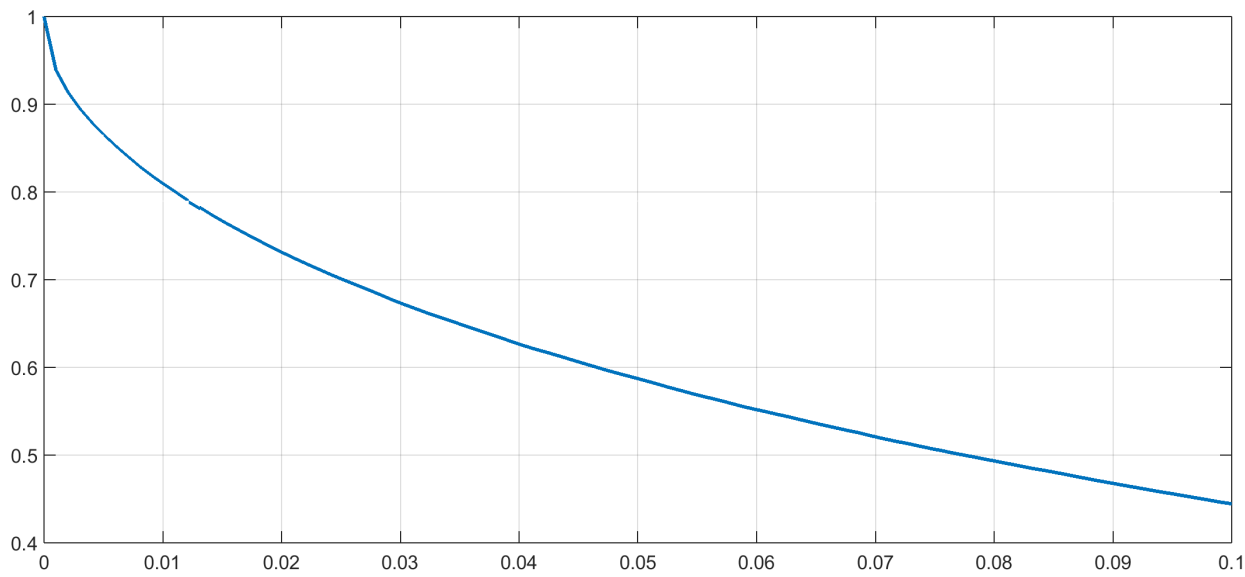

Figure C2: Share of relocating firms for different values of a - aggregate productivity shock $:+5 \%$ 


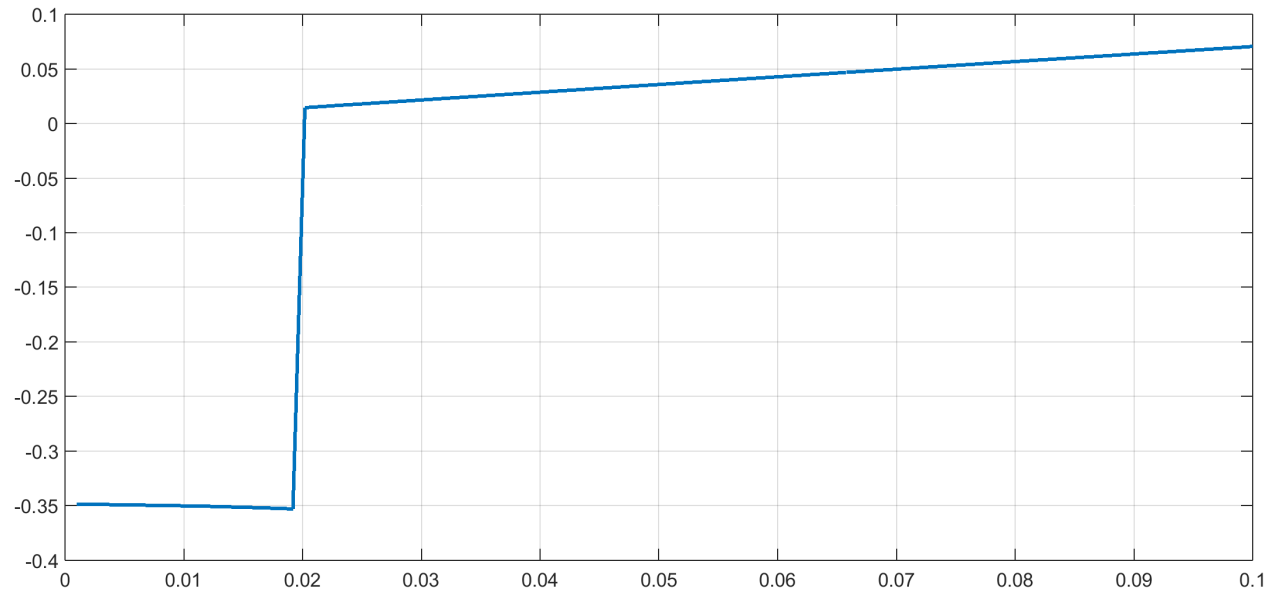

Figure C3: Difference between the smallest positive percentage change in real estate size that triggers relocation and the absolute value of the largest negative percentage change that triggers relocation for different values of $a$-aggregate productivity shock : $+5 \%$
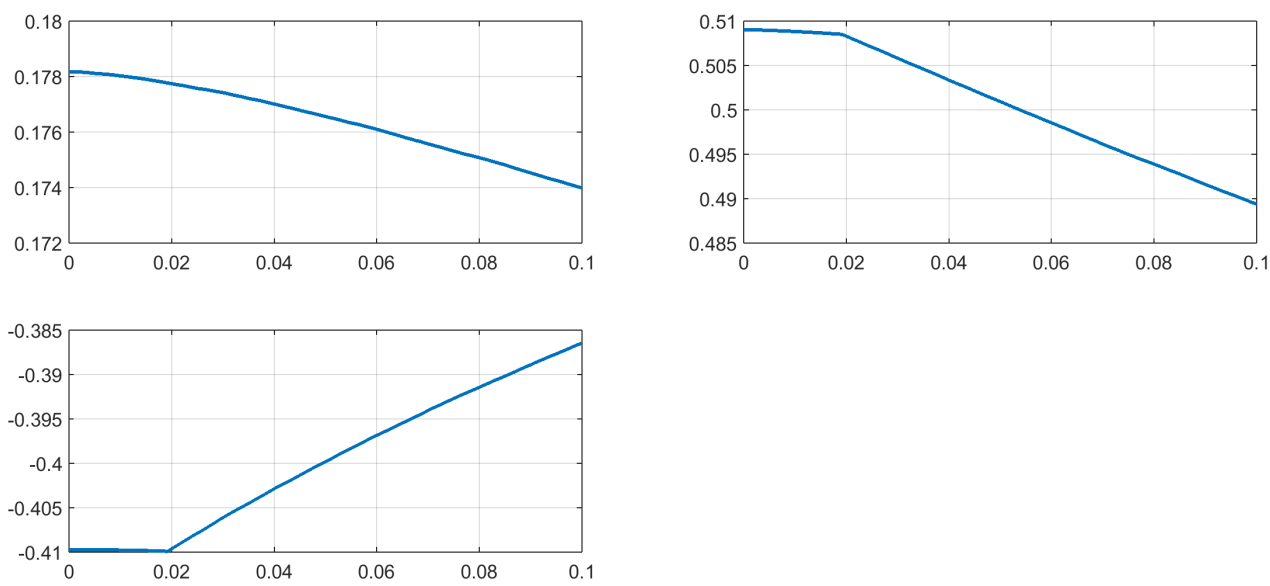

Figure C4: Mean employment growth as a function of a - aggregate productivity shock : $+5 \%$ 

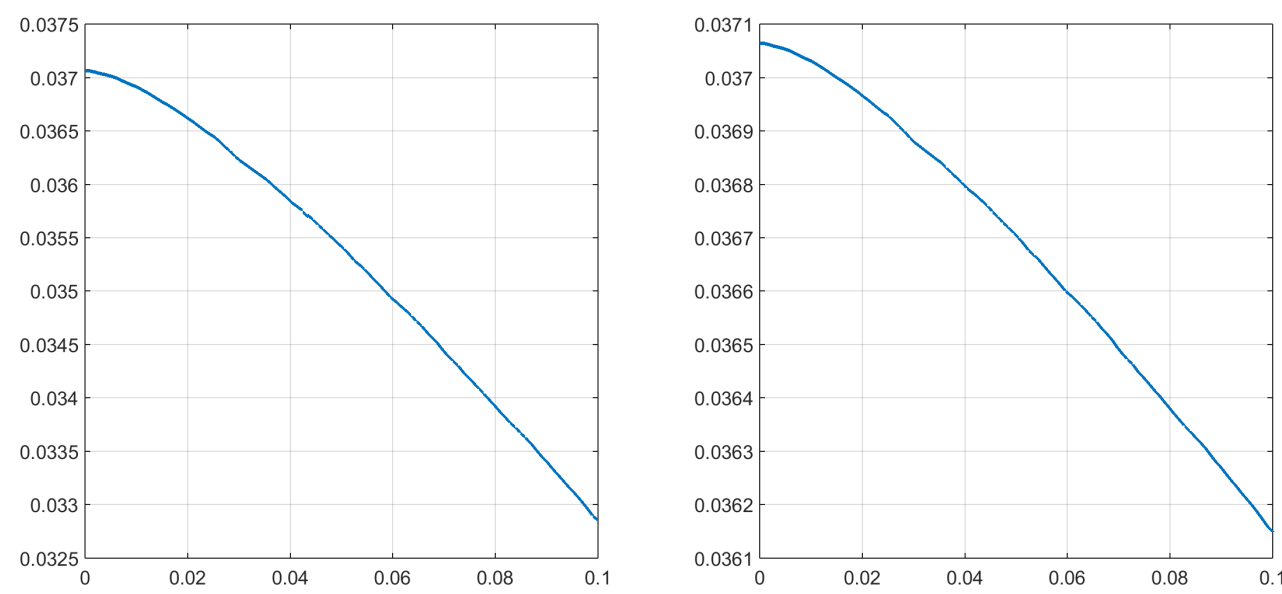

Figure C5: Covariance between $r(i)$ and $\theta(i)$ as a function of a - aggregate productivity shock : $+5 \%$

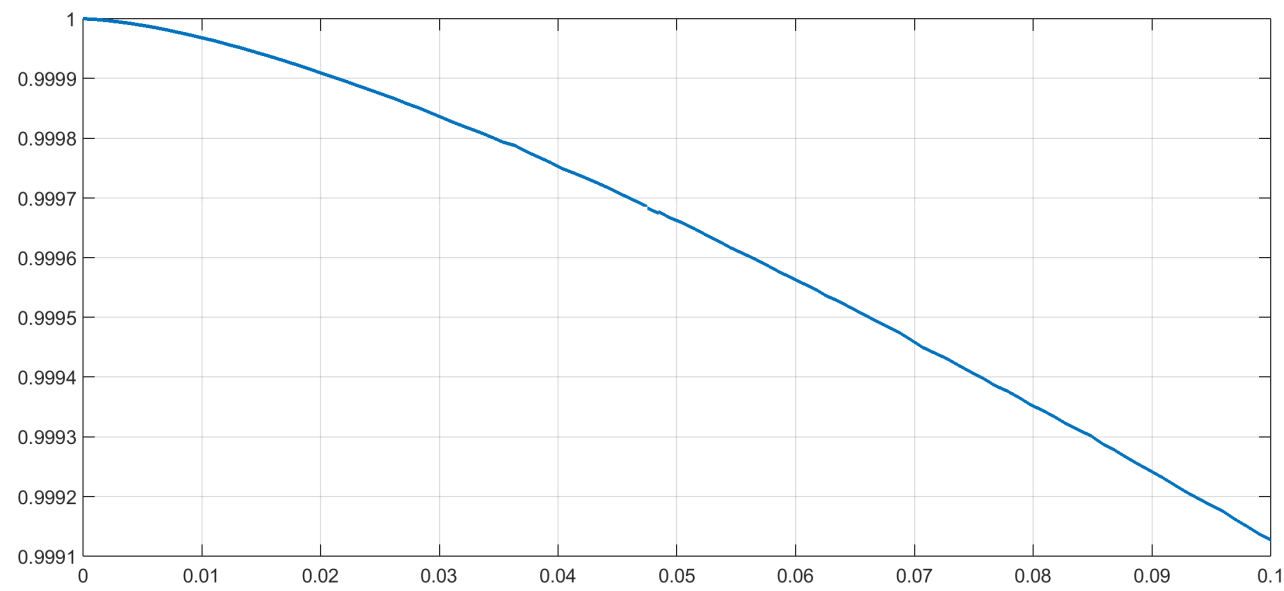

Figure C6: Aggregate output as a function of a (no friction =1) - aggregate productivity shock : $+5 \%$ 

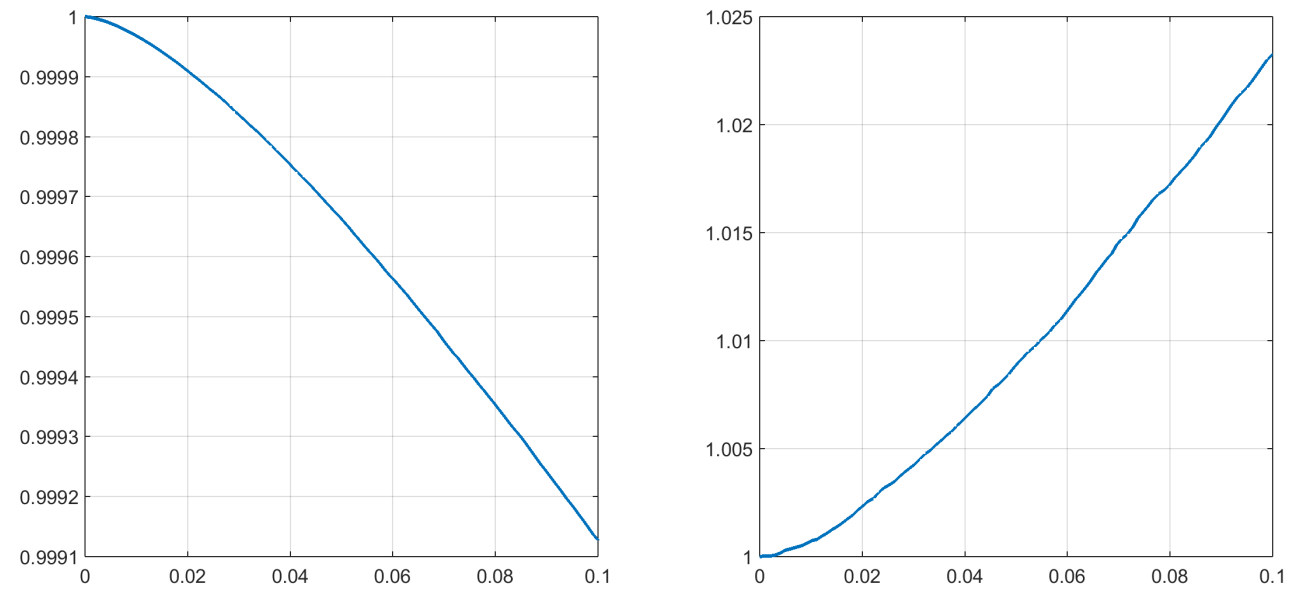

Figure C7: Equilibrium inputs' price as a function of a (no friction $=1)$ - aggregate productivity shock : $+5 \%$ 


\section{Additional empirical results}

\section{D.1 Robustness of results in section 4.1}

\section{Different definition of local relocations}

In our baselines methods, we have defined a relocation to be "local" if the distance between the municipalities of departure and the municipalities of arrival is below $15 \mathrm{~km}$. As shown in Figure A1, this corresponds to a large share of all the inter-municipalities relocations we see in the data. Table D1 also shows that increasing this threshold only marginally change the frequency of relocations, both for real-estate owners and renters.

Table D1: Frequency of relocations

\begin{tabular}{lcc}
\hline \hline & \multicolumn{2}{c}{ Share of relocating firms } \\
\cline { 2 - 3 } & Owners & Renters \\
\cline { 2 - 3 } Distance $<15 \mathrm{~km}$ & $10.8 \%$ & $18.0 \%$ \\
Relocations from $15 \mathrm{~km}$ to $25 \mathrm{~km}$ & $1.6 \%$ & $2.4 \%$ \\
Relocations from $25 \mathrm{~km}$ to $35 \mathrm{~km}$ & $0.7 \%$ & $0.9 \%$ \\
Other relocations & $2.8 \%$ & $2.8 \%$ \\
Within Labor Market Area relocations & $9.0 \%$ & $13.1 \%$ \\
\hline \hline
\end{tabular}

Notes: This table present the share of firms that have relocated at least once from 1994 to 2013. Relocations is split into four categories: local relocation (up to a distance of $15 \mathrm{~km}$ ), relocations at a distance ranging between 15 and $25 \mathrm{~km}$, relocations at a distance ranging between 25 and $35 \mathrm{~km}$, relocations at a distance above $35 \mathrm{~km}$ and relocation within a Labor Market Area (Zone d'Emploi).

In Tables D2, D3 and D4, we run OLS estimation of equation (14) respectively for all firms, growing firms and declining firms. In each of these three tables, column 1 uses our baseline threshold of $15 \mathrm{~km}$, column 2 and 3 use thresholds of $25 \mathrm{~km}$ and $35 \mathrm{~km}$ respectively and column 4 consider a relocation to be "local" if it is done within a Zone d'Emploi (Labor Market Area).

\section{Considering different time periods}

In our baseline regression presented in Table 3, we take all the characteristics of the firms in the first year it appears in the data. However, this year can be different across firms, especially for those who enter the dataset between 1994 and 2013. In this section, we show that our results are only marginally affected if we (i) restrict to firms that enter the dataset in 1994 (that is we do not consider entry); (ii) restrict to the first five years following entry in the dataset when computing aggregate employment and the frequency of relocation. These results are respetively presented in Tables D5 and D6. 
Table D2: Relocation and employment dynamics - All firms - Different distance thresholds - Cross section OLS

\begin{tabular}{lcccc}
\hline \multirow{2}{*}{ Dependent variable: Yearly average employment growth (in \%) } \\
\cline { 2 - 5 } Threshold & \multicolumn{4}{c}{ All firms } \\
\cline { 2 - 5 } & $\mathbf{1 5 k m}$ & $25 \mathrm{~km}$ & $35 \mathrm{~km}$ & Zone d'Emploi \\
& $\mathbf{( 1 )}$ & $\mathbf{( 2 )}$ & $\mathbf{( 3 )}$ & $\mathbf{( 4 )}$ \\
\hline Relocate & $0.069^{* * *}$ & $0.072^{* * *}$ & $0.104^{* * *}$ & $0.110^{* *}$ \\
& $(0.020)$ & $(0.019)$ & $(0.035)$ & $(0.052)$ \\
Age & $-0.081^{* * *}$ & $-0.081^{* * *}$ & $-0.080^{* * *}$ & $-0.081^{* * *}$ \\
& $(0.004)$ & $(0.004)$ & $(0.004)$ & $(0.004)$ \\
Size & $-3.904^{*}$ & $-3.902^{*}$ & $-3.915^{*}$ & $-3.875^{*}$ \\
& $(2.178)$ & $(2.178)$ & $(2.183)$ & $(2.170)$ \\
& & & & 0.058 \\
$\mathrm{R}^{2}$ & 0.057 & 0.058 & 0.058 \\
Observations & 118,980 & 118,980 & 118,980 & 118,980 \\
\hline \hline
\end{tabular}

Notes: The dependent variable, average employment growth, is measured as the mean of yearly employment growth over the period of observation and given in \%. Variables definitions are given in Table A3. Age and Size are taken in the first year the firm appears in the database. Relocate is equal to the yearly frequency of local relocation (with a distance below $15 \mathrm{~km}$ in column 1 , below $25 \mathrm{~km}$ in column 2 , below $35 \mathrm{~km}$ in column 3 and within a Labor Market Area in column 4) in \% from 1994 to 2013. Regressions include a département $\times$ sector fixed effect. Cross section OLS regression with robust standard errors clustered at the département $\times$ sector level reported in parenthesis. $* * *, * *$ and * respectively indicate $0.01,0.05$ and 0.1 levels of significance. 
Table D3: Relocation and employment dynamics - Growing firms - Different distance thresholds - Cross section OLS

\begin{tabular}{lcccc}
\hline \hline \multirow{2}{*}{ Dependent variable: Yearly average employment growth (in \%) } \\
\cline { 2 - 5 } Threshold & \multicolumn{4}{c}{ Growing firms } \\
\cline { 2 - 5 } & $\mathbf{1 5 \mathrm { km }}$ & $25 \mathrm{~km}$ & $35 \mathrm{~km}$ & Zone d'Emploi \\
& $\mathbf{( 1 )}$ & $\mathbf{( 2 )}$ & $\mathbf{( 3 )}$ & $\mathbf{( 4 )}$ \\
\hline Relocate & $0.157^{* * *}$ & $0.165^{* * *}$ & $0.230^{* * *}$ & $0.259^{* *}$ \\
& $(0.037)$ & $(0.035)$ & $(0.070)$ & $(0.104)$ \\
Age & $-0.122^{* * *}$ & $-0.121^{* * *}$ & $-0.120^{* * *}$ & $-0.121^{* * *}$ \\
& $(0.008)$ & $(0.008)$ & $(0.008)$ & $(0.008)$ \\
Size & $-8.121^{* *}$ & $-8.119^{* *}$ & $-8.092^{* *}$ & $-8.132^{* *}$ \\
& $(3.282)$ & $(3.281)$ & $(3.276)$ & $(3.277)$ \\
& & & & 0.108 \\
$\mathrm{R}^{2}$ & 0.108 & 0.108 & 0.109 \\
Observations & 56,983 & 56,983 & 56,983 & 56,983 \\
\hline \hline
\end{tabular}

Notes: The dependent variable, average employment growth, is measured as the mean of yearly employment growth over the period of observation and given in \%. Variables definitions are given in Table A3. Age and Size are taken in the first year the firm appears in the database. All columns restrict to firm with an overall positive employment growth in their observation period. Relocate is equal to the yearly frequency of local relocation (with a distance below $15 \mathrm{~km}$ in column 1 , below $25 \mathrm{~km}$ in column 2 , below $35 \mathrm{~km}$ in column 3 and within a Labor Market Area in column 4 ) in \% from 1994 to 2013. Regressions include a département $\times$ sector fixed effect. Cross section OLS regression with robust standard errors clustered at the département $\times$ sector level reported in parenthesis. $* * *, * *$ and ${ }^{*}$ respectively indicate $0.01,0.05$ and 0.1 levels of significance. 
Table D4: Relocation and employment dynamics - Declining firms - Different distance thresholds - Cross section OLS

\begin{tabular}{lcccc}
\hline \hline \multirow{2}{*}{ Dependent variable: Yearly average employment growth (in \%) } \\
\cline { 2 - 5 } Threshold & \multicolumn{4}{c}{ Declining firms } \\
\cline { 2 - 5 } & $\mathbf{1 5 \mathrm { km }}$ & $25 \mathrm{~km}$ & $35 \mathrm{~km}$ & Zone d'Emploi \\
& $\mathbf{( 1 )}$ & $\mathbf{( 2 )}$ & $\mathbf{( 3 )}$ & $\mathbf{( 4 )}$ \\
\hline Relocate & $-0.103^{* * *}$ & $-0.098^{* * *}$ & $-0.097^{* * *}$ & $-0.113^{* * *}$ \\
& $(0.010)$ & $(0.009)$ & $(0.009)$ & $(0.011)$ \\
Age & $0.020^{* * *}$ & $0.020^{* * *}$ & $0.020^{* * *}$ & $0.021^{* * *}$ \\
& $(0.001)$ & $(0.001)$ & $(0.001)$ & $(0.001)$ \\
Size & $4.485^{* * *}$ & $4.460^{* * *}$ & $4.481^{* * *}$ & $4.245^{* * *}$ \\
& $(1.725)$ & $(1.711)$ & $(1.722)$ & $(1.632)$ \\
& & & & 0.155 \\
$\mathrm{R}^{2}$ & 0.156 & 0.156 & 0.156 & 46,605 \\
Observations & 46,605 & 46,605 & 46,605 \\
\hline \hline
\end{tabular}

Notes: The dependent variable, average employment growth, is measured as the mean of yearly employment growth over the period of observation and given in \%. Variables definitions are given in Table A3. Age and Size are taken in the first year the firm appears in the database. All columns restrict to firm with an overall negative employment growth in their observation period. Relocate is equal to the yearly frequency of local relocation (with a distance below $15 \mathrm{~km}$ in column 1 , below $25 \mathrm{~km}$ in column 2 , below $35 \mathrm{~km}$ in column 3 and within a Labor Market Area in column 4 ) in \% from 1994 to 2013. Regressions include a département $\times$ sector fixed effect. Cross section OLS regression with robust standard errors clustered at the département $\times$ sector level reported in parenthesis. $* * *, * *$ and ${ }^{*}$ respectively indicate $0.01,0.05$ and 0.1 levels of significance. 
Table D5: Relocation and employment dynamics - No entry - Cross section OLS

Dependent variable: Yearly average employment growth (in \%)

\begin{tabular}{lccc}
\cline { 2 - 4 } & All & Growing & Declining \\
& $\mathbf{( 1 )}$ & $\mathbf{( 2 )}$ & $\mathbf{( 3 )}$ \\
\hline Relocate & $0.092^{* * *}$ & $0.193^{* * *}$ & $-0.070^{* * *}$ \\
& $(0.022)$ & $(0.044)$ & $(0.010)$ \\
Age & $-0.053^{* * *}$ & $-0.069^{* * *}$ & $0.006^{* * *}$ \\
& $(0.004)$ & $(0.008)$ & $(0.002)$ \\
Size & -19.408 & -30.184 & 5.674 \\
& $(23.539)$ & $(32.259)$ & $(9.926)$ \\
& & & \\
$\mathrm{R}^{2}$ & 0.112 & 0.218 & 0.203 \\
Observations & 43,550 & 19,985 & 20,446 \\
\hline \hline
\end{tabular}

Notes: The dependent variable, average employment growth, is measured as the mean of yearly employment growth over the period of observation and given in \%. Variables definitions are given in Table A3. Age and Size are taken in the first year the firm appears in the database. All columns exclude firms with a first year of observation that is higher than 1994. Column 1 uses all firms, column 2 (resp. 3) restricts to firms with positive (resp. negative) employment growth. Relocate is equal to the yearly frequency of local relocation (with a distance below $15 \mathrm{~km}$ ) in $\%$ from 1994 to 2013. Regressions include a département $\times$ sector fixed effect. Cross section OLS regression with robust standard errors clustered at the département $\times$ sector level reported in parenthesis. ${ }^{* *},{ }^{* *}$ and $*$ respectively indicate $0.01,0.05$ and 0.1 levels of significance. 
Table D6: Relocation and employment dynamics - First Five Years - Cross section OLS

Dependent variable: Yearly average employment growth (in \%)

\begin{tabular}{lccc}
\cline { 2 - 4 } & All & Growing & Declining \\
& $\mathbf{( 1 )}$ & $\mathbf{( 2 )}$ & $\mathbf{( 3 )}$ \\
\hline Relocate & $0.104^{* * *}$ & $0.210^{* * *}$ & $-0.078^{* * *}$ \\
& $(0.015)$ & $(0.027)$ & $(0.006)$ \\
Age & $-0.102^{* * *}$ & $-0.140^{* * *}$ & $0.022^{* * *}$ \\
& $(0.005)$ & $(0.009)$ & $(0.001)$ \\
Size & $-5.821^{* *}$ & $-11.646^{* * *}$ & $6.328^{* *}$ \\
& $(2.788)$ & $(4.164)$ & $(2.620)$ \\
& & & \\
$\mathrm{R}^{2}$ & 0.052 & 0.105 & 0.166 \\
Observations & 128,310 & 65,240 & 42,168 \\
\hline \hline
\end{tabular}

Notes: The dependent variable, average employment growth, is measured as the mean of yearly employment growth over the first five years of observation and given in \%. Variables definitions are given in Table A3. Age and Size are taken in the first year the firm appears in the database. Column 1 uses all firms, column 2 (resp. 3) restricts to firms with positive (resp. negative) employment growth. Relocate is equal to the yearly frequency of local relocation (with a distance below $15 \mathrm{~km}$ ) in \% during the first five years of observation. Regressions include a département $\times$ sector fixed effect. Cross section OLS regression with robust standard errors clustered at the département $\times$ sector level reported in parenthesis. ${ }^{* * *},{ }^{* *}$ and ${ }^{*}$ respectively indicate $0.01,0.05$ and 0.1 levels of significance. 
Table D7: Statistics on changes in local characteristics following a relocation - Growing firms and declining firms

\begin{tabular}{lccc}
\hline \hline & \multicolumn{2}{c}{ Mean } & Difference \\
\cline { 2 - 3 } & Declining firms & Growing firms & \\
\hline Population & -52.4 & -41.9 & -10.5 \\
& & & $(8.15)$ \\
Density & -0.80 & -0.67 & $-1.28^{* *}$ \\
& & & $(0.65)$ \\
Herfindahl index & 0.021 & 0.016 & 0.004 \\
& & & $0.005)$ \\
Local sectoral size & 0.017 & 0.019 & -0.002 \\
& & & $(0.006)$ \\
Nb of obs. & 7,634 & 11,215 & - \\
\hline \hline
\end{tabular}

Notes: This table shows the mean changes in some local characteristics following a relocation. We differentiate the firms for which we observed an overall increase in the headcount from firms for which we observe a overall decline in the headcount. The statistics reported correspond the difference between the value observed in the municipality of settlement in the year of the relocation and the value observed in the municipality of departure prior to the relocation. Population is in thousands inhabitants in 1990 at the municipality level. Density, at the municipality level, in thousands inhabitants per square kilometer. The Herfindahl index is computed at the 2-digit sector $\times$ municipality $\times$ year level. Finally, the local sectoral size is the sum of the sales at the 2 -digit sector $\times$ municipality $\times$ year level. The Period of observation: 1994-2013. Source: INSEE and FiBEn, see section A for more detail about the data.

\section{Agglomeration effect}

In Table D7, we compare the characteristics of the municipalities of departure and destination for both growing and declining firms. We see that overall, firms relocate to smaller and less dense areas that where their sector is more concentrated and larger. However, we do not observe any significantly different behaviour across the two groups of firms except as far as density is concerned. The difference in density dissapear when the Paris area is excluded from the sample.

\section{Place based program}

The displacement effect of publicly funded place-based programs has been documented in recent contributions (Givord et al. (2013); Mayer et al. (2015) for the French ZFUs (Zone Franche Urbaine) and Overman and Einio (2012) for the Local Enterprise Growth Initiative in the UK which shares similarities with the French program). Those programs are often blamed for causing a shift of economic activity from areas that do not benefit from the program to areas that do. In turns, this mechanism could offer an alternative explanation to the linkages between workforce growth and local relocations; that is to say an explanation that do not rely on premises' size constraint. If firms relocate in order to benefit from a more generous tax system that enables them to increase their workforce, we would observe a positive correlation between the occurrence of a local relocation and an increase in the workforce. Note, however, that this mechanism would not be able to account for the left branch in the documented U-shaped relationship between employment growth and location relocation presented in Figure 1. We check that this alternative mechanism does not alter 
our main results by excluded from our database firms that are located less than $15 \mathrm{~km}$ away from a $Z F U .^{33}$ In doing so, we discard all the potential relocation that could conduct a firm to relocate to a $Z F U s$. In columns 1 to 3 of Table D8 we estimate equation (14) with this restricted sample. We find no difference compared to our baseline results.

Table D8: Relocation and employment dynamics - No entry - Cross section OLS

Dependent variable: Yearly average employment growth (in \%)

\begin{tabular}{ccc}
\hline All & Growing & Declining \\
$\mathbf{( 1 )}$ & $\mathbf{( 2 )}$ & $\mathbf{( 3 )}$ \\
\hline $0.126^{* * *}$ & $0.214^{* * *}$ & $-0.067^{* * *}$ \\
$(0.018)$ & $(0.031)$ & $(0.010)$ \\
$-0.063^{* * *}$ & $-0.103^{* * *}$ & $0.021^{* * *}$ \\
$(0.004)$ & $(0.010)$ & $(0.002)$ \\
$-34.011^{* * *}$ & $-117.888^{* * *}$ & $19.633^{* * *}$ \\
$(10.651)$ & $(32.818)$ & $(7.569)$ \\
& & \\
\hline 0.082 & 0.145 & 0.206 \\
66,858 & 32,028 & 25,881 \\
\hline
\end{tabular}

Notes: The dependent variable, average employment growth, is measured as the mean of yearly employment growth over the period of observation and given in \%. Variables definitions are given in Table A3. Age and Size are taken in the first year the firm appears in the database. All columns exclude firms located less than $15 \mathrm{~km}$ from a $Z F U$. Column 1 uses all firms, column 2 (resp. 3) restricts to firms with positive (resp. negative) employment growth. Relocate is equal to the yearly frequency of local relocation (with a distance below 15km) in \% from 1994 to 2013. Regressions include a département $\times$ sector fixed effect. Cross section OLS regression with robust standard errors clustered at the département $\times$ sector level reported in parenthesis. ${ }^{* * *}, * *$ and ${ }^{*}$ respectively indicate $0.01,0.05$ and 0.1 levels of significance.

\section{D.2 Additional results}

\section{Difference between owners and renters}

Table D9 shows the difference between real-estate owning firms and renters. We see that the latter are significantly smaller, younger ans grow faster than the former. Real-estate renters also relocate more frequently which is consistent with the view that they face lower moving costs than real-estate owners.

\footnotetext{
${ }^{33}$ An alternative would consist in focusing on big firms. There are indeed size restrictions to be eligible to the favorable tax scheme offered within the limits of a $Z F U$; in particular, firms with headcount higher than 50 are not eligible. There is also often a less stringent criterion related to total sales. Nevertheless, our study being conducted on single establishment firms, this would restrict our database to a small number of observations.
} 
Table D9: Summary statistics - Owners and Renters

\begin{tabular}{|c|c|c|c|c|}
\hline & \multicolumn{2}{|c|}{ Mean } & \multicolumn{2}{|c|}{ Difference } \\
\hline & Owners & Renters & & \\
\hline Employment & 26.8 & 15.8 & $11.0^{* * *}$ & $(0.14)$ \\
\hline Sales & 3.88 & 2.49 & $1.39^{* * *}$ & $(0.043)$ \\
\hline BS Size & 2.75 & 1.76 & $0.99^{* * *}$ & $(0.14)$ \\
\hline Age & 18.6 & 10.6 & $8.1^{* * *}$ & $(0.079)$ \\
\hline Employment growth & $1.6 \%$ & $3.7 \%$ & $-2.1 \% * * *$ & $(0.099)$ \\
\hline Frequency of Relocation & $1.2 \%$ & $2.5 \%$ & $-1.3 \% * * *$ & $(0.034)$ \\
\hline $\mathrm{Nb}$ of obs. & 46,034 & 78,109 & - & \\
\hline
\end{tabular}

Notes: This table shows the mean of different key variables, in initial year of observation, for firms that own their real-estate (Owners) and for firms that rent their real-estate (Renters). Employment is given in full-time equivalent (FTE) number of workers as reported by the firm; Employment growth in the mean yearly percentage change in FTE over the observation period; Sales are in millions of euros; BS size is the net value of the assets reported in the balance sheet and is given in millions of euros; Profits is the Earning Before Interest and Tax margin (i.e., EBIT to Sales ratio); Age is the number of year since company's incorporation; Frequency of Relocation is the number of local relocation divided by the number of years of observation for the firm. Source: FiBEn, see Appendix A for more detail about the data. The latest column show the mean and standard deviation of the difference between the two coefficients and the Student $\mathrm{t}$-stat on the nullity of this difference. $* * *, * *$ and $*$ indicate that the null hypothesis of this test is rejected at the $1 \%, 5 \%$ and $10 \%$ level of significance.

\section{Changes in the samples}

In Table D10, we remove from the sample all the firms that switch from renters to owners (and conversely) as they locally relocated. There are $0.58 \%$ of the firms that changed their tenure status from owner to renter and $1.44 \%$ that do the opposite. In any case, excluding these firms from the sample does not affect our results.

In Table D11, we remove from the sample all the firms that relocate to a city located farther than $15 \mathrm{~km}$ away. Here again, results are only partially altered. 
Table D10: Relocation cost and relocation choice - Remove tenure status transition - Cross section OLS

\begin{tabular}{|c|c|c|c|c|c|c|}
\hline \multicolumn{7}{|c|}{ Dependent variable: Relocate } \\
\hline & \multirow{2}{*}{$\begin{array}{l}\text { All } \\
(1)\end{array}$} & \multicolumn{5}{|c|}{ Owners } \\
\hline & & $(2)$ & (3) & $(4)$ & (5) & (6) \\
\hline Real Estate Owner & $\begin{array}{c}-0.593^{* * *} \\
(0.035)\end{array}$ & & & & & \\
\hline $\operatorname{Tax}$ & & $\begin{array}{c}-1.960 * * * \\
(0.465)\end{array}$ & $\begin{array}{c}-2.101^{* * *} \\
(0.472)\end{array}$ & $\begin{array}{c}-2.549^{* * *} \\
(0.544)\end{array}$ & $\begin{array}{c}-2.752^{* * *} \\
(0.562)\end{array}$ & $\begin{array}{c}-2.059^{* * *} \\
(0.565)\end{array}$ \\
\hline Age & $\begin{array}{c}-0.021^{* * *} \\
(0.001)\end{array}$ & $\begin{array}{c}-0.012^{* * *} \\
(0.001)\end{array}$ & $\begin{array}{c}-0.012^{* * *} \\
(0.001)\end{array}$ & $\begin{array}{c}-0.007^{* * *} \\
(0.001)\end{array}$ & $\begin{array}{c}-0.006^{* * *} \\
(0.001)\end{array}$ & $\begin{array}{c}-0.006 * * * \\
(0.001)\end{array}$ \\
\hline Size & $\begin{array}{c}1.656 \\
(1.728)\end{array}$ & $\begin{array}{l}5.192^{*} \\
(3.062)\end{array}$ & $\begin{array}{l}5.159^{*} \\
(3.065)\end{array}$ & $\begin{array}{l}5.134^{*} \\
(3.058)\end{array}$ & $\begin{array}{l}5.048^{*} \\
(2.933)\end{array}$ & $\begin{array}{c}5.038^{*} \\
(2.938)\end{array}$ \\
\hline Volume Real Estate & & & $\begin{array}{c}-0.015^{* * *} \\
(0.005)\end{array}$ & $\begin{array}{l}-0.005 \\
(0.004)\end{array}$ & $\begin{array}{l}-0.003 \\
(0.004)\end{array}$ & $\begin{array}{l}-0.002 \\
(0.004)\end{array}$ \\
\hline Age Real Estate & & & & $\begin{array}{c}-0.023^{* * *} \\
(0.004)\end{array}$ & $\begin{array}{c}-0.021^{* * *} \\
(0.005)\end{array}$ & $\begin{array}{c}-0.019^{* * *} \\
(0.005)\end{array}$ \\
\hline $\mathrm{R}^{2}$ & 0.091 & 0.121 & 0.121 & 0.122 & 0.159 & 0.158 \\
\hline Observations & 118,515 & 44,999 & 44,999 & 44,274 & 44,274 & 44,274 \\
\hline
\end{tabular}

Notes: The dependent variable, Relocate, is equal to the yearly frequency of local relocation (with a distance below $15 \mathrm{~km}$ ) in \% from 1994 to 2013. Variables definitions are given in Table A3. All single-establishment firms that do not change their tenure status are considered. Column 1 uses all of these firms while columns 2 to 5 restrict to real estate owners. The dependent variable is a binary variable equal to 1 if the firm has locally relocated (with a distance below 15km) from 1994 to 2013. Other variables are taken in the first year of observation. Regressions include a département $\times$ sector fixed effect. Column 5 adds a département $\times$ first year of observation fixed effect. Column 6 uses an alternative proxy for the latent tax on capital gain built from national price level. Cross section OLS regression with robust standard errors clustered at the département $\times$ sector level reported in parenthesis. ***, ** and * respectively indicate $0.01,0.05$ and 0.1 levels of significance. 
Table D11: Relocation cost and relocation choice - Only local movers - Cross section OLS

\begin{tabular}{|c|c|c|c|c|c|c|}
\hline \multicolumn{7}{|c|}{ Dependent variable: Relocate } \\
\hline & \multirow{2}{*}{$\begin{array}{l}\text { All } \\
(1)\end{array}$} & \multicolumn{5}{|c|}{ Owners } \\
\hline & & $(2)$ & (3) & (4) & (5) & (6) \\
\hline Real Estate Owner & $\begin{array}{c}-0.603^{* * *} \\
(0.037)\end{array}$ & & & & & \\
\hline $\operatorname{Tax}$ & & $\begin{array}{c}-2.227^{* * *} \\
(0.484)\end{array}$ & $\begin{array}{c}-2.379^{* * *} \\
(0.491)\end{array}$ & $\begin{array}{c}-2.592^{* * *} \\
(0.548)\end{array}$ & $\begin{array}{c}-2.770^{* * *} \\
(0.571)\end{array}$ & $\begin{array}{c}-2.004^{* * *} \\
(0.596)\end{array}$ \\
\hline Age & $\begin{array}{c}-0.022^{* * *} \\
(0.001)\end{array}$ & $\begin{array}{c}-0.013^{* * *} \\
(0.001)\end{array}$ & $\begin{array}{c}-0.012^{* * *} \\
(0.001)\end{array}$ & $\begin{array}{c}-0.008^{* * *} \\
(0.001)\end{array}$ & $\begin{array}{c}-0.006^{* * *} \\
(0.001)\end{array}$ & $\begin{array}{c}-0.006^{* * *} \\
(0.001)\end{array}$ \\
\hline Size & $\begin{array}{c}1.906 \\
(1.849)\end{array}$ & $\begin{array}{c}6.881^{* * *} \\
(2.262)\end{array}$ & $\begin{array}{c}6.842^{* * *} \\
(2.268)\end{array}$ & $\begin{array}{c}6.501^{* * *} \\
(2.459)\end{array}$ & $\begin{array}{c}6.414^{* *} \\
(2.559)\end{array}$ & $\begin{array}{c}6.409^{* *} \\
(2.564)\end{array}$ \\
\hline Volume Real Estate & & & $\begin{array}{c}-0.016^{* * *} \\
(0.005)\end{array}$ & $\begin{array}{l}-0.005 \\
(0.005)\end{array}$ & $\begin{array}{l}-0.003 \\
(0.005)\end{array}$ & $\begin{array}{l}-0.002 \\
(0.005)\end{array}$ \\
\hline Age Real Estate & & & & $\begin{array}{c}-0.023^{* * *} \\
(0.005)\end{array}$ & $\begin{array}{c}-0.021^{* * *} \\
(0.005)\end{array}$ & $\begin{array}{c}-0.019^{* * *} \\
(0.005)\end{array}$ \\
\hline $\mathrm{R}^{2}$ & 0.095 & 0.128 & 0.128 & 0.128 & 0.166 & 0.166 \\
\hline Observations & 112,853 & 43,103 & 43,103 & 42390 & 42,390 & 42,390 \\
\hline
\end{tabular}

Notes: The dependent variable, Relocate, is equal to the yearly frequency of local relocation (with a distance below $15 \mathrm{~km}$ ) in \% from 1994 to 2013. Variables definitions are given in Table A3. All single-establishment firms that do not relocate to a distance over $15 \mathrm{~km}$ are considered. Column 1 uses all of these firms while columns 2 to 5 restrict to real estate owners. The dependent variable is a binary variable equal to 1 if the firm has locally relocated (with a distance below $15 \mathrm{~km}$ ) from 1994 to 2013 . Other variables are taken in the first year of observation. Regressions include a département $\times$ sector fixed effect. Column 5 adds a département $\times$ first year of observation fixed effect. Column 6 uses an alternative proxy for the latent tax on capital gain built from national price level. Cross section OLS regression with robust standard errors clustered at the département $\times$ sector level reported in parenthesis. ${ }^{* * *},{ }^{* *}$ and ${ }^{*}$ respectively indicate $0.01,0.05$ and 0.1 levels of significance. 
Table D12: Relocation cost and relocation choice - National level tax - Cross section OLS

\begin{tabular}{lcccc}
\hline \hline \multirow{4}{*}{ Dependent variable: Relocate } \\
\cline { 2 - 5 } & \multicolumn{4}{c}{ Owners } \\
\cline { 2 - 5 } & $\mathbf{( 1 )}$ & $\mathbf{( 2 )}$ & $\mathbf{( 3 )}$ & $\mathbf{( 4 )}$ \\
\hline Tax & $-1.882^{* * *}$ & $-2.001^{* * *}$ & $-2.030^{* * *}$ & $-2.180^{* * *}$ \\
& $(0.485)$ & $(0.489)$ & $(0.542)$ & $(0.588)$ \\
Age & $-0.014^{* * *}$ & $-0.013^{* * *}$ & $-0.008^{* * *}$ & $-0.007^{* * *}$ \\
& $(0.001)$ & $(0.001)$ & $(0.001)$ & $(0.001)$ \\
Size & $5.316^{*}$ & $5.279^{*}$ & $5.019^{*}$ & $5.029^{*}$ \\
Volume Real Estate & $(2.901)$ & $(2.904)$ & $(2.989)$ & $(2.863)$ \\
& & $-0.016^{* * *}$ & -0.005 & -0.003 \\
Age Real Estate & & $(0.005)$ & $(0.005)$ & $(0.005)$ \\
& & & $-0.023^{* * *}$ & $-0.021^{* * *}$ \\
& & & $(0.004)$ & $(0.005)$ \\
$\mathrm{R}^{2}$ & & & & \\
Observations & 0.121 & 0.121 & 0.121 & 0.160 \\
\hline \hline
\end{tabular}

Notes: The dependent variable, Relocate, is equal to the yearly frequency of local relocation (with a distance below $15 \mathrm{~km}$ ) in \% from 1994 to 2013. Variables definitions are given in Table A3. All columns restrict to real estate owners. The dependent variable is a binary variable equal to 1 if the firm has locally relocated (with a distance below $15 \mathrm{~km}$ ) from 1994 to 2013. Other variables are taken in the first year of observation. Regressions include a département $\times$ sector fixed effect. Column 5 add a département $\times$ first year of observation fixed effect. Cross section OLS regression with robust standard errors clustered at the département $\times$ sector level reported in parenthesis. ${ }^{* * *}, * *$ and ${ }^{*}$ respectively indicate $0.01,0.05$ and 0.1 levels of significance. 
Table D13: Relocation cost and relocation choice - Cross section OLS - Within Labor Market Area relocations.

\begin{tabular}{|c|c|c|c|c|c|c|}
\hline \multicolumn{7}{|c|}{ Dependent variable: Relocate } \\
\hline & \multirow{2}{*}{$\begin{array}{l}\text { All } \\
(1)\end{array}$} & \multicolumn{5}{|c|}{ Owners } \\
\hline & & $(2)$ & (3) & $(4)$ & (5) & $(6)$ \\
\hline Real Estate Owner & $\begin{array}{c}-0.463^{* * *} \\
(0.034)\end{array}$ & & & & & \\
\hline $\operatorname{Tax}$ & & $\begin{array}{c}-2.079^{* * *} \\
(0.457)\end{array}$ & $\begin{array}{c}-2.263^{* * *} \\
(0.464)\end{array}$ & $\begin{array}{c}-2.871^{* * *} \\
(0.527)\end{array}$ & $\begin{array}{c}-2.717^{* * *} \\
(0.540)\end{array}$ & $\begin{array}{c}-2.039^{* * *} \\
(0.520)\end{array}$ \\
\hline Age & $\begin{array}{c}-0.019^{* * *} \\
(0.001)\end{array}$ & $\begin{array}{c}-0.012^{* * *} \\
(0.001)\end{array}$ & $\begin{array}{c}-0.011^{* * *} \\
(0.001)\end{array}$ & $\begin{array}{c}-0.006^{* * *} \\
(0.001)\end{array}$ & $\begin{array}{c}-0.005^{* * *} \\
(0.001)\end{array}$ & $\begin{array}{c}-0.005^{* * *} \\
(0.001)\end{array}$ \\
\hline Size & $\begin{array}{l}-0.242 \\
(0.568)\end{array}$ & $\begin{array}{c}0.626 \\
(1.062)\end{array}$ & $\begin{array}{c}0.584 \\
(1.058)\end{array}$ & $\begin{array}{c}0.510 \\
(1.051)\end{array}$ & $\begin{array}{c}0.278 \\
(0.975)\end{array}$ & $\begin{array}{c}0.267 \\
(0.978)\end{array}$ \\
\hline Volume Real Estate & & & $\begin{array}{c}-0.019^{* * *} \\
(0.005)\end{array}$ & $\begin{array}{c}-0.007^{*} \\
(0.004)\end{array}$ & $\begin{array}{l}-0.006 \\
(0.005)\end{array}$ & $\begin{array}{l}-0.005 \\
(0.005)\end{array}$ \\
\hline Age Real Estate & & & & $\begin{array}{c}-0.027^{* * *} \\
(0.005)\end{array}$ & $\begin{array}{c}-0.023^{* * *} \\
(0.005)\end{array}$ & $\begin{array}{c}-0.021^{* * *} \\
(0.005)\end{array}$ \\
\hline $\mathrm{R}^{2}$ & 0.065 & 0.108 & 0.109 & 0.112 & 0.154 & 0.154 \\
\hline Observations & 118,980 & 45,181 & 45,181 & 44,412 & 44,412 & 44,412 \\
\hline
\end{tabular}

Notes: The dependent variable, Relocate, is equal to the yearly frequency of local relocation (with a distance below $15 \mathrm{~km}$ ) in \% from 1994 to 2013 . Variables definitions are given in Table A3. Column 1 uses all firms while columns 2 to 5 restrict to real estate owners. The dependent variable is a binary variable equal to the yearly frequency of relocation within the same Zone d'Emploi (Labor Market Area) in \% from 1994 to 2013. Other variables are taken in the first year of observation. Regressions include a département $\times$ sector fixed effect. Column 5 adds a département $\times$ first year of observation fixed effect. Column 6 uses an alternative proxy for the latent tax on capital gain built from national price level. Cross section OLS regression with robust standard errors clustered at the département $\times$ sector level reported in parenthesis. ${ }^{* * *},{ }^{* *}$ and ${ }^{*}$ respectively indicate $0.01,0.05$ and 0.1 levels of significance. 